INSTITUTO DE PESQUISAS ENERGÉTICAS E NUCLEARES AUTARQUIA ASSOCIADA À UNIVERSIDADE DE SÃO PAULO

\title{
INFLUÊNCIA DO HOSPEDEIRO (CHO) E DA ESTRATÉGIA DE CULTIVO NAS ESTRUTURAS GLICÍDICAS E PROPRIEDADES MOLECULARES DA TIREOTROFINA HUMANA
}

João Ezequiel de Oliveira

Tese apresentada como parte dos requisitos para obtenção do Grau de Doutor em Ciências na Área de Tecnologia Nuclear - Aplicações

Orientadora:

Dra. Maria Teresa de Carvalho Pinto Ribela

São Paulo 


\section{Dedico este trabalho}

Ao meu pai Luiz (in memorian), com quem aprendi que a paciência é a ciência da sabedoria.

À minha mãe Eduwilgem (in memorian) com quem aprendi a amar e ter esperança.

Aos meus irmãos e irmãs com os quais aprendi a crescer e lutar por meus ideais.

À minha família e amigos, pelo amor e apoio.

"O seu amor

Reluz

Que nem riqueza

Asa do meu destino

Clareza do tino

Pétala

De estrela caindo

Bem devagar

Ó meu amor

Viver

É todo sacrifício

Feito em seu nome

Quanto mais desejo

Um beijo seu

Muito mais eu vejo

Gosto em viver...

Por ser exato

O amor não cabe em si

Por ser encantado

O amor revela-se

Por ser amor

Invade

E fim" 


\section{AGRADECIMENTOS}

À Dra. Maria Teresa de Carvalho Pinto Ribela, pela orientação, confiança, incentivo, amizade e carinho dispensados na realização deste trabalho.

Ao Dr. Paolo Bartolini, pela confiança, orientação e colaboração no desenvolvimento deste trabalho.

Aos amigos, Carlos, Cibele, Kayo e Nanci, pela amizade, incentivo e colaboração.

À amigas, Renata, "aluninha” e braço direito no desenvolvimento deste trabalho, Beatriz e Cristiane, "aluninhas" sempre prontas para aprender e ajudar, Cláudia, Flávia, Susana e Taís, companheiras do dia-a-dia que proporcionaram momentos de alegrias e prazer, mesmo nos dias mais cinzentos...grande beijo.

Às amigas e companheiras, Diane, Eliza, Fernanda, Janaína, Márcia, Miriam, Neide, Rosangela, Rute e Sueli, pelo incentivo e ajuda ...grande beijo.

Aos amigos, José Maria, Junqueira, Nélio e Patrick, companheiros em todos os momentos e sempre prontos para ajudar...grande abraço.

A todos os colegas do Centro de Biotecnologia, que direta e/ou indiretamente contribuíram para a elaboração deste trabalho.

Ao Instituto de Pesquisas Energéticas e Nucleares, pela oportunidade de executar este trabalho.

"Se o sucesso não tivesse um custo, todo mundo seria um sucesso. Se as conquistas não tivessem um custo, todos seríamos conquistadores. Se a felicidade não exigisse dedicação, ela perderia o sentido. Temos a tendência de pensar em grandes conquistas levando em conta apenas o resultado final. Mas geralmente isso é só uma gota. A conquista mesmo está no fazer, no esforço, na dedicação, no custo exigido. Ter uma vida de sucessos não significa acumular troféus e prêmios, mas sim estar disposto a comprometer-se com o custo que esse sucesso exige.

Ser um sucesso exige esforço, dedicação, disciplina, foco, paixão, e muitas outras qualidades que não podem ser guardadas num armazém - mas que devem ser exercitadas em todos os momentos. No preço que você paga está o valor que você procura." 


\title{
INFLUÊNCIA DO HOSPEDEIRO (CHO) E DA ESTRATÉGIA DE CULTIVO NAS ESTRUTURAS GLICÍDICAS E PROPRIEDADES MOLECULARES DA TIREOTROFINA HUMANA
}

\author{
João Ezequiel de Oliveira
}

\section{RESUMO}

Neste trabalho foi desenvolvida pela primeira vez uma estratégia de purificação com duas etapas, uma cromatografia de troca iônica e uma cromatografia líquida de alta eficiência em fase-reversa (RP-HPLC), para obter um hTSH derivado de CHO (r-hTSH-IPEN), que mostrou-se rápida e prática, permitindo um rendimento de $70 \%$ e uma pureza $>99 \%$.

Um aumento de $\sim 60 \%$ na produtividade de r-hTSH-IPEN foi observado quando condições de cultura celular foram alteradas de $5 \%$ de $\mathrm{CO}_{2}$ para ar $\left(0,03 \% \mathrm{CO}_{2}\right)$. A qualidade dos produtos obtidos em ambas as condições foi avaliada com relação à estrutura dos $\mathrm{N}$-glicanos, aos isômeros de carga e à atividade biológica em comparação com a única preparação comercial conhecida (Thyrogen ${ }^{\circledR}$ ) e com uma preparação de referência de origem hipofisária (p-hTSH) do "National Hormone and Pituitary Program" (NIDDK, EUA).

Os $\mathrm{N}$-glicanos identificados nas preparações recombinantes foram do tipo complexo, apresentando estruturas bi-, tri- e tetra- antenárias, algumas fucosiladas, sendo $86-88 \%$ sialiladas com níveis variáveis. As três estruturas mais abundantes foram monosialiladas, representando $\sim 69 \%$ de todas as formas identificadas nas três preparações. A principal diferença foi encontrada em termos de antenaridade, com 8-10\% mais estruturas bi-antenárias na ausência de $\mathrm{CO}_{2} \mathrm{e}$ 7-9\% mais estruturas tri-antenárias na presença de $\mathrm{CO}_{2}$. No caso do p-hTSH foram identificadas estruturas do tipo complexo, com alta-manose e híbridas, a maioria delas contendo resíduos terminais de ácido siálico e/ou sulfato. As duas estruturas mais abundantes contem um ou dois resíduos de sulfato, sendo que no primeiro caso ele inesperadamente se liga a uma galactose. A porcentagem de 
ligação do ácido siálico à galactose nas conformações $\alpha 2-3$ e $\alpha 2-6$ foi de $68 \pm$ $10 \%$ e $32 \pm 10 \%$ respectivamente.

Não foram observadas diferenças fundamentais nos isômeros de carga, nas três preparações recombinantes, os perfis da focalização isoelétrica mostrando seis bandas distintas no intervalo de pl de 5,39 a 7,35. Uma distribuição consideravelmente diferente, com várias formas na região ácida, foi observada, no entanto, para duas preparações hipofisárias.

Uma bioatividade ligeiramente superior $(p<0,02)$ foi encontrada para o $r$ hTSH-IPEN obtido na presença de $\mathrm{CO}_{2}$ quando as preparações foram analisadas com boa precisão por um simples bioensaio em dose única; esta atividade, no entanto, não é significativamente diferente da atividade do Thyrogen, as duas preparações sendo 1,6 e 1,8 vezes mais potentes do que a preparação de referência ( $\mathrm{p}-\mathrm{hTSH})$.

Podemos concluir que, pelo menos para o caso dos r-hTSH derivados de $\mathrm{CHO}$, diferentes condições de cultivo não afetam significativamente as estruturas dos N-glicanos, distribuição de isómeros de carga ou atividade biológica.

Thyrogen e r-hTSH-IPEN, quando comparados com p-hTSH-NIDDK, apresentaram cerca de $7 \%$ de aumento da massa molecular determinada por MALDI-TOF-MS. Esta técnica, que permite uma avaliação exata da massa do heterodímero, apresentou valores de $M_{R}$ de 29611, 29839 e 27829, respectivamente.

Diferenças significativas foram encontradas entre o r-hTSH e o phTSH pelo que se refere às propriedades hidrofóbicas, avaliadas por RP-HPLC. Também foram observadas diferenças relacionadas à composição de carboidratos, principalmente de ácido siálico e galactose, tendo sido encontrado um menor teor destes resíduos no p-hTSH. 


\title{
INFLUENCE OF THE HOST (CHO) AND OF THE CULTIVATION STRATEGY ON GLYCAN STRUCTURES AND MOLECULAR PROPERTIES OF HUMAN THYROTROPHIN
}

\author{
João Ezequiel de Oliveira
}

\begin{abstract}
A novel, fast and practical two-step purification strategy, consisting of a classical ion exchange and a reversed-phase high performance liquid chromatography (RP-HPLC), for rapidly obtaining $\mathrm{CHO}$-derived hTSH, was set up providing r-hTSH with $70 \%$ yield and $>99 \%$ purity.

A consistent increase of $\sim 60 \%$ in the secretion yields of $r$-hTSH-IPEN was observed by changing cell culture $\mathrm{CO}_{2}$ conditions from $5 \% \mathrm{CO}_{2}$ to air environment $\left(0.03 \% \mathrm{CO}_{2}\right)$. The overall quality of the products obtained under both conditions was evaluated for what concerns $\mathrm{N}$-glycan structure, charge isomers and biological activity in comparison with a well known recombinant biopharmaceutical (Thyrogen $\left.{ }^{\circledR}\right)$ and with a pituitary reference preparation $(\mathrm{p}-\mathrm{hTSH})$ from National Hormone and Pituitary Program (NIDDK, USA).

The $\mathrm{N}$-glycans identified in the recombinant preparations were of the complex type, presenting bi-, tri- and tetra-antennary structures, sometimes fucosylated, $86-88 \%$ of the identified structures being sialylated at variable levels. The three most abundant structures were monosialylated glycans, representing $-69 \%$ of all identified forms in the three preparations. The main difference was found in terms of antennarity, with 8-10\% more bi-antennary structures obtained in the absence of $\mathrm{CO}_{2}$ and $7-9 \%$ more tri-antennary structures in its presence. In the case of p-hTSH, complex, high-mannose and hybrid N-glycan structures were identified, most of them containing sialic acid and/or sulphate terminal residues. The two most abundant structures were shown to contain one or two sulphate residues, one of which unexpectedly bound to galactose. The sialic acidgalactose linkage was also determined, having found that $68 \pm 10 \%$ was in the $\alpha 2,6$ and $32 \pm 10 \%$ in the $\alpha 2,3$ conformation.
\end{abstract}


No remarkable difference in charge isomers was observed between the three recombinant preparations, the isoelectric focusing profiles showing six distinct bands in the $5.39-7.35 \mathrm{pl} \mathrm{range.} \mathrm{A} \mathrm{considerably} \mathrm{different} \mathrm{distribution,} \mathrm{with}$ more forms in the acidic region, was observed, however, for two native pituitary preparations. When analyzed via a simple and precise single-dose bioassay, a slightly higher bioactivity $(p<0.02)$ was found for r-hTSH-IPEN obtained in the presence of $\mathrm{CO}_{2}$. This potency however, was not significantly different from that of Thyrogen, the two preparations being 1.6-1.8-fold more potent than the reference preparation of $\mathrm{p}-\mathrm{hTSH}$. We can conclude that, at least for the case of $\mathrm{CHO}$-derived r-hTSH, different production processes do not greatly affect its $\mathrm{N}$-glycan structures, charge isomer distribution or biological activity.

Thyrogen and r-hTSH-IPEN, when compared to p-hTSH-NIDDK, presented about a $7 \%$ increased relative molecular mass $\left(M_{R}\right)$ determined by MALDI-TOF-MS analysis. This technique, allowing accurate heterodimer mass determinations, provided $M_{R}$ values of 29611, 29839 and 27829, respectively. Significant differences in hydrophobic properties, evaluated by RP-HPLC, were found for $\mathrm{r}$ $\mathrm{hTSH}$ and $\mathrm{p}$-hTSH. Also differences related to carbohydrate moiety, mainly in the amount of sialic acid and galactose, were found for these preparations, a much lower content of these sugar residues being observed in p-hTSH. 


\section{SUMÁRIO}

1 INTRODUÇÃO

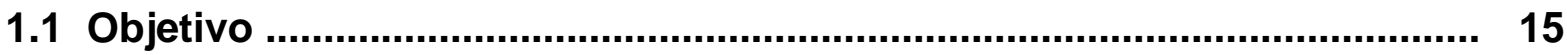

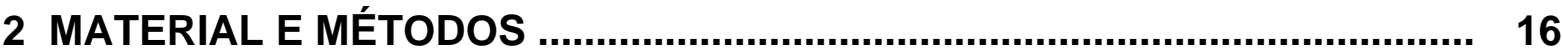

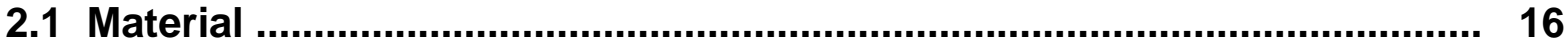

2.1.1 Preparações hormonais utilizadas .......................................................... 16

2.1.2 Material utilizado no cultivo celular ......................................................... 16

2.1.2.1 Meios de cultura .......................................................................... 16

2.1.2.2 Material plástico estéril .................................................................. 17

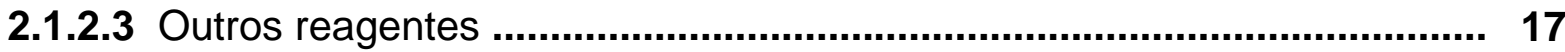

2.1.3 Material utilizado no processo de purificação e análise do hTSH ............. 17

2.1.3.1 Colunas cromatográficas ................................................................... 17

2.1.3.2 Resinas cromatográficas ................................................................. 18

2.1.3.3 Reagentes químicos .................................................................... 18

2.1.4 Material utilizado nos imunoensaios ..................................................... 19

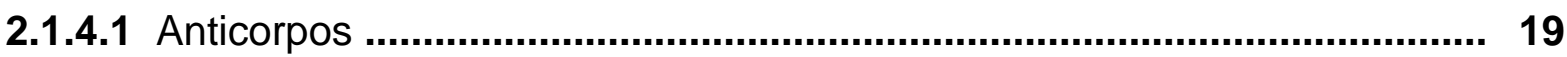

2.1.4.2 Reagentes para marcação do anticorpo de detecção .............................. 19

2.1.4.3 Outros reagentes ............................................................................. 19

2.1.5 Material utilizado no ensaio biológico ................................................... 20

2.1.6 Material utilizado na focalização isoelétrica ........................................... 20

2.1.7 Material utilizado no ensaio de dosagem de proteína total ........................ 20

2.2 Equipamentos e acessórios principais ................................................. 21

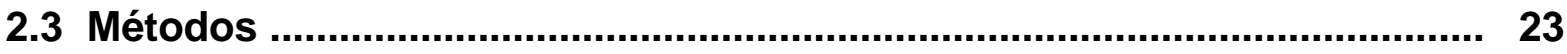

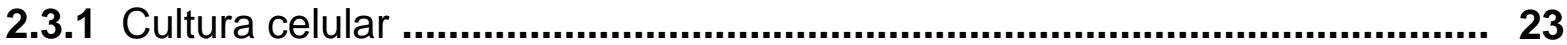

2.3.1.a Condição padrão de produção de hTSH............................................... 23

2.3.1.b Variação da temperatura na fase de produção do hTSH ........................ 23

2.3.1.c Variação de $\mathrm{CO}_{2}$ na fase de produção de hTSH ..................................... 24

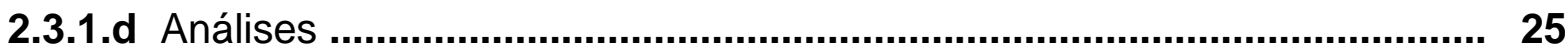




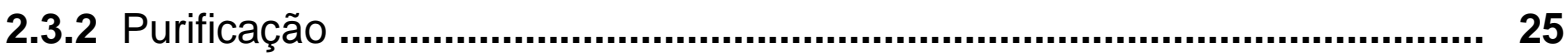

2.3.2.a Cromatografia de troca iônica (catiônica) ............................................... 25

2.3.2.b Cromatografia líquida de alta eficiência em fase reversa semipreparativa(RP-HPLC) ....................................................................... 25

2.3.3 Avaliação da proteína de interesse .......................................................... 26

2.3.3.1 Cromatografia líquida de alta eficiência (HPSEC e RP-HPLC) ............... 26

2.3.3.2 Ensaio imunorradiométrico (IRMA) do rec-hTSH .................................... 27

2.3.3.3 Determinação de proteína total ............................................................. 27

2.3.4 Atividade biológica mediante ensaio in vivo ............................................. 28

2.3.5 Espectometria de massa MALDI-TOF ................................................... 28

2.3.6 Distribuição de isômeros de carga .......................................................... 28

2.3.7 Análise da porção glicídica do hTSH ................................................... 29

2.3.7.1 Análise composicional .......................................................................... 29

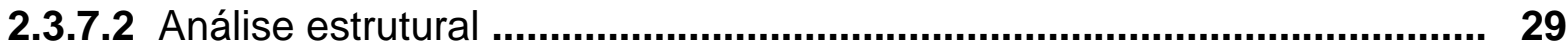

2.3.7.3 Análise da ligação do ácido siálico à galactose nas conformações $\alpha 2-3$ e $\alpha 2-6$ na preparação hipofisária ........................................................... 30

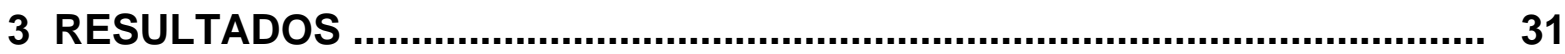

3.1 Obtenção do rec-hTSH IPEN ................................................................. 31

3.1.1 Condições de cultivo das células $\mathrm{CHO}$ produtoras de hTSH ..................... 31

3.1.1.a Variação da temperatura ........................................................................ 31

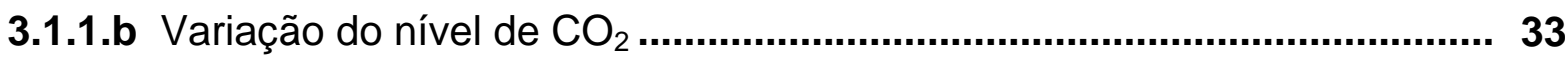

3.1.2 Purificação de r-hTSH .......................................................................... 37

3.2 Análise das diferentes preparações de hTSH ....................................... 42

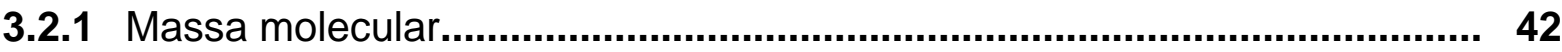

3.2.2 Hidrofobicidade ........................................................................................ 44

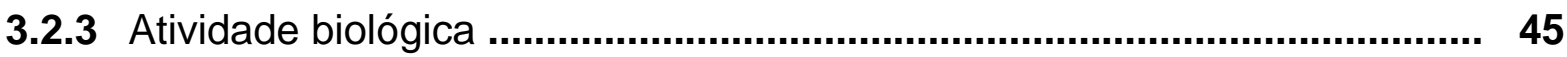

3.2.4 Distribuição dos isômeros de carga .......................................................47

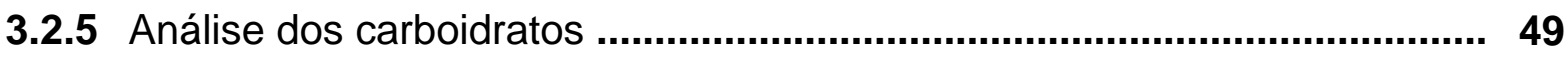

3.2.5.a Análise composicional ............................................................................ 49

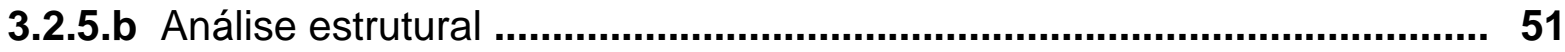


4 DISCUSSÃO

5 CONCLUSÕES

6 REFERÊNCIAS BIBLIOGRÁFICAS 


\section{INTRODUÇÃO}

A glicoproteína objeto do presente estudo é a tireotrofina. A tireotrofina humana (hTSH) é um hormônio sintetizado pelas células basófilas (tireotropos) da hipófise anterior que controla a diferenciação morfológica e a atividade metabólica das células tireoideanas, regulando a biossíntese e secreção dos hormônios tireoideanos, tiroxina $\left(T_{4}\right)$ e triiodotironina $\left(T_{3}\right)$. A síntese e secreção do hTSH é regulada por dois fatores opostos: por um lado, o hormônio liberador de hTSH (TRH), produzido pelo hipotálamo, atua sobre os tireotropos estimulando a síntese e secreção de hTSH enquanto os hormônios tireoideanos por sua vez atuam decrescendo a resposta dos tireotropos ao TRH. O papel fisiológico do TSH inclui o estímulo de funções tireoideanas tais como a captação e organificação do iodo, produção e liberação de iodotironinas pela tireóide e a promoção do crescimento desta glândula. Este hormônio também atua protegendo da apoptose as células tireoideanas e ocupa um papel crítico na ontogenia (77).

O TSH tem alto interesse clínico, seja em aplicações diagnósticas que terapêuticas e tem sido amplamente utilizado, há mais de 40 anos, para avaliação clínica da função tireoideana, para melhorar a qualidade e a interpretação de testes utilizados na medicina nuclear para a tireóide, no tratamento do bócio multinodular e de outras patologias e no diagnóstico e tratamento de câncer de tireóide $(5,6,8,35$, $46,47,55,64,65,72,83$ ).

Antes do advento da tecnologia de DNA recombinante eram utilizadas, na prática clínica, preparações de TSH bovino (bTSH), uso que foi abandonado em virtude das reações adversas que causavam $(\mathbf{4 0 , 4 1 )}$ e do desenvolvimento de anticorpos ao TSH humano, interferindo nos ensaios de TSH e afetando adversamente a função tireoideana. Também limitado tornou-se 0 uso de preparações de TSH derivadas da hipófise de cadáveres ( $p-h T S H)$, especialmente em virtude dos sérios riscos de contaminação por vírus ou prions (doença de Creutzfeld-Jacob, AIDS, hepatite, por exemplo), além das dificuldades ético-legais para obtenção de hipófises de cadáveres. Atualmente, apenas preparações recombinantes são utilizadas. Uma única preparação de hTSH, derivada de células 
de ovário de hamster Chinês ( $\mathrm{CHO})$, Thyrogen, da Genzyme Therapeutics, está disponível comercialmente.

Vários usos do hTSH recombinante (r-hTSH) tem sido propostos e estudados (Tabela 1). O r-hTSH teve seu uso aprovado nos Estados Unidos, em 1998 e na Europa, em 2001. O uso clínico de r-hTSH foi aprovado principalmente para a monitoração diagnóstica e terapia de pacientes com câncer de tireóide. O procedimento padrão para pacientes com carcinoma da tireóide é a tireoidectomia total, seguida da administração de iodo ${ }^{131}$ I (ablação com radioiodo) como uma terapia adjuvante contra qualquer tumor oculto e para destruir qualquer tecido de tireóide remanescente. Após a tireoidectomia, os pacientes são submetidos à terapia de reposição dos hormônios tireoideanos para restaurar um estado clinicamente eutireoideo. O acompanhamento e a monitoração dos pacientes com carcinoma da tireóide se faz, em geral, através da medição da tireoglobulina $(\mathrm{Tg})$ no soro e do mapeamento de corpo inteiro após administração de ${ }^{131} \mathrm{I}$. Uma pré-condição para estes testes é a presença de níveis altos de TSH no soro, que asseguram ampla produção de $\mathrm{Tg}$ e captação e estocagem de radioiodo pelas células tumorais da tireóide. A elevação do nível sérico de TSH pode ser obtida endogenamente, através da suspensão da terapia dos hormônios tireoideanos, ou exogenamente, pela administração de hTSH. No último caso, a morbidez e os efeitos deletérios decorrentes do hipotireoidismo induzido pela suspensão da terapia hormonal podem ser evitados, proporcionando uma melhor qualidade de vida aos pacientes. 
Tabela 1 Usos potenciais do r-hTSH. De: Sugino, 2006 (72)

- Seguimento de câncer de tireóide (uso indicado e aprovado pelo FDA)

Estímulo para teste de tireoglobulina e mapeamento de corpo inteiro

- Tratamento de câncer da tireóide

Estímulo para ablação com radioiodo

Adjuvante à quimioterapia

- Detecção de câncer de tireóide

Estímulo para o 18-fluordeoxiglicose (18-FDG) em PET

- Avaliação clínica da função tireoideana

Diagnóstico de hipotireoidismo

Diagnóstico diferencial de hipotireoidismo primário e secundário

Diagnóstico da diminuição da reserva tireoideana

- Avaliação da estrutura-função da tireóide

Função do receptor do TSH

Estudo das proteínas da tireóide e iodotironinas

- Mapeamento da tireóide

Melhoramento da qualidade do mapeamento da tireóide e de sua interpretação

- Tratamento com radioiodo

Tratamento de tireotoxicoses e de bócio

- Preparação de reagentes de imunoensaios (padrões e traçadores)

- Testes laboratoriais de bioatividade de TSH 
O TSH humano tem estrutura dimérica, sua molécula contendo duas subunidades ( $\alpha$ e $\beta$ ), não covalentemente ligadas. A subunidade $\alpha$ contém 92 aminoácidos com 5 pontes dissulfeto contribuindo para sua estrutura terciária e a subunidade $\beta$ contém 118 aminoácidos com 6 pontes dissulfeto (Tabela 2 e Figura 1) $(62,77)$. As cadeias de carboidratos no hTSH recombinante constituem $15-25 \%$ de seu peso. Ambas as subunidades são glicosiladas, com duas cadeias de oligossacarídeos de ligação- $\mathrm{N}$ na subunidade $\alpha$, localizadas na metade C-terminal da molécula, na asparagina 52 e 78 e uma na subunidade $\beta$, na asparagina 23 . Os oligosacarídeos da subunidade $\alpha$ são particularmente importantes na ação do hTSH durante a tradução pós-receptor do sinal (81), enquanto a glicosilação da subunidade $\beta$ é essencial para sua estabilidade e secreção (79). As duas cadeias na subunidade $\alpha$ tem funções intracelulares diferentes; o sítio de glicosilação 78 tem um papel na integridade do hormônio pois os oligossacarídeos ligados à Asn 78 participam no "folding" da subunidade $\beta$, enquanto os ligados ao sítio de glicosilação 52 aumentam a estabilidade do heterodímero sendo, portanto, importante para a associação das duas subunidades no heterodímero de hTSH intacto $(\mathbf{9}, \mathbf{2 0})$.

Tabela 2 Propriedades das subunidades $\alpha$ e $\beta$ de hTSH. De: Ribela, 2006 (62)

\begin{tabular}{c|c|c}
\hline Propriedade & Subunidade $\alpha$ & Subunidade $\beta$ \\
\hline \hline Estrutura primária & 92 aa & 118 aa \\
\hline Aminoácido N-terminal & Ala & Phe \\
\hline & $7-31$ & $2-52$ \\
Pontes dissulfeto & $10-60$ & $16-67$ \\
(Cys-Cys) & $28-82$ & $19-105$ \\
& $32-84$ & $31-83$ \\
& $59-87$ & $88-95$ \\
\hline \multirow{2}{*}{ Sítios de N-glicosilação } & Asn 52 & Asn 23 \\
\hline \hline
\end{tabular}


Subunidade alfa

Ala Pro Asp Val Gln Asp Cys Pro Glu Cys 10

Thr Leu Gln Glu Asn Pro Phe Phe Ser Gln 20

Pro Gly Ala Pro lle Leu Gln Cys Met Gly 30

$\begin{array}{lllllllll}\text { Cys Cys Phe Ser Arg Ala Tyr Pro } & \text { Thr }\end{array}$

Leu Arg Ser Lys Lys Thr Met Leu Val 50

Lys Asn Val Thr Ser Glu Ser Thr Cys Cys 60

$\begin{array}{lllllllll}\text { Val Ala Lys Ser Tyr Asn Arg Val Thr } 70 & \end{array}$

Met Gly Gly Phe Lys Val Glu Asn His Thr 80

Ala Cys His Cys Ser Thr Cys Tyr Tyr His 90

Lys Ser

\section{Subunidade beta}

Phe Cys lle Pro Thr Glu Tyr Thr Met His 10

Ile Glu Arg Arg Glu Cys Ala Tyr Cys Leu 20

Thr Ile Asn Thr Thr lle Cys Ala Gly 30

Cys Met Thr Arg Asp lle Asn Gly Lys Leu 40

$\begin{array}{llllllll}\text { Phe Leu Pro Lys Tyr Ala Leu Ser } & 50\end{array}$

Val Cys Thr Tyr Arg Asp Phe lle Tyr Arg 60

Thr Val Glu Trp Pro Gly Cys Pro Leu His 70

Val Ala Pro Tyr Phe Ser Tyr Pro Val Ala 80

Leu Ser Cys Lys Cys Gly Lys Cys Asn 90

Asp Tyr Ser Asp Cys lle His Glu Ala lle 100

Lys Thr Asn Tyr Cys Thr Lys Pro Gln Lys 110

$\begin{array}{lllllll}\text { Ser Tyr Leu Val Gly } & \text { Phe Ser Val }\end{array}$

Figura 1-Estrutura primária das subunidades $\alpha$ e $\beta$ de hTSH. De: Szkudlinski, 2002 (77) 
Um aspecto importante na produção de glicoproteínas com potencial uso terapêutico é a sua glicosilação e heterogeneidade de glicoformas.

A glicosilação é uma modificação pós-traducional sendo um processo de múltiplas etapas envolvendo centenas de enzimas. No processo de biossíntese in vivo, os carboidratos são inicialmente ligados a um lipídeo de cadeia longa (dolicol fosfato) e então transferidos à cadeia polipeptídica nascente. Isto ocorre no retículo endoplasmático. Aí ocorre uma série de reações catalisadas por exoglicosidases. $\mathrm{O}$ processamento dos oligosacarídeos continua no compartimento de Golgi catalisado por diferentes exoglicosidases e glicosiltransferases levando às estruturas complexas de carboidratos. Os oligossacarídeos basicamente podem estar ligados covalentemente a um resíduo de asparagina (Asn), glicosilação-N, ou à serina (Ser) ou treonina (Thr), glicosilação-O. No hTSH não há glicosilação -O.

Os oligossacarídeos do hTSH recombinante compreendem um núcleo pentassacarídeo $\left(\mathrm{Man}_{3} \mathrm{GlcNAC}_{2}\right)$ ligado a um resíduo de asparagina de uma sequência de aminoácidos ("sequon") Asn-X-Ser/Thr, onde X pode ser qualquer aminoácido exceto prolina (Figura 2), com a adição variável de resíduos de açúcar de fucose, galactose, ácido siálico e $\mathrm{N}$-acetil glucosamina. No caso do hTSH natural também são encontrados resíduos de $\mathrm{N}$-acetil galactosamina e sulfato. Morelle e colaboradores (51) observaram que os $\mathrm{N}$-glicanos do r-hTSH são diferentes em cada sítio de glicosilação e que os $\mathrm{N}$-glicanos fucosilados estão presentes apenas na subunidade $\alpha$, na Asn-52. Hiyama e colaboradores (36) observaram no p-hTSH que os componentes sulfatados/sialilados foram predominantes em ambos os sítios de glicosilação da subunidade $\alpha$. Com base na natureza e na localização dos resíduos de açúcar adicionados ao núcleo, os glicanos podem ser classificados em três subgrupos: os glicanos que possuem somente resíduos de manose ligados à estrutura do núcleo são chamados de "alta manose" ou "oligomanose", os glicanos que contem $\mathrm{N}$-acetilglucosamina na região da antena são chamados do "tipo complexo" e os que contem ambos os resíduos, manose e $\mathrm{N}$-acetilglucosamina, ligados ao núcleo são do "tipo híbrido" (50) (Figura 3). 


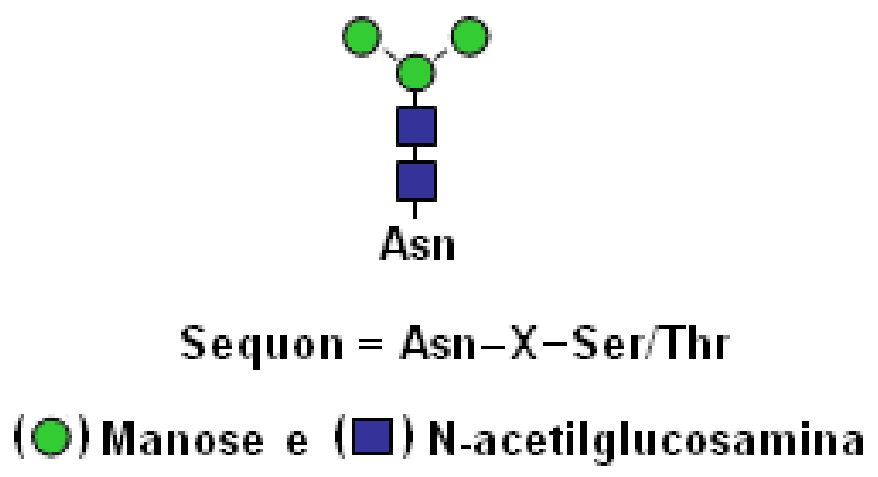

Figura 2 Núcleo de um N-glicano. De: Butler, 2006 (11)

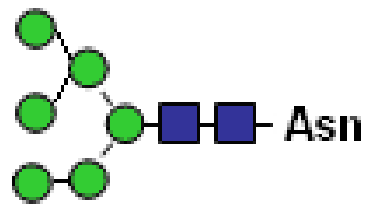

Alta manose

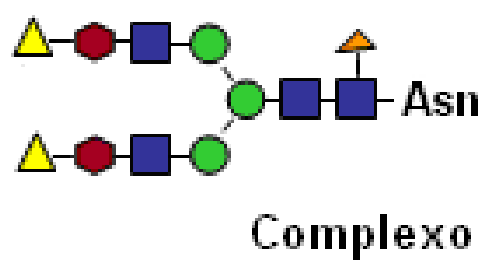

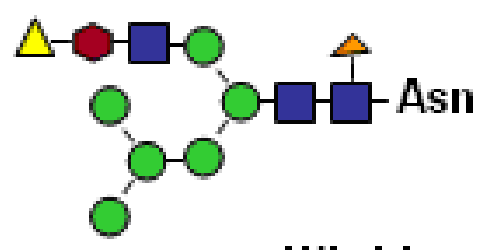

Híbrido

(O) Manose, ( $\square$ ) N-acetilglucosamina, $(\Delta)$ Fucose, ( $(\Delta)$ Galactose e $(\Delta)$ Ácido siálico

Figura 3 Tipos de glicosilação-N. De: Butler, 2006 (11) 
Tem sido mostrado que os glicanos tem um papel fundamental na associação das subunidades, na secreção, no "clearance" metabólico, na atividade biológica e na imunoreatividade do hormônio. A remoção de uma pequena parte das cadeias de carboidratos do TSH resulta na perda quase total da atividade do hormônio, enquanto com relação a atividade de ligação ao receptor não há nenhuma perda, podendo até ocorrer um aumento desta atividade. Estudos com o TSH usando tunicamicina para inibir a glicosilação, sugeriram que os oligossacarídeos são necessários para prevenir a agregação intracelular e a degradação das subunidades (4). No caso de eliminação da galactose foi mostrado que este monossacarídeo não afeta a atividade do hormônio, enquanto a eliminação de $\mathrm{N}$-acetil glucosamina reduz severamente a bioatividade in vivo do r-hTSH (80).

A composição terminal dos carboidratos possue importante papel na depuração metabólica in vivo do hTSH. De fato, os resíduos terminais de ácido siálico tem mostrado influenciar a bioatividade do hTSH recombinante, sendo a sialilação terminal responsável por proteger os hormônios de um "clearance" renal rápido, pois evitam o seu reconhecimento pelo receptor de asialo glicoproteínas, na superfície das células do fígado, que são as principais responsáveis pelo "clearance" sangüíneo das glicoproteínas (34). Sendo assim, preparações com baixo teor de ácido siálico permanecem um tempo menor na circulação comparadas àquelas com maior teor de ácido siálico e menor será sua atividade biológica in vivo $(\mathbf{7 4 , 7 5 , 7 6}$, $77,80,81,82$ ). Por outro lado, a atividade biológica in vitro foi demonstrada ser inversamente proporcional ao grau de sialilação $(12,33)$. Este efeito da sialilação na bioatividade in vitro do hTSH deve-se provavelmente ao fato de que quanto menos ácido siálico, maior a afinidade do hTSH ao seu receptor (74).

A variabilidade no conteúdo de ácido siálico ou de sulfato, ambos de carga negativa, causam uma heterogeneidade de carga no hTSH, o que leva a um perfil de focalização isoelétrica complexo (94). Szkudlinski e colaboradores (77) mostraram uma variação no ponto isoelétrico (pl) do $\mathrm{hTSH}$ recombinante em função do conteúdo de ácido siálico de 6,2 a 8,8 e mostraram que a amostra, sem ácido siálico, é homogênea, com um ponto isoelétrico de 8,8 . Glicoformas do hTSH hipofisário variaram no intervalo de $\mathrm{pH} \mathrm{6,8-8,3} \mathrm{(69).}$ 
A glicosilação é determinada pela estrutura primária da própria proteína e por uma cascata de modificações pós-transducionais realizadas pela célula hospedeira e conseqüentemente pode variar de hospedeiro para hospedeiro. Um exemplo representativo deste fato é a diferente estrutura das cadeias de açúcar do TSH humano recombinante produzido em células de ovário de hamster Chinês, que terminam em galactose-ácido siálico e do rec-hTSH produzido em células de insetos, que terminam em manose (Figura 4). Também uma mesma linhagem celular pode sintetizar diferentes estruturas dos carboidratos em moléculas que possuem a mesma seqüência de aminoácidos, como é por exemplo o caso das cadeias de alfa tireotrofina, alfa luteotrofina e alfa folitrofina que exibem diferentes padrões de glicosilação. Isto é devido à cadeia $\beta$ (diferente para cada hormônio) que já estando acoplada à cadeia $\alpha$, exerce sua influência nas glicosilações subseqüentes (78).

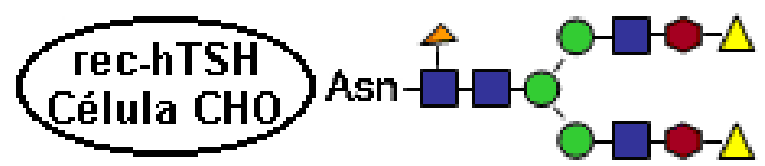

rec-hTSH Célula de inseto

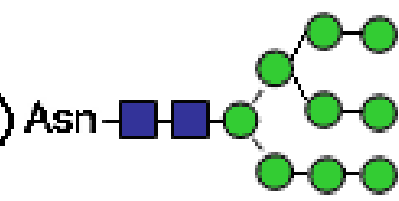

(O) Manose, $(\square)$ N-acetilglucosamina, $(\Delta)$ Fucose, ( $(\bullet)$ Galactose e $(\Delta)$ Ácido siálico

Figura 4- Estrutura de N-glicanos em r-hTSH obtido em diferentes hospedeiros. De: Grossmann, 1997 (33) 
Devido à complexa estrutura das glicoproteínas a sua síntese só pode ser obtida em sistemas de células eucariotas. Entre os sistemas eucariotas, levedura e plantas são incapazes de realizar glicosilação complexa como a dos mamíferos. As leveduras (Picchia pastoris ou Sacharomyces, por exemplo) realizam apenas glicosilação manosilada enquanto as plantas não possuem enzimas para processar a glicosilação-N das cadeias de oligossacarídeos terminando em galactose (Gal) e/ou ácido siálico (NeuAc). No caso de células de insetos estas não adicionam $\mathrm{N}$-acetilglucosamina (GlcNAc), Gal ou NeuAc $(42,61)$.

As células mais usadas na produção de proteínas recombinantes utilizadas em terapia humana são as células de ovário de hamster Chinês ( $\mathrm{CHO}$ ), principalmente em virtude destas terem um crescimento rápido e possuírem mecanismo de glicosilação muito semelhante ao das células humanas, podendo executar a complexa glicosilação necessária para a atividade biológica. Uma diferença entretanto encontrada entre estas células e as humanas é relativa à sialilação: as células de origem humana sialilam nas conformações $\alpha 2,3$ e $\alpha 2,6$, enquanto as células $\mathrm{CHO}$ tem deficiência de um gene codificando a enzima $\alpha 2,6$ sialiltransferase, apresentando apenas ácido siálico terminal em conformação $\alpha 2,3$. As células $\mathrm{CHO}$ também não possuem sulfotransferases, enzimas responsáveis pela sulfatação do carboidrato $\mathrm{N}$-acetilgalactosamina. Sendo assim, uma das terminações mais comuns das glicoproteínas humanas de origem hipofisária, o sulfato, não existe nos produtos derivados de células $\mathrm{CHO}$.

Diversos sub-clones das células $\mathrm{CHO}$, utilizando tecnologia de seleção e amplificação específica, tal como, por exemplo, aquela baseada no DHFR (sistema diidrofolato redutase), tornaram-se sistemas de expressão padrão. Uma linhagem celular $\mathrm{CHO}$ DHFR' mutante é transfectada com um vetor contendo o gene de interesse junto com o gene marcador DHFR. A seleção ocorre na ausência dos nucleosídeos hipoxantina e timidina e a amplificação do gene é realizada por exposição da célula a concentrações crescentes de Metotrexato (MTX), que inibem a atividade da enzima DHFR. Desta forma, a célula para sobreviver precisa amplificar continuamente a porção de DNA que contém o gene do DHFR e conseqüentemente, acaba amplificando também o gene de interesse (43). 
Tem sido reportado na literatura que diferentes condições da cultura celular podem afetar a glicosilação das proteínas recombinantes em vários níveis, levando a produtos com diferentes características, como peso molecular, ponto isoelétrico, hidrofobicidade ou atividade biológica $(3,10,11,26,27,28,39,58,67,93)$. Várias alterações das estratégias de cultivo tem sido reportadas visando aumentar a produtividade de proteínas recombinantes derivadas de células $\mathrm{CHO}$. Os rendimentos em proteínas de interese são diretamente proporcionais ao número de células viáveis e à longevidade da cultura celular. O crescimento celular ocorre em quatro fases: fase lag, log, estacionária e fase de declínio. Estratégias de controle da proliferação celular são realizadas na fase mediana ou na fase mais tardia do crescimento exponencial. A produção da proteína é dependente da fase do ciclo celular, sendo a fase G1 aquela de maior produção. Sendo assim, estratégias do cultivo celular que bloqueiam as células na fase $\mathrm{G} 1$ tem sido exploradas para aumentar a produtividade e sobrevida durante produções baseadas em cultura de células $\mathrm{CHO}(\mathbf{4 2}, \mathbf{4 8})$. A otimização do bioprocesso tem sido alcançada em resposta à alteração na temperatura de cultivo $(23,24,68,70,91)$, no nível de oxigênio dissolvido (84 e 85), no pH do meio (95), no dióxido de carbono dissolvido $\left(\mathrm{CO}_{2}\right)(86)$ ou nos aditivos ao meio $(\mathbf{1 4}, \mathbf{6 6}, \mathbf{7 3}, \mathbf{8 9})$. Não há na literatura estudos sobre o efeito destes fatores em relação à tireotrofina. No presente trabalho, com relação à estratégia de cultivo de células $\mathrm{CHO}$ produtoras de tireotrofina, dois destes fatores serão abordados: temperatura e $\mathrm{CO}_{2}$.

Tem sido amplamente descrita na literatura a influência da temperatura na produção de diversas proteínas recombinantes como Anticorpo IL-2 (Interleucina-2) $(68,70), \alpha$-amilase (25), Eritropoietina $(84,85,87,89,90,91)$, hGM-CSF (human granulocyte-macrophage colony-simulating factor) (22, 23), Interferon- $\beta$ (66), Interferon- $\gamma$ (24) e SEAP (secreted alkaline phosphatase) (37). Linhagens de células de mamíferos são usualmente cultivadas a $37^{\circ} \mathrm{C}$. Vários trabalhos mostram que a redução da temperatura de cultivo resulta na diminuição da taxa de crescimento celular, no aumento da longevidade da cultura e em uma maior produtividade da proteína recombinante $(22,68,70,87)$. Um processo ideal de produção é aquele em que ocorre uma fase de proliferação inicial, onde um nível desejável de densidade 
celular é atingido, seguida de uma fase de produção na qual as células tem uma taxa de crescimento baixa enquanto a produção específica da proteína de interesse é mantida em um nível alto e estável. Para um eficiente aumento de produtividade de proteínas recombinantes tem sido estudadas estratégias de cultura bifásica, que consistem de uma fase inicial de crescimento celular projetada para maximizar a biomassa e de uma fase de produção estendida, otimizada. Assim, a fase de proliferação das células ocorre a $37^{\circ} \mathrm{C}$ e a fase de produção ocorre em temperaturas menores $\left(28-33^{\circ} \mathrm{C}\right)$. Com este procedimento, quando ocorre a mudança de temperatura as células são bloqueadas na fase $\mathrm{G} 1$ do ciclo celular $(\mathbf{2 2}, \mathbf{2 3}, \mathbf{6 8}, \mathbf{8 4}$, $85,87)$. Células bloqueadas na fase $G 1$ do ciclo celular são metabolicamente mais ativas e maiores no tamanho do que células não bloqueadas $(7,13)$. Por estas razões, a fase G1 do ciclo celular é considerada a ideal para incrementar a produtividade da proteína de interesse. Os mecanismos pelos quais esta produtividade é aumentada em baixas temperaturas são ainda pouco entendidos, apesar de recentes estudos terem demonstrado que uma temperatura reduzida leva a uma resposta coordenada envolvendo ciclo celular, maquinaria de transcrição e transdução e arranjo celular (citoesqueleto) $(\mathbf{1}, \mathbf{4 2}, \mathbf{8 7})$. Um metabolismo reduzido associado à baixa temperatura leva a um retardo no início de apoptose e ajuda o prolongamento da fase estacionária/produção. A redução de temperatura ainda leva a um aumento dos níveis de mRNA devido ao aumento da transcrição do gene de interesse ou ao aumento da estabilidade do mRNA. Em condições de hipotermia discreta, a qualidade dos produtos recombinantes já descritos na literatura com relação à distribuição de isoformas, conteúdo de ácido siálico e atividade biológica in vivo é mantida. É importante ressaltar que os efeitos da temperatura na produtividade da proteína variam entre clones, linhagens celulares e proteínas.

Outro importante fator a ser avaliado nos estudos de otimização da produção de proteínas recombinantes é a concentração de dióxido de carbono $\left(\mathrm{CO}_{2}\right)$. Há evidências na literatura que $\circ \mathrm{CO}_{2}$ inibe o crescimento de células $\mathrm{CHO}$ de uma maneira dose-dependente (38). Um crescimento celular inicial lento seguido da cessação do crescimento foi observado por Yoon e colaboradores (86) quando células $\mathrm{CHO}$ foram cultivadas na ausência quase total de $\mathrm{CO}_{2}\left(0,03 \% \mathrm{CO}_{2}\right)$. O 
crescimento das mesmas células numa atmosfera de $5 \% \mathrm{CO}_{2}$ não sofreu inibição. A produção da eritropoietina recombinante ( $r$-EPO) foi maior na condição de 0,03\% $\mathrm{CO}_{2}$ do que sob $5 \% \mathrm{CO}_{2}$. Células $\mathrm{CHO}$ incubadas sob atmosfera de $5 \% \mathrm{CO}_{2}$ e no ar $\left(0,03 \% \mathrm{CO}_{2}\right)$ foram analisadas quanto ao ciclo celular e foi mostrado que após 48 horas de cultivo a porcentagem de células na fase G0/G1 dobrou, no caso da condição de $0,03 \% \mathrm{CO}_{2}$, enquanto na condição de $5 \% \mathrm{CO}_{2}$ permaneceu praticamente constante. Com relação à qualidade da proteína produzida nestas duas condições não foram observadas diferenças tanto na análise da bioatividade in vivo, por ensaio da medida de reticulócitos, como também no perfil de distribuição do peso molecular, analisado por Western blot. Com base nessas observações estes mesmos autores propuseram uma estratégia bifásica para o cultivo das células $\mathrm{CHO}$ produtoras da eritropoietina em que mantinham as células sob atmosfera de $5 \%$ de $\mathrm{CO}_{2}$ durante a fase de proliferação celular e reduziam o nível de $\mathrm{CO}_{2}$ na fase de produção da proteína, prolongando portanto a permanência das células na fase G1. Nestas condições foi observado um aumento na produtividade da eritropoietina recombinante de 2,2 vezes e uma diminuição no número de células de $\sim 40 \%$ com relação à condição padrão, isto é $5 \% \mathrm{CO}_{2}$, durante as duas fases do processo.

Estes mesmos autores ainda fizeram considerações sobre a possibilidade do $\mathrm{CO}_{2}$ afetar o metabolismo das células $\mathrm{CHO}$ via mudanças no $\mathrm{pH}$ da cultura celular, uma vez que se sabe que um dos papeis do $\mathrm{CO}_{2}$ no cultivo in vitro de células de mamíferos é manter o pH da cultura em $6,9-7,4$, o que é conseguido com $5 \%$ de $\mathrm{CO}_{2}$. Ao realizarem um estudo simulando uma elevação de $\mathrm{pH}$, via adição de bicarbonato de sódio, os autores observaram que não houve aumento da produção de EPO, nas condições de $5 \% \mathrm{CO}_{2}$, enquanto, a produção de EPO aumentou proporcionalmente à quantidade de bicarbonato de sódio adicionada, nas condições de $\mathrm{CO}_{2}$ reduzida. A partir destes resultados concluiram, portanto, que as alterações na produtividade da EPO não se devem apenas à mudanças de $\mathrm{pH}$.

É preciso ainda observar que no aumento de escala da produção de uma proteína recombinante, em bioreatores, a pressão parcial de $\mathrm{CO}_{2}\left(\mathrm{pCO}_{2}\right)$ pode facilmente ultrapassar níveis correspondentes ao range fisiológico $(31-54 \mathrm{mmHg})$. Vários trabalhos reportados na literatura $(\mathbf{1 7}, \mathbf{1 8}, \mathbf{3 0}, \mathbf{9 5})$ verificaram que aumentando 
a $\mathrm{pCO}_{2}$ acima de $105 \mathrm{mmHg}$, sob $\mathrm{pH}$ e osmolaridade $(\sim 350 \mathrm{mOsm} / \mathrm{Kg})$ controlados, ocorre uma inibição do crescimento celular e uma redução na produtividade da proteína. Alterações da qualidade da glicoproteína recombinante relativas à sialilação foram reportadas com o aumento de $\mathrm{pCO}_{2}$. Grampp e colaboradores (29) e Zanghi e colaboradores (92) observaram, em $\mathrm{pCO}_{2}$ elevadas, um decréscimo da sialilação.

Com excessão dos estudos aqui relatados, não há outros estudos relativos à influência da redução de $\mathrm{CO}_{2}$ na produção de glicoproteínas recombinantes em células de mamíferos.

Para o desenvolvimento de um processo consistente e robusto de produção de uma proteína recombinante fica claro, à luz do acima exposto, a necessidade de se conhecer a influência das condições de bioprocesso e do hospedeiro na qualidade do produto, juntamente com o incremento da produtividade. 


\subsection{Objetivo}

O objetivo do presente trabalho foi estudar a influência do hospedeiro $(\mathrm{CHO})$ e da estratégia de cultivo destas células nas estruturas glicídicas e propriedades moleculares da tireotrofina humana, juntamente com o aumento da produtividade. Para tanto, duas estratégias de cultivo foram estudadas:

Variação do nível de $\mathrm{CO}_{2}$

Variação da temperatura

Preparações recombinantes e de origem hipofisária foram estudadas no que se refere à massa molecular, à hidrofobicidade relativa, à atividade biológica, à distribuição de isômeros de carga e à composição e estrutura de carboidratos. Este estudo é de grande importância para o controle do produto final obtido, especialmente no que se refere à sua potência. Também podemos considerar que, alterando de uma maneira controlada os parâmetros mencionados, possam ser obtidas isoformas de hTSH (superagonistas ou antagonistas) de interesse clínico ou para a pesquisa sobre a estrutura-função deste hormônio. 


\section{MATERIAL E MÉTODOS}

\subsection{MATERIAL}

\subsubsection{Preparações hormonais utilizadas}

- $\quad$ hTSH de origem hipofisária (p-hTSH NIDDK, hTSH-SIAFP-B2) produzido e fornecido pelo "National Hormone and Pituitary Program" (Torrance, CA, EUA).

- $\quad$ hTSH de origem hipofisária (p-hTSH NOR), produzido e fornecido pelo $\mathrm{Dr}$. Peter A. Torjesen do "Aker University Hospital" (Oslo, Noruega).

- $\quad$ hTSH derivado de células de ovário de Hamster Chines (CHO) (Thyrogen ${ }^{\circledR}$ ), produzido por "Genzyme Corporation" (Cambridge, EUA) e fornecido pela Collect (São Paulo, SP, Brasil).

- $\quad$ hTSH derivado de células $\mathrm{CHO}$, produzido no laboratório de Hormônios do Centro de Biotecnologia do IPEN-CNEN/SP (hTSH IPEN), a partir de células $\mathrm{CHO}$, deficientes no gene da enzima diidrofolato redutase (DHFR), (linhagem mutante DXB-11), co-transfectadas com vetores dicistrônicos (pEDdc- $\alpha$ e pEAdc- $\beta-T S H)$ e submetidas à amplificação gênica com metotrexato (MTX) (57).

\subsubsection{Material utilizado no cultivo celular}

\subsubsection{Meios de cultura}

"Minimum Essential Medium" ( $\alpha-M E M)$ Gibco-BRL (Gaithersburg, MD, EUA).

- $\quad$ "Serum Free Medium" (CHO-S-SFM II), com nucleosídeo (hipoxantina e timidina), Gibco-BRL (Gaithersburg, MD, EUA). 


\subsubsection{Material plástico estéril}

- $\quad$ Garrafas de 75 e $225 \mathrm{~cm}^{2}$, Corning Costar Corp. (NY, EUA).

- $\quad$ Pipetas de 2, 5, 10 e $25 \mathrm{~mL}$, Corning Costar Corp. (NY, EUA).

- $\quad$ Placas de petri de $20 \mathrm{~cm}^{2}$, Corning Costar Corp. (NY, EUA).

- $\quad$ Sistema de filtração de $500 \mathrm{~mL}, 0,22 \mu \mathrm{m}$, Corning Costar Corp. (NY, EUA).

- $\quad$ Tubos criogênicos de $2 \mathrm{~mL}$, Corning Costar Corp. (NY, EUA).

- $\quad$ Tubos para centrífuga de 15 e 50 mL, Corning Costar Corp. (NY, EUA).

\subsubsection{Outros reagentes}

- $\quad$ Anfotericina B, Gibco-BRL (Gaithersburg, MD, EUA).

- $\quad$ Bicarbonato de sódio p.a., Sinth (São Paulo, Brasil).

- $\quad$ Gentamicina, Schering-Plougt (Rio de Janeiro, Brasil).

- $\quad$ Metotrexato (MTX), Sigma (St. Louis, MO, EUA).

- $\quad$ Penicilina - Streptomicina, Gibco-BRL (Gaithersburg, MD, EUA).

- $\quad$ Soro fetal bovino dialisado (SFBd), Gibco-BRL (Gaithersburg, MD, EUA).

- $\quad$ Tripsina, Gibco-BRL (Gaithersburg, MD, EUA).

\subsubsection{Material utilizado no processo de purificação e análise do hTSH}

\subsubsection{Colunas cromatográficas}

a) Coluna de vidro utilizada em cromatografia clássica

- $\quad$ Coluna XK $(20 \mathrm{~cm}$ X 16mm DI), GE Healthcare (Buckinghamshire, Inglaterra).

b) Colunas de aço inoxidável utilizadas em cromatografia líquida de alta eficiência (HPLC)

- $\quad$ Coluna TSK G $2000 \mathrm{SW}$ (60 cm X 7,5 mm D.I.), acoplada a uma pré-coluna $\mathrm{SW}$ (7,5 cm x 7,5 mm DI), Tosohaas (Montgomeryville, PA, EUA), para HPLC de exclusão molecular. 
- $\quad$ Coluna $\mathrm{C}_{4}, 214$ TP54 (25 cm X 4,6 mm D.I.), acoplada à pré-coluna $214 \mathrm{FSK}$ $54(5 \mu \mathrm{m}, 1,0 \mathrm{~cm} \times 4,6 \mathrm{~mm}$ D.I.), Vydac Separations Group (Hesperia, CA, EUA), para HPLC de fase reversa analítica.

- $\quad$ Coluna $\mathrm{C}_{4}, 214$ TP510 (25 cm X $10 \mathrm{~mm}$ D.I.), acoplada à pré-coluna $214 \mathrm{FSK}$ $54(5 \mu \mathrm{m}, 1,0 \mathrm{~cm} \times 4,6 \mathrm{~mm}$ D.I.), Vydac Separations Group (Hesperia, CA, EUA), para HPLC de fase reversa semi-preparativa.

\subsubsection{Resinas cromatográficas}

- Resina cromatográfica SP Sepharose Fast Flow (SPFF), GE Healthcare (Buckinghamshire, Inglaterra), para cromatografia clássica.

- $\quad$ Sílica gel, grupo funcional Diol, tamanho das partículas $10 \mu \mathrm{m}$ e poros de 125 A, Tosohaas (Montgomeryville, PA, EUA), para HPLC de exclusão molecular.

- $\quad$ Sílica com grupos de ligação butil alifático, tamanho das partículas $5 \mu \mathrm{m}$ e diâmetro dos poros de 300 A, Vydac Separations Group (Hesperia, CA, EUA) para HPLC de fase reversa.

\subsubsection{Reagentes químicos}

Acetonitrila grau HPLC, Mallinckrodt (Phillipsburg, EUA).

- $\quad$ Acetato de sódio, Merck (São Paulo, Brasil).

- $\quad$ Ácido Acético, Labsynth (São Paulo, Brasil).

- $\quad$ Cloreto de Sódio p.a., Merck (São Paulo, Brasil).

- $\quad$ Fosfato de sódio monobásico p.a., Merck (São Paulo, Brasil).

- $\quad$ Fosfato de sódio bibásico p.a., Merck (São Paulo, Brasil).

- $\quad$ Metanol, grau HPLC, Mallinckrodt (Phillipsburg, EUA). 


\subsubsection{Material utilizado nos imunoensaios}

\subsubsection{Anticorpos}

- $\quad$ Anticorpo monoclonal (mAB) anti hTSH (anticorpo de detecção utilizado no radioensaio), fornecido pelo Netria, North East Thames Region Immunoassay Unit (Londres, Inglaterra).

- $\quad$ Anticorpo policlonal anti hTSH acoplado a celulose (anticorpo de captura, fase sólida), fornecido pelo Netria, North East Thames Region Immunoassay Unit (Londres, Inglaterra).

\subsubsection{Reagentes para marcação do anticorpo de detecção}

- $\quad$ Cloramina T p. a., Merck (São Paulo, Brasil).

- $\quad$ lodeto de Potássio p.a., Merck (São Paulo, Brasil).

- $\quad$ Metabissulfito de Sódio, Carlo Erba (São Paulo, Brasil).

- $\quad \mathrm{Na}^{125}$ I comercial livre de carregadores e oxidantes, com atividade específica de $11100-22200 \mathrm{MBq} / \mathrm{mL}(300-600 \mathrm{mCi} / \mathrm{mL})$, Nordion Europe S.A. (Fleurus, Bélgica).

\subsubsection{Outros reagentes}

Azida Sódica, Sigma (St. Louis, EUA).

- $\quad$ Controles de qualidade para imunoensaios baseados em sangue humano, Lyphochek Immunoassay Plus control (1, 2, 3), Bio Rad (Invinu, CA, EUA).

- $\quad$ Fosfato de sódio monobásico p.a., Merck (São Paulo, Brasil).

- $\quad$ Fosfato de sódio bibásico p.a., Merck (São Paulo, Brasil).

- $\quad$ Soro albumina bovina (BSA) RIA Grade (fração V), Sigma (St. Louis, EUA).

- $\quad$ Tween 20, Sigma (St. Louis, EUA). 


\subsubsection{Material utilizado no ensaio biológico}

- Camundongos machos da linhagem isogênica Balb-C, com peso de 22 - 30g, oriundos do Biotério de Criação e Manutenção de Animais de Laboratório do IPEN/CNEN - SP.

- $\quad$ Microtubos de homo-polímero, de 1,5mL, Axygen (Union City, CA, EUA).

- $\quad$ Pipeta Pasteur de vidro, Corning (New York, EUA).

- $\quad$ Sal de sódio de 3,3',5-triiodo-L-tironina ( $\left.T_{3}\right)$, Sigma (St. Louis, MO, EUA).

- $\quad$ Sistema de radioimunoensaio para dosagem de tiroxina total $\left(T_{4}\right)$, RIA Coat-ACount ${ }^{\circledR}$ Total $T_{4}$, Diagnostic Products Corporation (DPC) (Los Angeles, CA, EUA).

\subsubsection{Material utilizado na focalização isoelétrica}

Ácido Acético p.a., Labsynth (São Paulo, Brasil).

- $\quad$ Ácido fosfórico p.a., Mallinckrodt (Phillipsburg, EUA).

- $\quad$ Anfolina, pH 3,5 - 9,5, GE Healthcare (Buckinghamshire, Inglaterra)

- Bisacrilamida, Merck (São Paulo, Brasil).

- $\quad$ Coomassie Brilliant Blue R 250, GE Healthcare (Buckinghamshire, Inglaterra).

- Dodecil Sulfato de Sódio (SDS), GE Healthcare (Buckinghamshire, Inglaterra).

- $\quad$ Glicina, GE Healthcare (Buckinghamshire, Inglaterra).

- $\quad$ Hidróxido de sódio p.a., Merck (São Paulo, Brasil).

- Marcador para focalização isoelétrica, pH 3,0 - 10, GE Healthcare (Buckinghamshire, Inglaterra).

- $\quad$ Membrana de PVDF (0,2 $\mu \mathrm{m})$, Sequi-Blot - Biorad (Hercules, CA, EUA).

- $\quad$ Metanol p.a., Merck (São Paulo, Brasil).

- $\quad$ Persulfato de amônio, Merck (São Paulo, Brasil).

- $\quad$ TRIS-base, GE Healthcare, (Buckinghamshire, Inglaterra).

\subsubsection{Material utilizado no ensaio de dosagem de proteína total} Kit micro BCA, Pierce (Rockford, EUA).

- Placas de microtitulação com fundo em "U”, Dynatech (Chantilly, EUA). 


\subsection{Equipamentos e acessórios principais}

- $\quad$ Agitador magnético modelo 258, Fanem (São Paulo, Brasil).

- Agitador rotatório de tubos ("rotator"), fornecido pelo laboratório NETRIA, North East Thames Region Immunoassay Unit (Londres, Inglaterra).

- $\quad$ Agitador rotatório tipo vortex, modelo 162, Marconi (São Paulo, Brasil).

- $\quad$ Aparelho de cromatografia líquida de alta eficiência (HPLC), modelo SCL-10A, acoplado a um detector de UV SPD-10AV e a um programa de computador Class VP, Shimadzu (MD, EUA).

- $\quad$ Aparelho para dosagem de glicose Accu-Check Active, Roche (Boeringher, Mannhein, Alemanha).

- $\quad$ Autoclave vertical, modelo 103, Fabbe-Primar (São Paulo, Brasil).

- $\quad$ Balança analítica, modelo H20T, Mettler (Zurich, Suíça).

- $\quad$ Balança analítica, modelo P100N, Mettler (Zurich, Suíça).

- $\quad$ Balança analítica, modelo M5AS, Mettler (Zurich, Suíça).

- $\quad$ Bomba peristáltica modelo P-1, GE Healthcare (Buckinghamshire, Inglaterra).

- Câmera de Neubauer, Boeco (Hamburg, Alemanha).

- $\quad$ Centrífuga, modelo LS-3 plus, Celm (São Paulo, Brasil).

- Centrífuga refrigerada automática modelo Super Speed RC - 2B, Sorvall (Newtown, Connecticut, EUA).

- Coletor de frações, modelo Frac-200, GE Healthcare (Buckinghamshire, Inglaterra).

- $\quad$ Contador gama tipo "poço", com troca automática de amostra, modelo Cobra auto-gama, eficiência aproximada para ${ }^{125} \mid$ de $80 \%$, Packard Instrument Company (Illinois, EUA).

- $\quad$ Destilador de água, modelo 016, Fabbe-Primar (São Paulo, Brasil).

- $\quad$ Estufa de cultura celular, modelo 3159, Forma Scientific (Marietta, Ohio, EUA).

- $\quad$ Fluxo Laminar classe II A/B 3, modelo 1140, Forma Scientific (Marietta, Ohio, EUA).

- $\quad$ Fonte de alta tensão para eletroforese ECPS 3000/150, GE Healthcare (Buckinghamshire, Inglaterra). 
- Fonte de alta tensão para eletroforese EPS 600, GE Healthcare (Buckinghamshire, Inglaterra).

- $\quad$ Freezer $-20^{\circ} \mathrm{C}$, modelo 0651, Prosdócimo (São Paulo, Brasil).

- $\quad$ Freezer $-40^{\circ} \mathrm{C}$, modelo AB 240, Metalfrio (São Paulo, Brasil).

- $\quad$ Freezer $-80^{\circ} \mathrm{C}$, modelo 8425 , Forma Scientific (Marietta, Ohio, EUA).

- $\quad$ Leitor de placas de microtitulação modelo MR400 (Dynatech, Bethesda, EUA).

- $\quad$ Liofilizador, modelo Dura Stop - TDS - 3 DURA DRY, FTS Systems (Stone Ridge, EUA).

- $\quad$ Medidor digital de pH, modelo 420A, Orion (Boston, MA, EUA).

- Membrana para diálise modelo SnakeSkin, 3.500 MWCO, Pierce (Rockford, IL, EUA).

- Membranas de filtração de 0,22 $\mu \mathrm{m}$, Millipore (Bedford, MA, EUA).

- $\quad$ Microscópio invertido, modelo ID 03, Carl Zeiss (Oberkochen, Alemanha).

- $\quad$ Refrigerador duplex, modelo 320 clear, Brastemp (São Paulo, Brasil).

- $\quad$ Refrigerador com porta de vidro modelo VE 730, Metalfrio (São Paulo, Brasil).

- $\quad$ Sistema de purificação de água Milli-Q plus, Millipore (Bedford, EUA).

- Tubos de poliestireno para imunoensaios (7,5x1,2 cm), EMTEL (São Paulo, Brasil).

- Sistema de focalização isoelétrica Multiphor II, GE Healthcare (Buckinghamshire, Inglaterra).

- Sistema de transferência semi-seco Hoefer TE 70, GE Healthcare (Buckinghamshire, Inglaterra). 


\subsection{MÉTODOS}

\subsubsection{Cultura celular}

$\mathrm{O}$ cultivo de células $\mathrm{CHO}$ produtoras de hTSH foi realizado em três condições:

\section{a- Condição padrão de produção de hTSH}

As células $\mathrm{CHO}$ transfectadas $\left(\sim 10^{6}\right.$ células) foram cultivadas a $37^{\circ} \mathrm{C} \mathrm{e}$ atmosfera de $5 \%$ de $\mathrm{CO}_{2}$, em frascos de $225 \mathrm{~cm}^{2}$ com $40 \mathrm{~mL}$ de meio de cultura $\alpha$ MEM contendo $10 \%$ de soro fetal bovino dialisado (dFBS). Durante aproximadamente cinco dias as células foram mantidas nesse meio até atingirem $80 \%$ de confluência. Após a confluência, o meio foi substituído por meio CHO-S-SFM II suplementado com penicilina/estreptomicina $(50 \mu \mathrm{g} / \mathrm{mL})$, gentamicina $(40 \mu \mathrm{g} / \mathrm{mL})$, anfotericina $B(0,25 \mu \mathrm{g} / \mathrm{mL})$ e metotrexato MTX $(0,1 \mu \mathrm{M})$. O meio de cultura (sem soro) de diferentes frascos foi trocado e coletado diariamente, centrifugado a $1000 \mathrm{x}$ $\mathrm{g}$ por 5 minutos, sendo as células removidas e o sobrenadante coletado e armazenado a $-20^{\circ} \mathrm{C}$. Durante todo o cultivo, o $\mathrm{hTSH}$ produzido foi quantificado mediante ensaio imunorradiométrico (IRMA).

\section{b- Variação da temperatura na fase de produção do hTSH}

$\mathrm{O}$ esquema de cultivo das células $\mathrm{CHO}$ produtoras de hTSH utilizado neste caso é apresentado na Tabela 3. Para este tipo de cultivo, foram seguidos os mesmos passos da produção na condição padrão, até as células atingirem $80 \%$ de confluência, quando então a temperatura foi reduzida para $30^{\circ} \mathrm{C}$, assim permanecendo até o final do processo de produção. Após um dia de adaptação das células à nova condição de temperatura, o meio $\alpha$-MEM foi trocado para meio SFMII. O meio de cultura (sem soro) de diferentes frascos foi trocado e coletado diariamente e centrifugado a $1000 \times$ g por 5 minutos, sendo as células removidas e o sobrenadante coletado armazenado a $-20^{\circ} \mathrm{C}$. O hTSH coletado durante todo período de produção foi quantificado via IRMA. 
Tabela 3 Esquema de cultivo utilizado para células $\mathrm{CHO}$ produtoras de hTSH

\begin{tabular}{|c|c|c|c|}
\hline & \multicolumn{2}{|c|}{$\begin{array}{c}\text { Fase de crescimento } \\
\text { das células } \mathrm{CHO} \\
\text { Meio } \alpha-\mathrm{MEM} \\
\end{array}$} & $\begin{array}{c}\text { Fase de produção } \\
\text { de hTSH } \\
\text { Meio SFM-II } \\
\end{array}$ \\
\hline Condição 1 & \multicolumn{2}{|c|}{$37^{\circ} \mathrm{C}$} & $37^{\circ} \mathrm{C}$ \\
\hline Condição 2 & $\begin{array}{c}37^{\circ} \\
\text { Até confluência } \\
\text { (3-5 dias) }\end{array}$ & $\begin{array}{c}30^{\circ} \mathrm{C} \\
\text { Adaptação } \\
\text { (1 dia) }\end{array}$ & $\begin{array}{l}30^{\circ} \mathrm{C} \\
\text { Coletas diárias } \\
\text { (20 dias) }\end{array}$ \\
\hline
\end{tabular}

c- Variação de $\mathrm{CO}_{2}$ na fase de produção de hTSH

$\mathrm{O}$ esquema de cultivo das células $\mathrm{CHO}$ produtoras de $\mathrm{hTSH}$, utilizado neste caso, é apresentado na Tabela 4. Para este tipo de cultivo, foram seguidos os mesmos passos da produção na condição padrão, até as células atingirem $80 \%$ de confluência quando então $\mathrm{o}^{\mathrm{CO}_{2}}$ foi reduzido de $5 \%$ para $0,03 \%$, assim permanecendo durante todo período de produção. Após um dia de adaptação das células à nova condição de $\mathrm{CO}_{2}$, o meio $\alpha$-MEM foi substituído por meio $\mathrm{CHO}-\mathrm{SFM}$ II. O meio de cultura (sem soro) de diferentes frascos foi trocado e coletado diariamente e centrifugado a $1000 \times \mathrm{g}$ por 5 minutos, sendo as células removidas e o sobrenadante coletado armazenado a $-20^{\circ} \mathrm{C}$. O hTSH coletado durante todo período de produção foi quantificado via IRMA.

Tabela 4 Esquema de cultivo utilizado para células $\mathrm{CHO}$ produtoras de hTSH

\begin{tabular}{|c|c|c|c|}
\hline & \multicolumn{2}{|c|}{$\begin{array}{c}\text { Fase de crescimento } \\
\text { das células CHO } \\
\text { Meio } \alpha-\text { MEM }\end{array}$} & $\begin{array}{c}\text { Fase de produção } \\
\text { de hTSH } \\
\text { Meio SFM-II }\end{array}$ \\
\hline Condição 1 & \multicolumn{2}{|c|}{$5 \% \mathrm{CO}_{2}$} & $5 \% \mathrm{CO}_{2}$ \\
\hline Condição 2 & $\begin{array}{l}5 \% \mathrm{CO}_{2} \\
\text { Até confluência } \\
\text { (3-5 dias) }\end{array}$ & $\begin{array}{l}0,03 \% \mathrm{CO}_{2} \\
\text { Adaptação } \\
\text { (1 dia) }\end{array}$ & $\begin{array}{l}0,03 \% \mathrm{CO}_{2} \\
\text { Coletas diárias } \\
(20 \text { dias })\end{array}$ \\
\hline
\end{tabular}




\section{d- Análises}

Em todos os experimentos descritos anteriormente o número de células foi contado diariamente em câmera de Neubauer, após a tripsinização das células e a homogeneização da suspensão celular.

A concentração de glicose $(\mathrm{mg} / \mathrm{dL})$ no meio de cultura condicionado foi medida em um aparelho digital "Accu-Check Active", cujo range de leitura é de 0-400 mg/dL.

$\mathrm{O} \mathrm{pH}$ do meio de cultura condicionado foi medido diretamente em um pHmetro digital, a temperatura ambiente $\left(25^{\circ} \mathrm{C}\right)$.

\subsubsection{Purificação}

O processo de purificação do hTSH empregado neste trabalho consistiu de duas etapas cromatográficas, uma cromatografia clássica de troca iônica seguida de uma cromatografia líquida de alta eficiência de fase reversa.

\section{a- Cromatografia de troca iônica (catiônica)}

Em uma purificação típica, o meio condicionado, após ter seu pH acertado para 5,0 , foi aplicado a uma coluna de $2,6 \mathrm{~cm}$ de diâmetro $X 10 \mathrm{~cm}$ de altura, contendo a resina SP Sepharose Fast Flow (SPFF) (resina de troca catiônica), previamente equilibrada em 0,02M de acetato de sódio, $\mathrm{pH} 5,0$ com 0,05M de $\mathrm{NaCl}$. Após lavagens sucessivas (cinco volumes de coluna no mínimo) com este mesmo tampão, as proteínas foram eluídas neste mesmo tampão com um gradiente linear de $\mathrm{NaCl}$ $(0,05 \mathrm{M}$ a $0,25 \mathrm{M})$. O fluxo utilizado foi de $200 \mathrm{~mL} / \mathrm{h}$ e as frações coletadas foram de $5 \mathrm{~mL}$.

\section{b- Cromatografia líquida de alta eficiência em fase reversa semi-preparativa (RP-HPLC)}

O pool das frações contendo hTSH, detectado por IRMA, resultante da primeira etapa de purificação, foi concentrado para $10 \mathrm{~mL}$ em um dispositivo filtrante de centrífuga Amicon Ultra-15 e aplicado a uma coluna $\mathrm{C}_{4}$ semi-preparativa de fase reversa. A coluna, conectada a um HPLC, foi mantida a $25^{\circ} \mathrm{C}$ e foram usados na fase 
móvel dois tampões $A$ e $B$ (tampão $A$ : fosfato de sódio $0,05 \mathrm{M}$ pH 7,0 e tampão $B$ : $50 \%$ de $A+50 \%$ de acetonitrila). A eluição das proteínas foi realizada com um gradiente linear de 25 a $100 \%$ de tampão B, durante 40 minutos. Um fluxo de trabalho de $2,5 \mathrm{~mL} / \mathrm{min}$ e detecção por luz ultra-violeta (UV) no comprimento de onda de $220 \mathrm{~nm}$ foram utilizados. O pool final foi dialisado contra tampão fosfato de sódio 0,02M, pH 7,0, contendo $0,15 \mathrm{M} \mathrm{NaCl}$ e $5 \mathrm{mg} / \mathrm{mL}$ de glicina. Após a diálise, o hTSH foi liofilizado sob vácuo controlado entre $100-200 \mathrm{mT}$ na fase primária e sob vácuo máximo na fase secundária para retirada da umidade residual.

\subsubsection{Avaliação da proteína de interesse}

\subsubsection{Cromatografia líquida de alta eficiência (HPSEC e RP-HPLC)}

A avaliação qualitativa e quantitativa do rec-hTSH, nas diferentes etapas do processo de purificação e no meio condicionado, foi realizada por técnica de cromatografia líquida de alta eficiência de exclusão molecular (HPSEC) e em fase reversa (RP-HPLC) $(\mathbf{1 6}, \mathbf{5 2}, \mathbf{6 3})$. Em ambas, a detecção foi feita mediante luz ultravioleta (UV), no comprimento de onda de $220 \mathrm{~nm}$.

No caso da HPSEC, a técnica de eluição foi isocrática tendo sido utilizada como fase móvel o tampão fosfato de sódio $0,02 \mathrm{M}, \mathrm{pH} 7,0$ contendo cloreto de sódio $0,15 \mathrm{M}$, sendo o fluxo de trabalho de $1,0 \mathrm{~mL} / \mathrm{min}$.

Na RP-HPLC a coluna foi mantida a $25^{\circ} \mathrm{C}$ e foram usados na fase móvel dois tampões A e B (tampão A: fosfato de sódio 0,05M, pH 7,0 e tampão B: $50 \%$ de $A+$ $50 \%$ de acetonitrila). Um gradiente linear de 25 a $100 \%$ de tampão $B$ foi estabelecido durante 40 minutos, com fluxo de trabalho de $0,5 \mathrm{~mL} / \mathrm{min}$.

Tanto em HPSEC quanto em RP-HPLC a determinação do tempo de retenção e a quantificação se fez sempre comparativamente à preparação recombinante comercial Thyrogen (Genzyme). 


\subsubsection{Ensaio imunorradiométrico (IRMA) do rec-hTSH}

A cada ensaio uma curva dose-resposta é determinada relacionando a fração ligada de anticorpo marcado com ${ }^{125}$ I (cpm) com concentrações conhecidas de hTSH $(\mu \mathrm{Ul} / \mathrm{mL})$, no intervalo de $0,15-100 \mu \mathrm{Ul} / \mathrm{mL}(\mathbf{5 6}, \mathbf{6 0})$. Os seguintes reagentes são adicionados simultaneamente e mantidos por 16 horas ("overnight") a temperatura ambiente, em um agitador rotatório de tubos ("rotator"):

$100 \mu \mathrm{L}$ de amostra padrão ou de amostra desconhecida;

$50 \mu \mathrm{L}$ de ${ }^{125} \mathrm{I}-\mathrm{mAB}$ anti-hTSH ( $\left.60000 \mathrm{cpm}\right)$;

$300 \mu \mathrm{L}$ de tampão fosfato de sódio $0,05 \mathrm{M}, \mathrm{pH} 7,4$ contendo $1 \%$ de BSA e $0,5 \%$ de Tween 20;

$50 \mu \mathrm{L}$ de fase sólida (anticorpo anti-hTSH acoplado à celulose).

A seguir são adicionados $2,0 \mathrm{~mL}$ de tampão de lavagem (fosfato de sódio $0,05 \mathrm{M}, \mathrm{pH} 7,4+0,1 \%$ de azida sódica $+0,5 \%$ tween 20 ) e a separação entre a fração livre e a fração ligada se dá por centrifugação a $5000 \times \mathrm{g}$ por $30 \mathrm{~min}$ a $4^{\circ} \mathrm{C}$, sendo esta etapa de lavagem repetida por duas vezes. Em todos os ensaios foram utilizados paralelamente preparações comerciais de controle de qualidade com diferentes níveis de concentração de hTSH. Todas as amostras são incubadas em duplicata.

\subsubsection{Determinação de proteína total}

A concentração de proteína total foi estimada usando o método "Micro BCA". Este consiste na detecção colorimétrica e quantificação da proteína total em solução diluída após reação com ácido bicinconínico (BCA). A cada ensaio é determinada uma curva padrão de calibração que relaciona diferentes concentrações de soro albumina bovina (BSA) pura $(0,5-200 \mu \mathrm{g} / \mathrm{mL})$ com a absorvância correspondente, no comprimento de onda de $540 \mathrm{~nm}$. Os seguintes reagentes são adicionados simultaneamente em cada poço de placas de microtitulação: $125 \mu \mathrm{L}$ de amostra; $125 \mu \mathrm{L}$ de reagente de trabalho. O reagente de trabalho é constituído por: $50 \%$ solução A (carbonato de sódio, bicarbonato de sódio, tartarato de sódio e hidróxido de sódio); $48 \%$ solução $B$ (solução aquosa de ácido bicinconínico $4 \%$ ) e $2 \%$ solução C (sulfato cúprico penta-hidratado $4 \%$ ). 


\subsubsection{Atividade biológica mediante ensaio in vivo}

A atividade biológica das preparações de hTSH foi avaliada em um ensaio in vivo em camundongos Balb C (19), no qual o $\mathrm{T}_{4}$ induzido pelo $\mathrm{hTSH}$ é determinado por radioimunoensaio (RIA) utilizando um kit da Diagnostic Products Corporation (DPC). Após supressão do TSH endógeno por administração, durante cinco dias, de $\mathrm{T}_{3}(3 \mathrm{mg} / \mathrm{mL})$ dissolvido em água do bebedouro dos camundongos, uma única dose $(10 \mu \mathrm{g})$ de hTSH por animal é injetada intraperitonealmente. Seis horas após esta injeção é coletada uma amostra de sangue do plexo retro-orbital, na qual é dosado o $\mathrm{T}_{4}$. Em cada ensaio são utilizados seis animais para cada preparação.

\subsubsection{Espectometria de massa MALDI-TOF}

A massa molecular de amostras de hTSH ( 20-30 pmoles de cada hormônio) foi determinada por espectrometria de massa MALDI-TOF (Matrix Assisted Laser Desorbtion lonization-Time of Flight mass espectrometry) no laboratório Commonwealth Biotechnologies Inc. (Richmond, VA, EUA). A espectrometria de massa foi realizada em um espectrômetro de massa Voyager $D E$, operando no modo linear do íon-positivo, utilizando o ácido sinapínico (AS) como matriz (solução saturada de AS em $50 \%$ de acetonitrila/0,1\% de ácido trifluoroacético).

\subsubsection{Distribuição de isômeros de carga}

A distribuição de isômeros de carga de amostras de hTSH, foi obtida por focalização isoelétrica. Nesta técnica eletroforética as proteínas migram até encontrar um $\mathrm{pH}$ no meio eletroforético que seja correspondente ao seu ponto isoelétrico. Para que isto ocorra é necessário que seja estabelecido um gradiente de $\mathrm{pH}$ entre o anodo e o catodo. Tal gradiente é formado pela migração rápida de certas substâncias poliméricas denominadas anfólitos. A focalização isoelétrica foi feita em gel de poliacrilamida a $6 \%$, utilizando anfólitos de $\mathrm{pH} 3,5-9,5$. Durante trinta minutos foram utilizados 500 volts para proporcionar um gradiente de $\mathrm{pH}$ no gel. As amostras focalizam utilizando 1500 volts durante uma hora. Em cada corrida eletroforética 
utiliza-se um marcador de ponto isoelétrico no intervalo de 3,5-9,5. As bandas protéicas resultantes da focalização são transferidas, via eletroblotting, a uma membrana de PVDF por duas horas, utilizando 25 volts. A visualização das bandas é conseguida após mergulhar a membrana, durante 2 minutos, em solução corante Coomassie Brilliant Blue R250.

\subsubsection{Análise da porção glicídica do hTSH}

\subsubsection{Análise composicional}

O número de nmoles de açúcar por $\mu \mathrm{g}$ de proteína de cada um dos seguintes monossacarídeos que compõem a parte glicídica do hTSH foi determinado: Fucose, $\mathrm{N}$-acetilgalactosamina, $\mathrm{N}$-acetilglucosamina, galactose, manose e ácido neuramínico ou siálico. Para esta determinação foram utilizadas cromatografia gasosa e espectrometria de massa (GC/MS) para separação e análise dos monossacarídeos após sua liberação mediante metanólise acídica. Estas análises foram realizadas no "Complex Carbohydrate Research Center de Atlanta (EUA)".

\subsubsection{Análise estrutural}

As análises das estruturas dos carboidratos ligados à asparagina ( $\mathrm{N}$-glicanos) que compõem as diferentes preparações de hTSH em estudo foram realizadas após clivar os glicanos com a glicosidase PNGase F de F. meningosepticum, separá-los da proteína e marcá-los com ácido amino benzóico fluorescente (4-ABA). Após a marcação, os carboidratos foram analisados por HPLC em fase-normal, usando uma coluna de TSK-gel Amide-80 (4,6 X 250 mm, $5 \mu \mathrm{m}$; TOSOH Bioscience, Stuttgart, Alemanha). Os tempos de retenção dos picos detectados foram comparados aos tempos de retenção de padrões de açúcares comerciais da Dextra Laboratories (Residing, Inglaterra) e Glyko (Novato, CA, EUA). As análises foram realizadas em colaboração com o "Department of Biotechnology, University of Natural Resources and Applied Life Sciences, Vienna, Austria". 
2.3.7.3 Análise da ligação do ácido siálico à galactose nas conformações

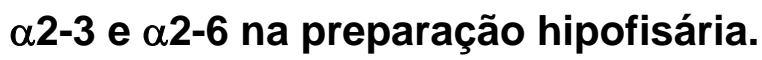

Para esta análise foram utilizadas lectinas com afinidades específicas para o

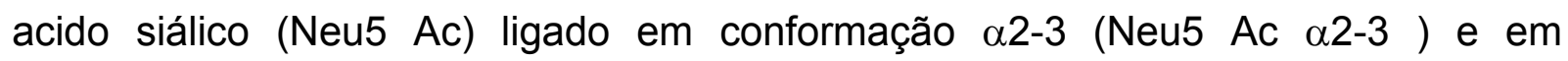
conformação $\alpha 2-6$ (Neu5 Ac $\alpha 2-6$ ) à galactose. Para a detecção da interação dos Nglicanos foi usado um anticorpo anti-hTSH biotinilado posteriormente conjugado à estreptavidina. $\mathrm{O} \mathrm{TSH}$ foi tratado ou com uma neuraminidase ativa nas duas ligações ou com a neuraminidase predominantemente específica para ligação $\alpha 2-3$. Esta determinação foi realizada no laboratório "Proteodynamics" (Saint Beauzine, França). 


\section{RESULTADOS}

\subsection{Obtenção do rec-hTSH IPEN}

\subsubsection{Condições de cultivo das células $\mathrm{CHO}$ produtoras de hTSH}

\subsection{1.a- Variação da temperatura}

Neste estudo, tanto na condição um como na condição dois de cultura das células $\mathrm{CHO}$, não foram observadas diferenças de comportamento nas duas temperaturas analisadas quanto ao $\mathrm{pH}$ e à glicose.

O número de células nos primeiros quatro dias de cultivo foi maior na temperatura de $37^{\circ} \mathrm{C}$, tornando-se praticamente igual nos dias subseqüentes (Figura $5 A)$.

Durante os cinco primeiros dias de cultivo, a concentração de hTSH no meio de cultura foi maior a $30^{\circ} \mathrm{C}$, tornando-se inferior nos quatro dias subseqüentes (Figura 5B).

Quanto à produtividade específica (Figura $5 \mathrm{C}$ ), na temperatura de $37^{\circ} \mathrm{C}$, nos primeiros quatro dias, a produtividade média de $\mathrm{hTSH}$ foi de $0,55 \mu \mathrm{g}$ $\mathrm{hTSH} / 10^{6}$ cels./dia, tendo aumentado nos últimos cinco dias, chegando a $1,3 \mu \mathrm{g}$ hTSH $/ 10^{6}$ cels./dia. Com a temperatura de $30^{\circ} \mathrm{C}$ ocorreu o contrário, houve uma maior produtividade de hTSH nos primeiros cinco dias $\left(1,45 \mu \mathrm{g} \mathrm{hTSH} / 10^{6}\right.$ cels./dia), do que nos quatro dias restantes $\left(0,61 \mu \mathrm{g} \mathrm{hTH} / 10^{6}\right.$ cels./dia).

Não observamos melhora significativa da produtividade de hTSH $(\mu \mathrm{g} / \mathrm{mL}) \mathrm{com}$ variação da temperatura de $37^{\circ} \mathrm{C}$ para $30^{\circ} \mathrm{C}$ e, por esta razão, este produto não foi purificado para posteriores análises. 

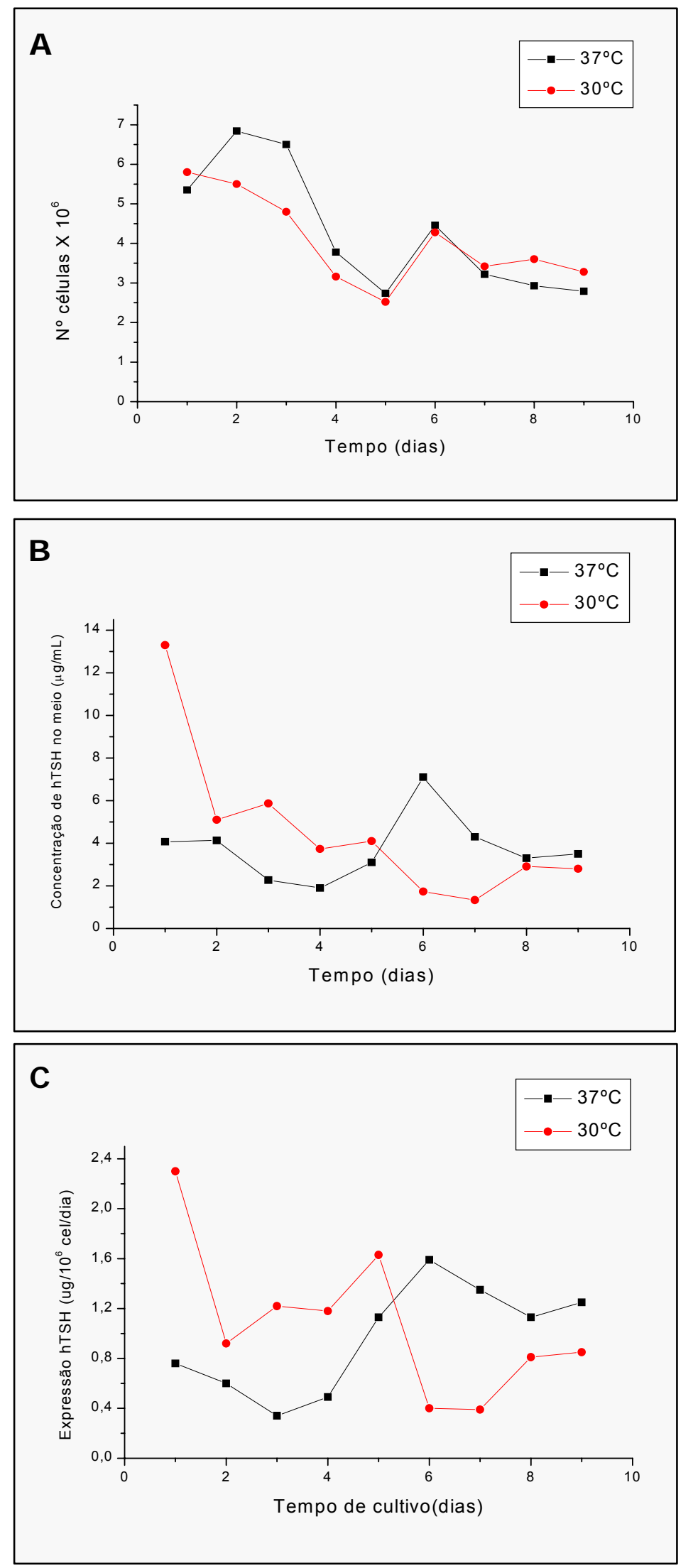

Figura 5 Variação do $n^{\circ}$ de células $(A)$, da concentração $(B)$ e da expressão específica de hTSH (C), na fase de produção, em diferentes condições de temperatura. ( $\square) 37^{\circ} \mathrm{C} ;(\bullet) 30^{\circ} \mathrm{C}$ 


\subsection{1.b- Variação do nível de $\mathrm{CO}_{2}$}

Nas duas diferentes condições de cultivo em que o nível de $\mathrm{CO}_{2}$ foi variado, não foram observadas diferenças significativas relativas ao $\mathrm{pH}$ e à concentração de glicose.

Nos primeiros sete dias de cultivo o número de células foi levemente maior na presença de $5 \%$ de $\mathrm{CO}_{2}$, tornando-se menor nos treze dias subseqüentes (Figura 6).

A concentração de TSH no meio de cultura foi, durante todo o tempo de produção, maior na ausência de $\mathrm{CO}_{2}$, especialmente do segundo ao décimo primeiro dia (Figura 7).

Em relação à expressão específica de $\mathrm{hTSH}$, nos primeiros dez dias de cultivo, ela foi substancialmente maior na ausência de $\mathrm{CO}_{2}$ (Figura 8).

Uma avaliação qualitativa e quantitativa, mediante RP-HPLC, do hTSH presente no meio condicionado, em três ensaios independentes, mostrou idêntico comportamento cromatográfico para os dois produtos obtidos em condições diferentes e um aumento médio da produtividade de $61 \%$ na condição de $\mathrm{CO}_{2}$ reduzida (Tabela 5, Figura 9). 


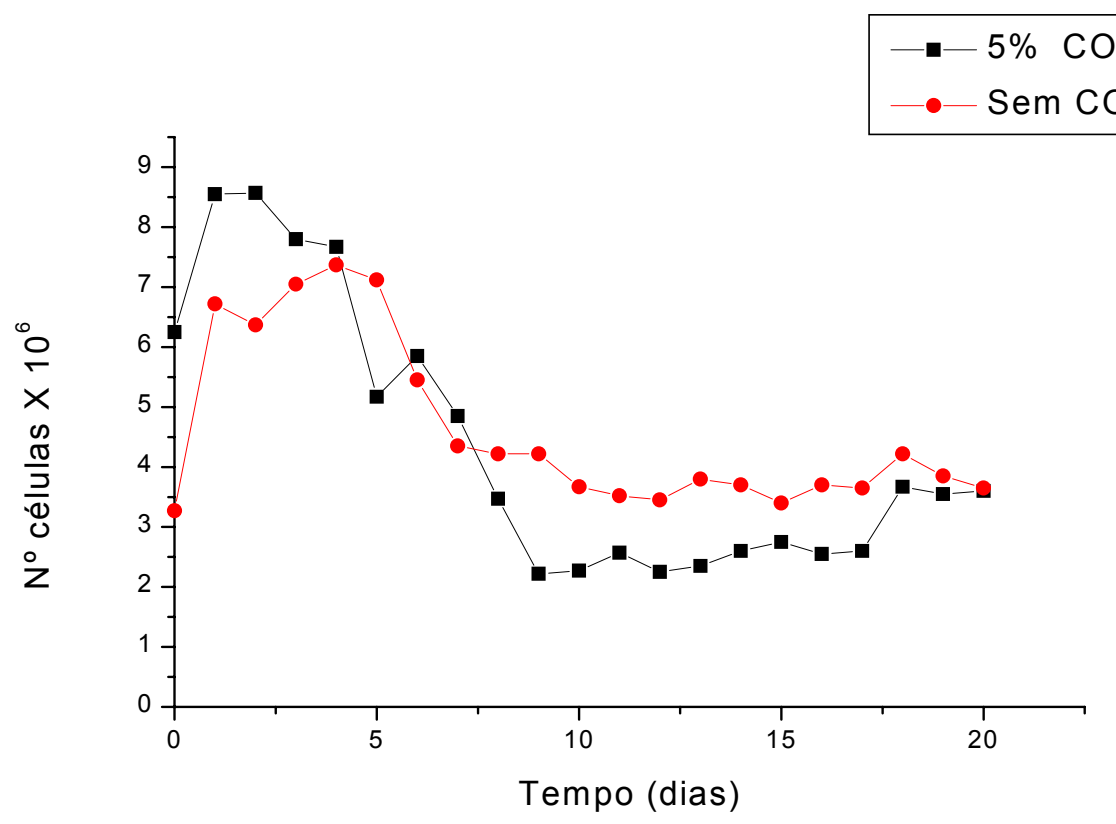

Figura 6 Variação do número de células no meio de cultura ao longo de $\mathbf{2 0}$ dias, na fase de produção, em diferentes condições de $\mathrm{CO}_{2}$. ( $(\square) 5 \% \mathrm{CO}_{2} ;(\bullet)$ sem $\mathrm{CO}_{2}$.

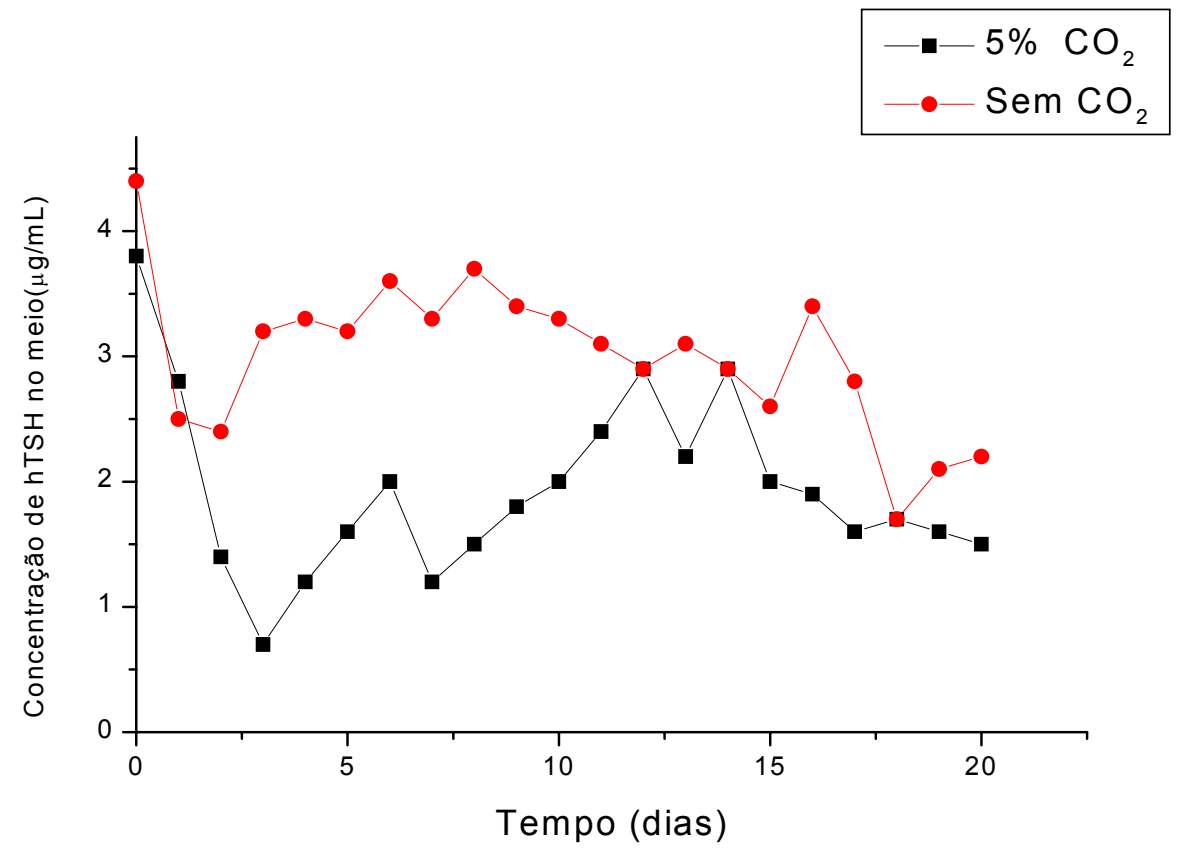

Figura 7 Variação da concentração de TSH no meio de cultura ao longo de $\mathbf{2 0}$ dias, na fase de produção, em diferentes condições de $\mathrm{CO}_{2}$. (घ) $5 \% \mathrm{CO}_{2} ;$ (•) sem $\mathrm{CO}_{2}$. 


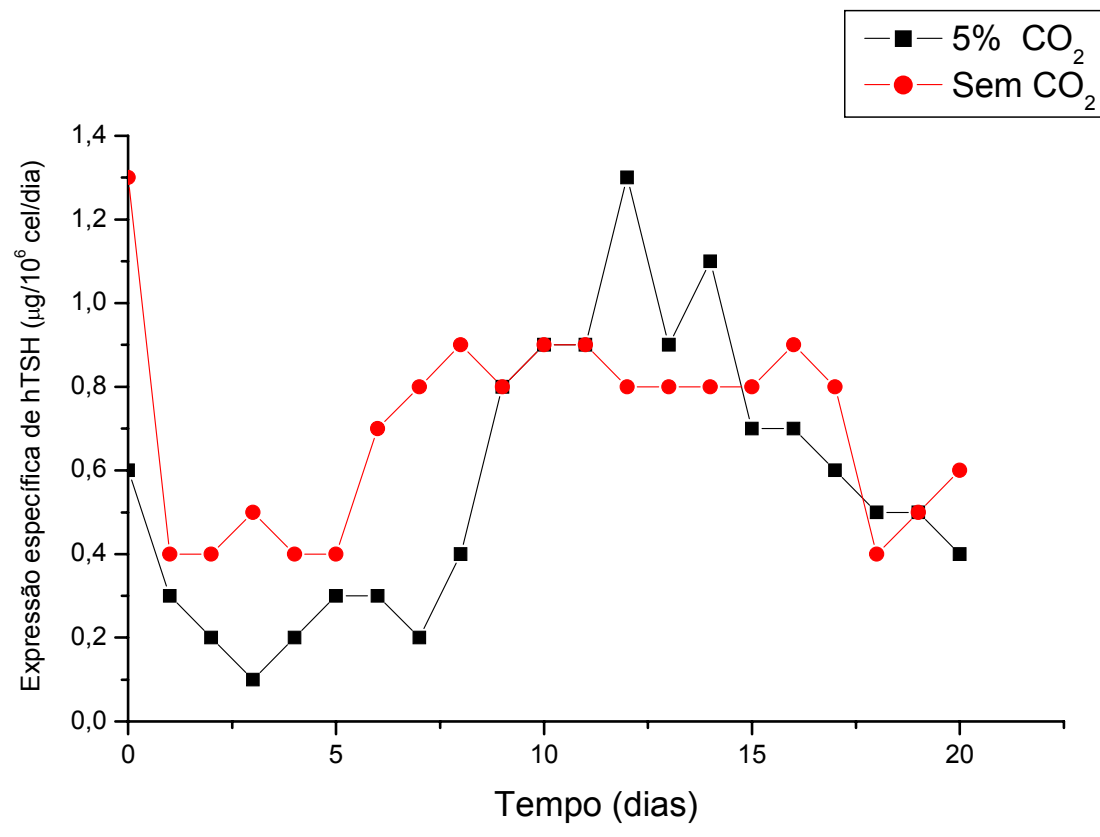

Figura 8 Variação da expressão específica de TSH ( $\mu$ g / $10^{6}$ cel./ dia), na fase de produção, em diferentes condições de $\mathrm{CO}_{2}$. (匹) $5 \% \mathrm{CO}_{2} ;(\bullet)$ sem $\mathrm{CO}_{2}$.

Tabela 5 Concentração de r-hTSH no meio condicionado, obtido com $5 \%$ de $\mathrm{CO}_{2}\left(+\mathrm{CO}_{2}\right)$ e em condições de $\mathrm{CO}_{2}$ reduzida $\left(-\mathrm{CO}_{2}\right)$.

\begin{tabular}{cccc}
\hline $\begin{array}{c}\text { Número } \\
\text { do ensaio }\end{array}$ & $\begin{array}{c}\text { Rendimento } \\
\text { hTSH }\left(+\mathrm{CO}_{2}\right) \\
\mu \mathrm{g} / \mathrm{L}\end{array}$ & $\begin{array}{c}\text { Rendimento } \\
\text { hTSH }\left(-\mathrm{CO}_{2}\right) \\
\mu \mathrm{g} / \mathrm{L}\end{array}$ & $\begin{array}{c}\text { Aumento de } \\
\text { produtividade } \\
(\%)\end{array}$ \\
\hline \hline 1 & 895 & 1270 & 42 \\
2 & 909 & 1570 & 73 \\
3 & 546 & 925 & 69 \\
\hline \hline
\end{tabular}



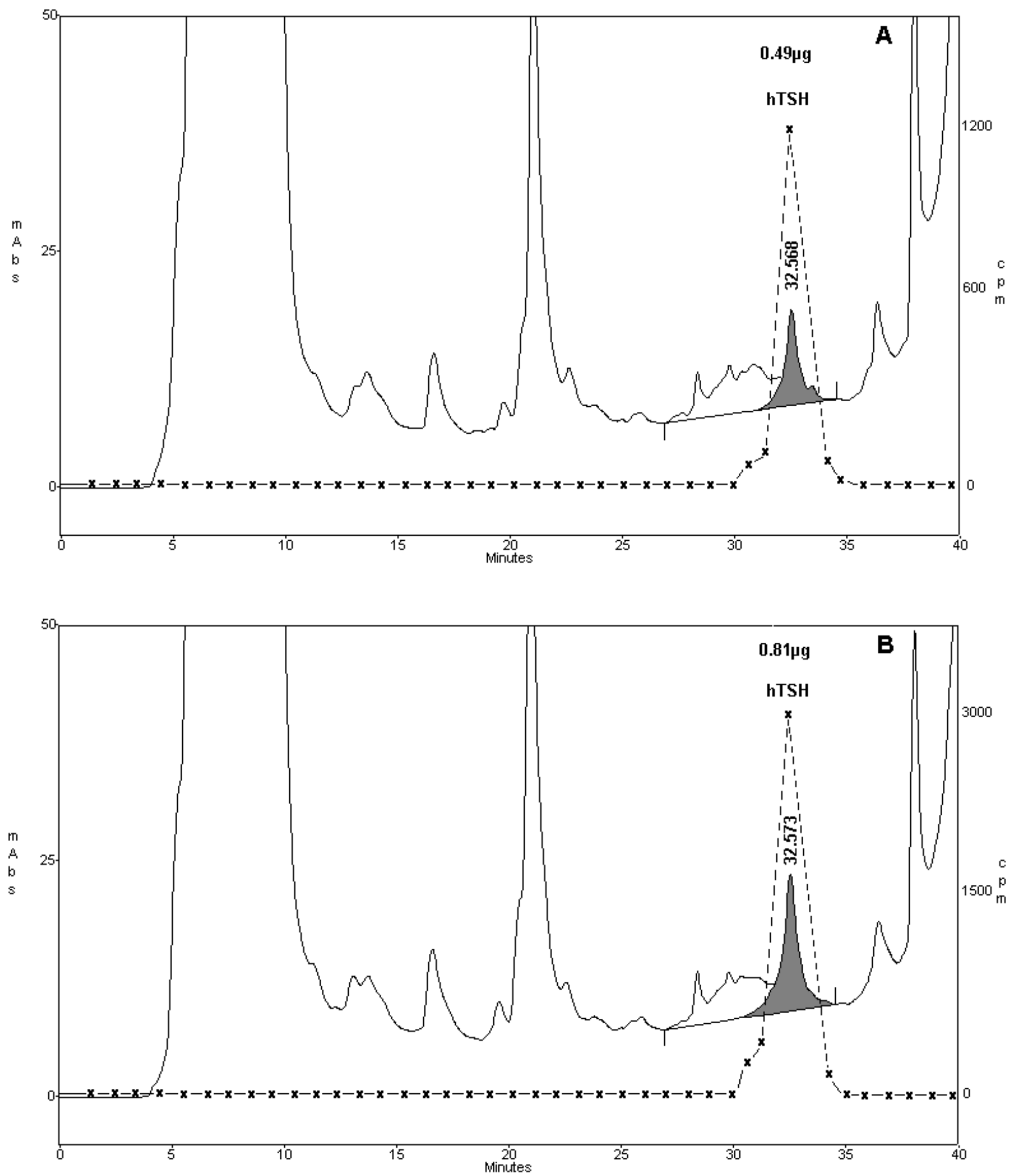

Figura 9 Perfil de RP-HPLC do meio condicionado obtido em diferentes condições: (A) $5 \% \mathrm{CO}_{2}$; (B) $0,03 \% \mathrm{CO}_{2}$. A220; $\quad$-----X Imunoatividade determinada via hTSH IRMA. 


\subsubsection{Purificação de r-hTSH}

Em uma purificação típica, o meio condicionado, contendo 0,6 $\mu \mathrm{g}$ de hTSH/mL (hTSH determinado por IRMA) e com uma fração de massa de hTSH da ordem de apenas $0,35 \%$, foi aplicado a uma coluna de SP-Sepharose FF, obtendo-se um pool bastante enriquecido, com fração de massa de hTSH de 12,7\% (Tabela 6 e Figura 10 A). A recuperação desta etapa foi de $84 \%$ com um fator de purificação de 36 vezes. O controle de qualidade do pool selecionado nesta etapa foi feito mediante HPLC de exclusão molecular (HPSEC) e de fase reversa (RP-HPLC), sendo os perfis obtidos mostrados respectivamente nas Figuras $11 \mathrm{~A}$ e $12 \mathrm{~A}$, onde se observa a presença de contaminantes com maior massa molecular que o $\mathrm{hTSH}\left(\mathrm{t}_{\mathrm{R}}=12,4 \mathrm{~min}\right.$ e $\left.15,7 \mathrm{~min}\right)$ e com menor hidrofobicidade $\left(t_{R}<10 \mathrm{~min}\right)$.

$\mathrm{Na}$ etapa posterior, utilizando uma coluna semi-preparativa de fase reversa (Figura $10 \mathrm{~B}$ ), foi possível eliminar estes contaminantes como é mostrado nas Figuras 11 B e 12 B, onde uma pureza > 99\% é mostrada nos dois sistemas analíticos, respectivamente HPSEC e RP-HPLC. Uma recuperação de $83 \%$ e um fator de purificação de $\sim 8$ vezes foram observados nesta etapa de purificação, cuja duração não ultrapassa 1 hora, além de dar origem a um produto relativamente concentrado $(1,2 \mathrm{mg} / \mathrm{mL})$.

O produto dialisado e liofilizado não sofreu praticamente perdas e houve um aumento mínimo das impurezas relacionadas ao produto, as quais ainda foram $<1,5 \%$ em HPSEC e $<3,5 \%$ em RP-HPLC. 
Tabela 6 Purificação de hTSH recombinante, partindo de aproximadamente $10 \mathrm{~L}$ de meio condicionado.

\begin{tabular}{|c|c|c|c|c|}
\hline $\begin{array}{l}\text { Etapa da } \\
\text { Purificação }\end{array}$ & $\begin{array}{l}\text { Proteína total } \\
\quad(\mathrm{mg})\end{array}$ & $\begin{array}{l}\text { hTSH } \\
\text { (mg) }\end{array}$ & $\begin{array}{c}\text { Rendimento } \\
\text { da etapa } \\
(\%)\end{array}$ & $\begin{array}{c}\text { Fração de } \\
\text { massa } \\
(\%) \\
\end{array}$ \\
\hline $\begin{array}{c}\text { Meio } \\
\text { Condicionado }\end{array}$ & 1603,9 & $5,67^{2}$ & 100 & 0,35 \\
\hline $\begin{array}{l}\text { Eluato da } \\
\text { troca catiônica }\end{array}$ & 37,4 & $4,76^{3}$ & 84 & 12,7 \\
\hline $\begin{array}{l}\text { Eluato da } \\
\text { RP-HPLC }\end{array}$ & 2,84 & $2,95^{3}$ & 83 & 103,9 \\
\hline
\end{tabular}



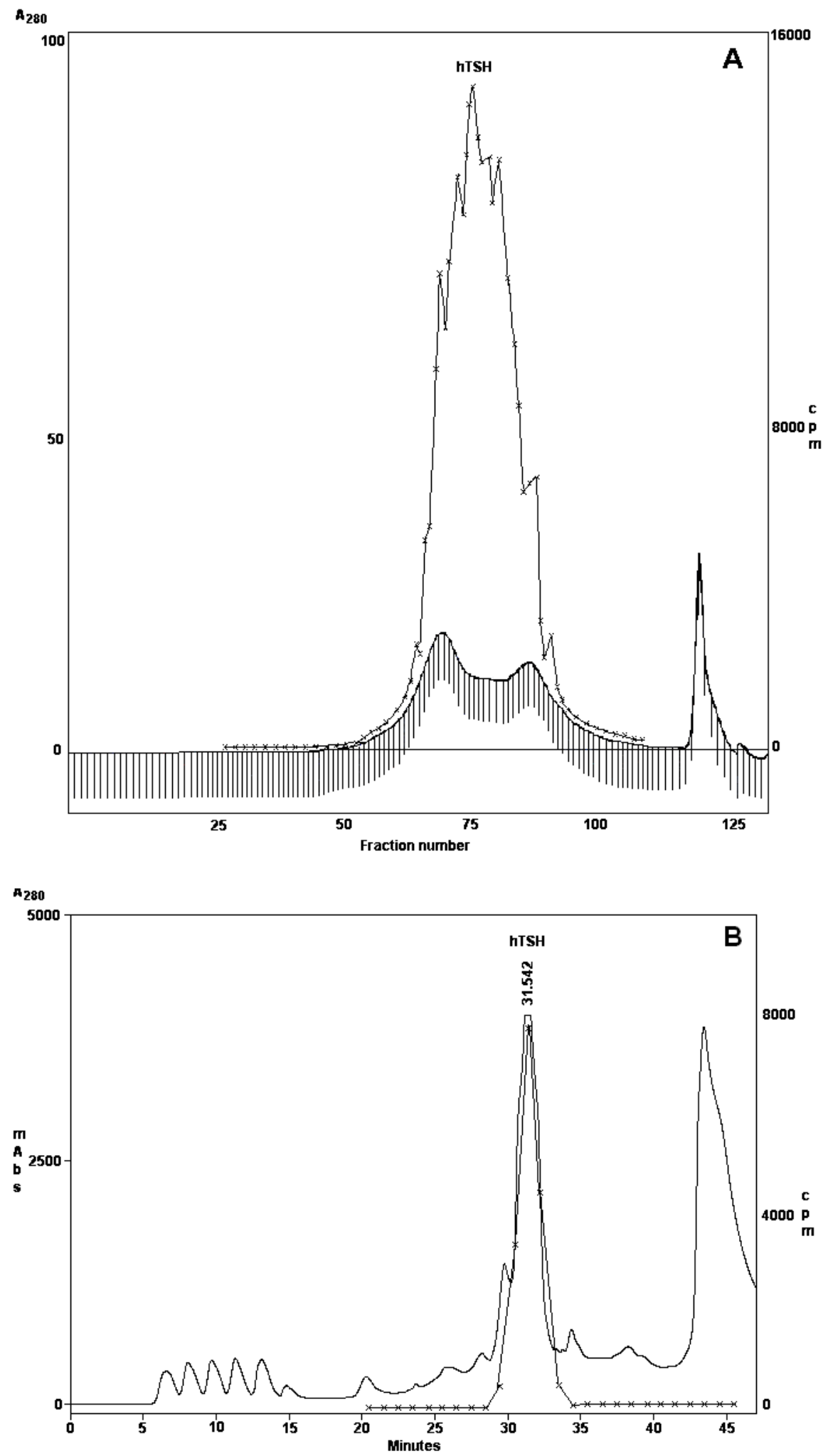

Figura 10 Estratégia de purificação do hTSH IPEN. (A) SP Sepharose FF (10 cm X 2,6 cm D.I.). (B) RP-HPLC semi-preparativa (25 cm x $10 \mathrm{~mm}$ D.I.). Neste experimento a preparação referência de $h T S H$ apresentou $T_{R}=31,3 \mathrm{~min}$.

A220; x-----x Imunoatividade determinada via hTSH IRMA. 

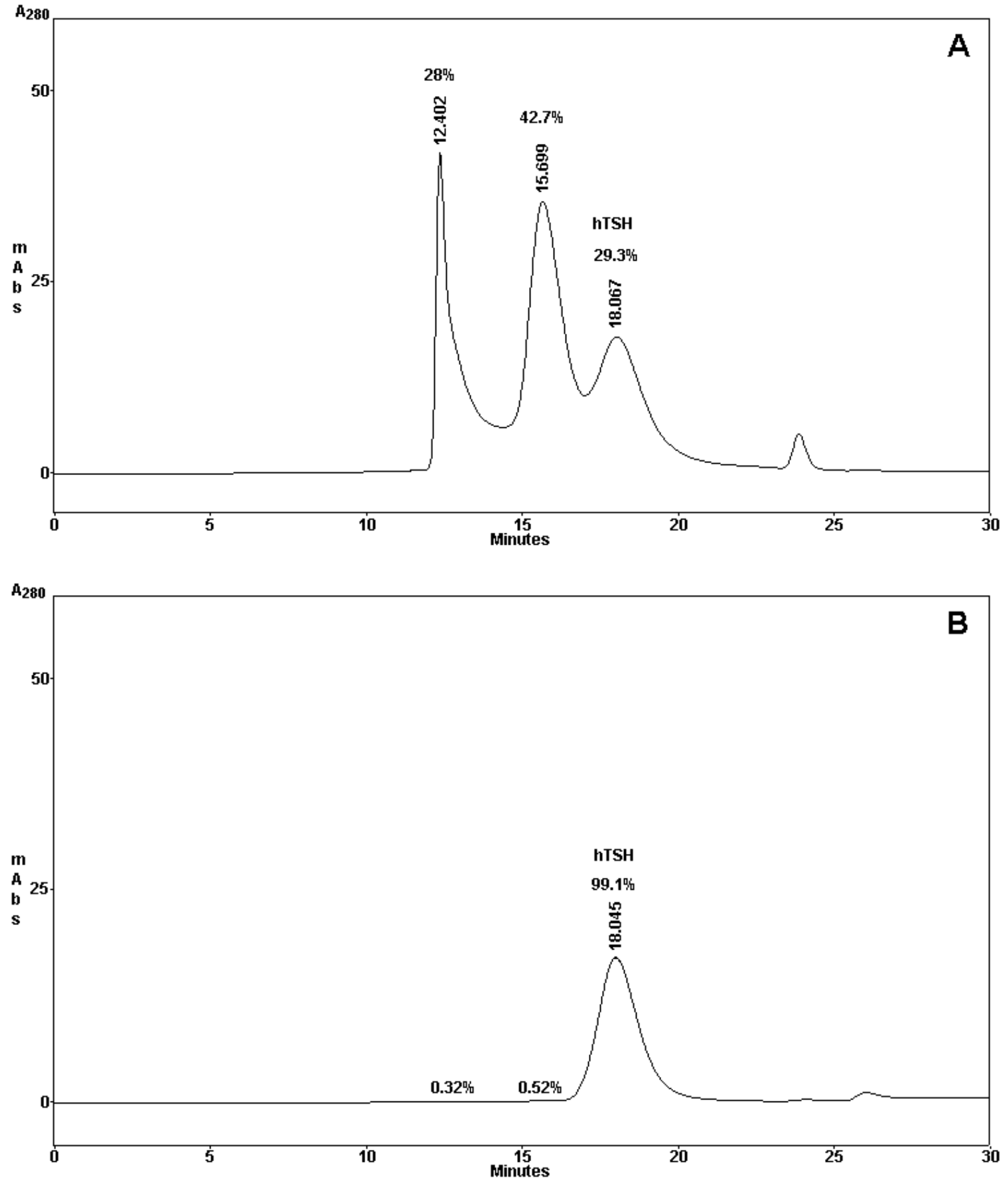

Figura 11 Perfis obtidos em HPSEC dos pools obtidos em duas etapas de purificação: (A) Cromatografia catiônica em SP-Sepharose FF. (B) RP-HPLC semi-preparativa. Neste experimento a preparação referência de hTSH apresentou $T_{R}=18,06$ min. 

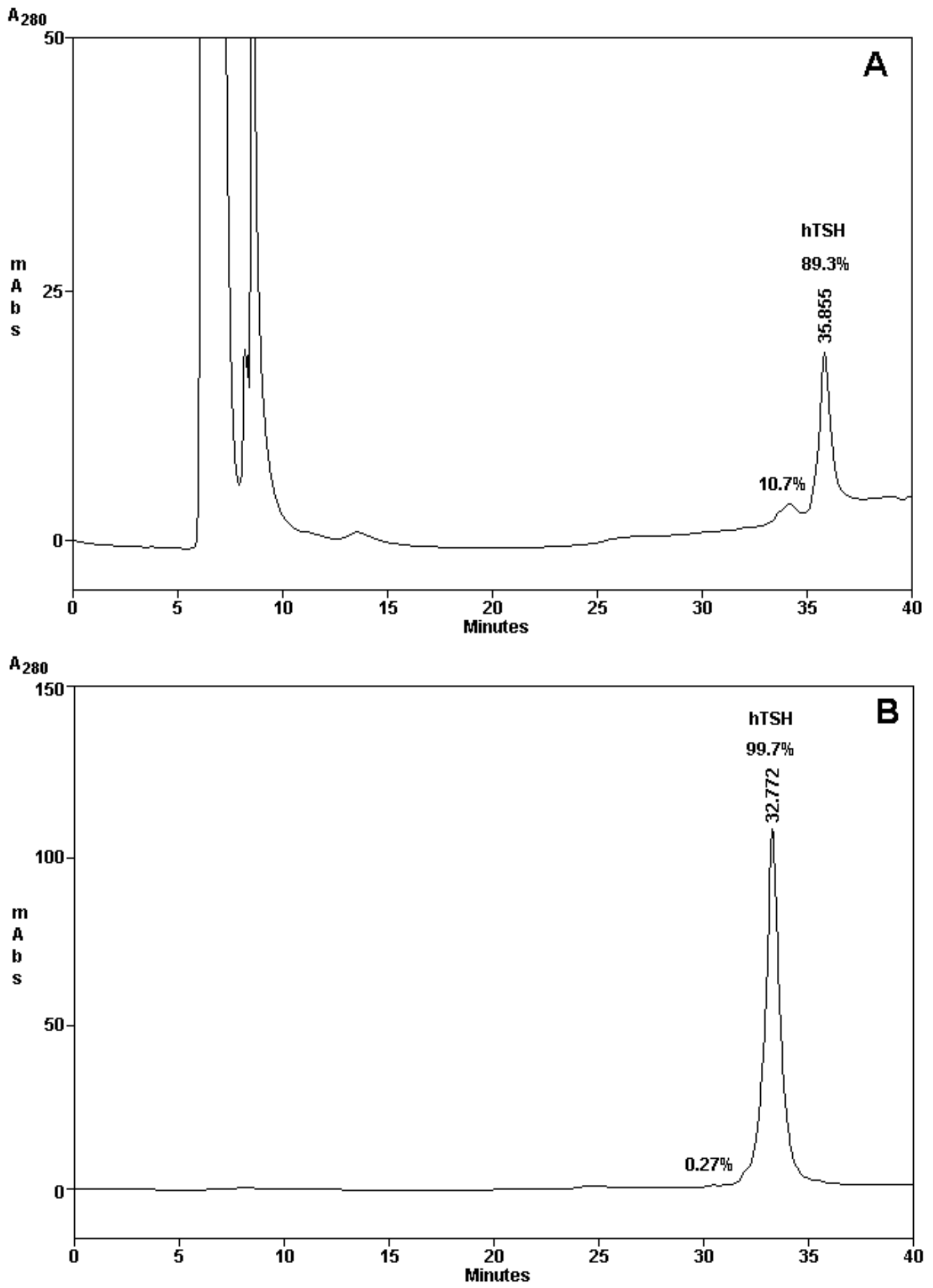

Figura 12 Perfis obtidos em RP-HPLC dos pools obtidos após as duas etapas de purificação: (A) Cromatografia catiônica em SP-Sepharose FF. (B) RP-HPLC semi-preparativa. Neste experimento a preparação referência de hTSH apresentou $T_{R}=32,83$ min. 


\subsection{Análise das diferentes preparações de hTSH}

\subsubsection{Massa molecular}

As massas moleculares das preparações de r-hTSH (Thyrogen), r-hTSH-IPEN $\left(+\mathrm{CO}_{2}\right)$ e p-hTSH-NIDDK foram determinadas por espectrometria de massa MALDI TOF, em dois ensaios independentes (Tabela 7). Uma alta precisão interensaio foi observada para estas determinações, com coeficientes de variação iguais ou menores a $1 \%$.

Nesta determinação foi possível identificar simultaneamente a massa do heterodímero e de suas subunidades $\alpha$ e $\beta$. Observa-se uma diferença mínima entre a massa molecular determinada diretamente (experimental) para o heterodímero e aquela resultante da soma de suas respectivas subunidades, $1,7 \%$ para o $\mathrm{r}-\mathrm{hTSH}$ IPEN, 1,2\% para o $\mathrm{p}$-hTSH NIDDK e 0,6\% para o r-hTSH Thyrogen.

A massa molecular do rec-hTSH-IPEN de 29839,4 mostrou similaridade (diferença de $+0,77 \%$ ) com a massa molecular do Thyrogen, ambas determinadas por espectrometria de massa MALDI-TOF, enquanto uma diferença de $+7,2 \%$ foi detectada com relação à preparação hipofisária. Em relação ao valor teórico reportado para o Thyrogen, a diferença experimental observada foi de $0,16 \%$ o que confirma a excelente exatidão do método. 
Tabela 7 Massa molecular relativa média (Mr) do heterodímero e subunidades relacionadas de diferentes preparações de $\mathrm{hTSH}$, determinadas por espectrometria de massa MALDI TOF ( $n=2$ determinações independentes), em comparação com valores teóricos da literatura

\begin{tabular}{lccccc}
\multicolumn{1}{c}{ Preparação } & $\begin{array}{c}\text { Subunidade } \alpha \\
\text { Mr } \pm \text { DP }\end{array}$ & Subunidade $\beta$ & \multicolumn{2}{c}{ Heterodímero } \\
& & $M r \pm D P$ & & Mr \pm DP & \\
& & & experimental & $\alpha+\beta$ & calc/exp \\
\hline \hline p-hTSH-NIDDK & $13018,5 \pm 355,7$ & $14475,5 \pm 21,8$ & $27829,0 \pm 26,9$ & 27494,0 & 0,988 \\
r-hTSH-IPEN & $13960,6 \pm 55,9$ & $15359,2 \pm 73,3$ & $29839,4 \pm 208,7$ & 29319,8 & 0,983 \\
r-hTSH-Thyrogen & $13859,5 \pm 58,7$ & $15580,5 \pm 0.71$ & $29611,5 \pm 176,1$ & 29440,0 & 0.994 \\
& & & & & \\
$\begin{array}{l}\text { Valor teórico para o } \\
\text { Thyrogen (Cole, 1993) }\end{array}$ & 13820 & 15840 & & 29660 & \\
\hline \hline
\end{tabular}




\subsubsection{Hidrofobicidade}

A Tabela 8 mostra a excelente reprodutibilidade dos tempos de retenção correspondentes a quatro preparações de hTSH, com um coeficiente de variação $\leq 0,6 \%$.

As três preparações recombinantes de $\mathrm{hTSH}$, Thyrogen, IPEN $\left(+\mathrm{CO}_{2}\right)$ e IPEN $\left(-\mathrm{CO}_{2}\right)$, mostraram-se ligeiramente menos hidrofóbicas do que a preparação hipofisária (NIDDK), em análises por técnica de HPLC em fase reversa (RP-HPLC). A preparação r-hTSH-Thyrogen apresentou um tempo de retenção que é 1,23\% menor do que o tempo de retenção da preparação hipofisária, enquanto no caso do r-hTSH-IPEN esta diferença foi de $1,17 \%$ e $1,38 \%$ respectivamente para as preparações obtidas na presença e na ausência de $\mathrm{CO}_{2}$.

Os três produtos recombinantes não apresentaram diferença significativa entre os tempos de retenção. Entretanto, as preparações recombinantes apresentaram tempos de retenção estatisticamente diferentes $(p<0,02)$ do tempo de retenção encontrado para a preparação hipofisária (NIDDK).

Tabela 8 Estatística dos tempos de retenção inter-dias para quatro diferentes preparações de hTSH, analisadas por RP-HPLC

$\begin{array}{lllcc}\text { Preparações de hTSH } & t_{R} \pm D P(\min ) & C V & \text { Diferença relativa à } & \text { Número de } \\ & (\%) & \text { preparação hipofisária } & \text { determinações }\end{array}$

(\%)

\begin{tabular}{lcccc}
\hline \hline p-hTSH-NIDDK & $32,79 \pm 0,186$ & 0,57 & - & 6 \\
r-hTSH-Thyrogen & $32,39 \pm 0,193$ & 0,60 & $-1,23$ & 6 \\
r-hTSH-IPEN $\left(+\mathrm{CO}_{2}\right)$ & $32,41 \pm 0,175$ & 0,54 & $-1,17$ & 6 \\
r-hTSH-IPEN $\left(-\mathrm{CO}_{2}\right)$ & $32,37 \pm 0,189$ & 0,58 & $-1,38$ & 6 \\
\hline
\end{tabular}




\subsubsection{Atividade biológica}

A atividade biológica das quatro preparações de hTSH avaliada em um ensaio in vivo em camundongos, é apresentada na Tabela 9. A precisão intra-ensaio variou de $12,5 \%$ a $21,7 \%$.

A Tabela 10 apresenta a potência das diferentes preparações de hTSH relativa à preparação de referência hipofisária (NIDDK) e à preparação de referência recombinante, Thyrogen. A preparação $r-h T S H-I P E N\left(-\mathrm{CO}_{2}\right)$ foi menos ativa $(p<$ $0,02)$ do que a preparação $r$-hTSH-IPEN $\left(+\mathrm{CO}_{2}\right)$, a qual foi equipotente $(p>0,05)$ ao Thyrogen. As três preparações recombinantes estudadas foram 1,25 , 1,6 e 1,8 vezes mais potentes do que a preparação hipofisária, com níveis de significância de $p<0,05, p<0,001$ e $p<0,001$ respectivamente.

A atividade biológica absoluta, determinada considerando a potência de 4 IU/mg para o Thyrogen (49), foi de 2,52, 4,6 e 3,2 IU/mg respectivamente para o pit-hTSH-NIDDK, r-hTSH-IPEN $\left(+\mathrm{CO}_{2}\right)$ e r-hTSH-IPEN $\left(-\mathrm{CO}_{2}\right)$. 
Tabela 9 - Bioensaio in vivo: níveis de $\mathrm{T}_{4}$ determinados por RIA após administração de $\mathrm{hTSH}$ à camundongos tratados com $\mathrm{T}_{3}$

\begin{tabular}{|c|c|c|c|c|}
\hline Preparação & $\begin{array}{l}\text { Número de } \\
\text { camundongos }\end{array}$ & $\begin{array}{c}\text { T4 } \\
(\mu \mathrm{g} / \mathrm{dL})^{1}\end{array}$ & $\begin{array}{l}\text { Desvio } \\
\text { Padrão }\end{array}$ & $\begin{array}{c}\text { Coeficiente de } \\
\text { variação (\%) }\end{array}$ \\
\hline Salina & 6 & n.d. ${ }^{2}$ & - & $\ldots$ \\
\hline p-hTSH-NIDDK & 6 & 2,0 & 0,31 & 15,5 \\
\hline r-hTSH-Thyrogen & 6 & 3,2 & 0,40 & 12,5 \\
\hline r-hTSH-IPEN $\left(+\mathrm{CO}_{2}\right)$ & 6 & 3,6 & 0,78 & 21,7 \\
\hline r-hTSH-IPEN $\left(-\mathrm{CO}_{2}\right)$ & 6 & 2,5 & 0,40 & 15,8 \\
\hline
\end{tabular}

Tabela 10 - Bioensaio in vivo: potências de preparações de hTSH relativas aos padrões de referência NIDDK e Thyrogen

\begin{tabular}{lcc}
\hline \multicolumn{1}{c}{ Preparação } & $\begin{array}{c}\text { Potência relativa à } \\
\text { NIDDK }\end{array}$ & $\begin{array}{c}\text { Potência relativa à } \\
\text { Thyrogen }\end{array}$ \\
\hline p-hTSH-NIDDK & 1,00 & 0,63 \\
r-hTSH-Thyrogen & 1,59 & 1,00 \\
r-hTSH-IPEN $\left(+\mathrm{CO}_{2}\right)$ & 1,82 & 1,15 \\
r-hTSH-IPEN $\left(-\mathrm{CO}_{2}\right)$ & 1,27 & 0,80 \\
\hline \hline
\end{tabular}




\subsubsection{Distribuição dos isômeros de carga}

A análise dos isômeros de carga das diferentes preparações de hTSH foi feita mediante focalização isoelétrica (IEF), sendo os perfis encontrados mostrados na Figura 13. Uma grande heterogeneidade de cargas foi observada tanto para as preparações recombinantes (amostras 4, 5 e 6) quanto para as preparações hipofisárias (amostras 2 e 3 ). As preparações recombinantes apresentaram seis bandas, distribuídas entre $\mathrm{pH} 5,39$ e pH 7,35, enquanto as hipofisárias mostraram oito ou nove bandas no intervalo de $\mathrm{pH}$ de 4,82 - 7,35. A principal diferença no perfil de bandas obtido para as preparações hipofisárias e recombinantes foi a presença de 2-3 isômeros de carga mais ácidos nas preparações hipofisárias. Não houve diferenças consideráveis nos perfis obtidos para as duas preparações IPEN originárias de cultivos em diferentes condições, bem como no Thyrogen. A maior parte do material, no caso das preparações recombinantes, focou em três bandas de pl 5,85, 6,20 e 6,63 e, no caso das preparações hipofisárias, em três bandas de pl $4,82,4,98$ e 5,20 . 


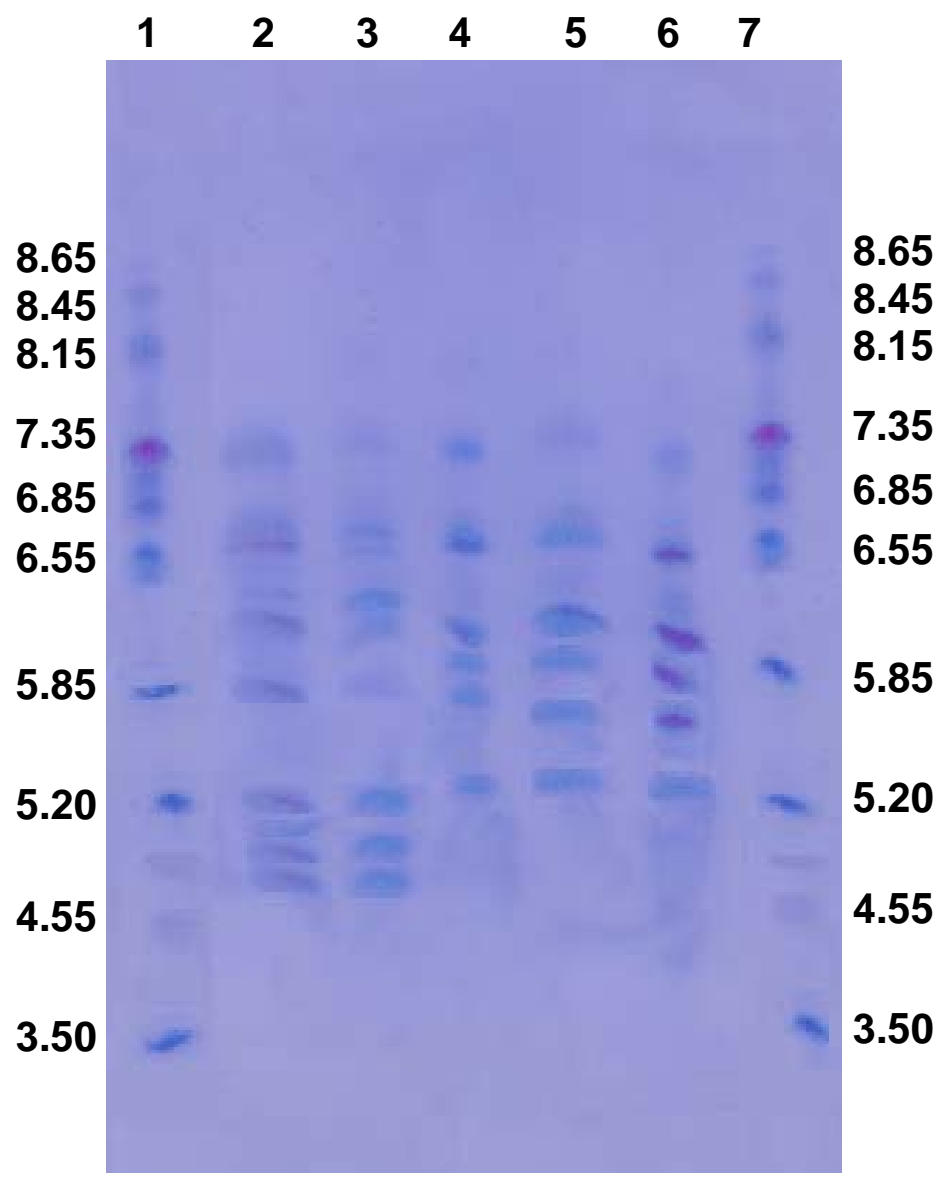

Figura 13 Perfil de distribuição dos isômeros de carga de preparações de hTSH

1 - marcadores de ponto isoelétrico

2 - p-hTSH-NOR

3 - p-hTSH -NIDDK

4 - r-hTSH-Thyrogen

5 - r-hTSH-IPEN $\left(+\mathrm{CO}_{2}\right)$

6 - r-hTSH-IPEN $\left(-\mathrm{CO}_{2}\right)$

7 - marcadores de ponto isoelétrico 


\subsubsection{Análise dos carboidratos}

\subsection{5.a Análise composicional}

A percentagem de carboidratos encontrada em cada uma das preparações de hTSH analisadas foi de 14,5\%, 20\% e 6\% respectivamente para o Thyrogen, r-hTSHIPEN e p-hTSH-NIDDK.

A análise composicional de monossacarídeos destas três preparações de hTSH mostrou que a glicosilação das preparações recombinantes difere daquela da preparação hipofisária tanto na extenção quanto no tipo de glicosilação observada (Tabela 11). O nível total de glicosilação das preparações recombinantes é maior daquele encontrado para o hormônio hipofisário como visto pelas maiores quantidades de N-acetil glucosamina (GlcNAc) e Manose (Man) presentes. A N-acetil galactosamina (GalNAc) apareceu apenas na preparação hipofisária, um conteúdo de 0,12 nmoles/ $\mu \mathrm{g}$ sendo determinado, valor este da mesma ordem daquele encontrado por Szkudlinski e colaboradores (74). Isto é consistente com a falta de Nacetilgalactosamina transferase e sulfotransferase nas células $\mathrm{CHO}$ (15). Um maior conteúdo de Galactose ( $\mathrm{Gal}$ ), freqüentemente ligado ao ácido siálico e do próprio ácido siálico (NeuAc) nas preparações recombinantes com relação à preparação hipofisária foi também observado. O conteúdo de ácido siálico da preparação recombinante IPEN foi maior (2,4 vezes) do que o obtido para a preparação recombinante Thyrogen, e ambos foram maiores do que o conteúdo de ácido siálico da preparação hipofisária (3,6-8,6 vezes), sendo as porcentagens de ácido siálico por massa protéica $1,4 \%, 3,4 \%$ e $0,4 \%$ respectivamente para Thyrogen, r-hTSHIPEN e p-hTSH-NIDDK. 
Tabela 11 Análise de monossacarídeos de preparações de hTSH recombinantes e hipofisária.

\begin{tabular}{|c|c|c|c|c|c|}
\hline Preparação & $\begin{array}{l}\text { GIcNAc } \\
\mathrm{nmol} / \mu \mathrm{g} \\
\end{array}$ & $\begin{array}{c}\text { Gal } \\
\mathrm{nmol} / \mu \mathrm{g} \\
\end{array}$ & $\begin{array}{c}\text { Man } \\
\mathrm{nmol} / \mu \mathrm{g} \\
\end{array}$ & $\begin{array}{c}\text { NeuAc } \\
\mathrm{nmol} / \mu \mathrm{g} \\
\end{array}$ & $\begin{array}{r}\text { GalNAc } \\
\mathrm{nmol} / \mu \mathrm{g}\end{array}$ \\
\hline r-hTSH-Thyrogen & 0,267 & 0,212 & 0,171 & 0,064 & ----- \\
\hline r-hTSH-IPEN & 0,402 & 0,221 & 0,183 & 0,154 & ----- \\
\hline p-hTSH-NIDDK & 0,153 & 0,025 & 0,110 & 0,018 & 0,12 \\
\hline
\end{tabular}




\subsection{5.b Análise estrutural}

As Figuras 14,15 e 16 e a Tabela 12 mostram as estruturas dos oligossacarídeos identificadas nas diferentes preparações recombinantes de hTSH estudadas, respectivamente, IPEN $\left(-\mathrm{CO}_{2}\right)$, IPEN $\left(+\mathrm{CO}_{2}\right)$ e Thyrogen.

Os $\mathrm{N}$-glicanos identificados são do tipo complexo, com estruturas bi-, tri- e tetra-antenárias e níveis variáveis de sialilação. Foram identificadas também espécies fucosiladas e não fucosiladas.

As estruturas mais abundantes foram as biantenárias monosialiladas, representando $\sim 69 \%$ de todas as formas identificadas nas três preparações recombinantes: $\mathrm{N}_{2} \mathrm{G}_{2} \mathrm{~S}_{1}, \mathrm{~N}_{2} \mathrm{G}_{1} \mathrm{~S}_{1}$ e $\mathrm{N}_{2} \mathrm{G}_{2} \mathrm{~S}_{1} \mathrm{~F}$.

A maior parte dos carboidratos do r-hTSH são sialilados (86 - 88 \%), com 3,37; 3,61 e 3,57 moles de ácido siálico/moles de proteína nas preparações recombinantes r-hTSH-IPEN $\left(-\mathrm{CO}_{2}\right),\left(+\mathrm{CO}_{2}\right)$ e Genzyme respectivamente. Entre as espécies sialiladas identificadas nas três preparações de hTSH analisadas (Figura 17), observou-se que os glicanos bi-antenários são os mais freqüentes. $O$ mesmo ocorreu entre as espécies neutras identificadas nas duas preparações IPEN. Por outro lado, no r-hTSH Thyrogen, as espécies neutras mais freqüentes são as triantenárias (Figura 18). A preparação IPEN $\left(-\mathrm{CO}_{2}\right)$ apresentou $8 \%$ mais espécies biantenárias que a preparação IPEN $\left(+\mathrm{CO}_{2}\right)$ e cerca de $10 \%$ mais que o Thyrogen. Esta diferença é principalmente relativa às espécies neutras, como pode ser observado na Figura 18. Por outro lado, a preparação IPEN $\left(-\mathrm{CO}_{2}\right)$ apresentou aproximadamente duas vezes menos estruturas tri-antenárias que as duas outras preparações de $\mathrm{hTSH}$. As estruturas tetra-antenárias aparecem em baixa freqüência $(<4 \%)$ nas três preparacões. Entre as espécies bi-antenárias, a freqüência de espécies fucosiladas foi de $27 \%, 19 \%$ e $21 \%$, respectivamente para o r-hTSHThyrogen, r-hTSH-IPEN $\left(+\mathrm{CO}_{2}\right)$ e r-hTSH-IPEN $\left(-\mathrm{CO}_{2}\right)$.

Quanto a freqüência dos N-glicanos nas três preparações de hTSH de acordo com o nível de sialilação, as espécies monosialiladas foram as mais freqüentes (cerca de 70\%), seguidas das espécies neutras ( 13\%). As formas menos abundantes $(\sim 1 \%)$ foram os glicanos tetra-sialilados. 


\section{$\mathbf{r}-\mathrm{hTSH}\left(-\mathrm{CO}_{2}\right)$}
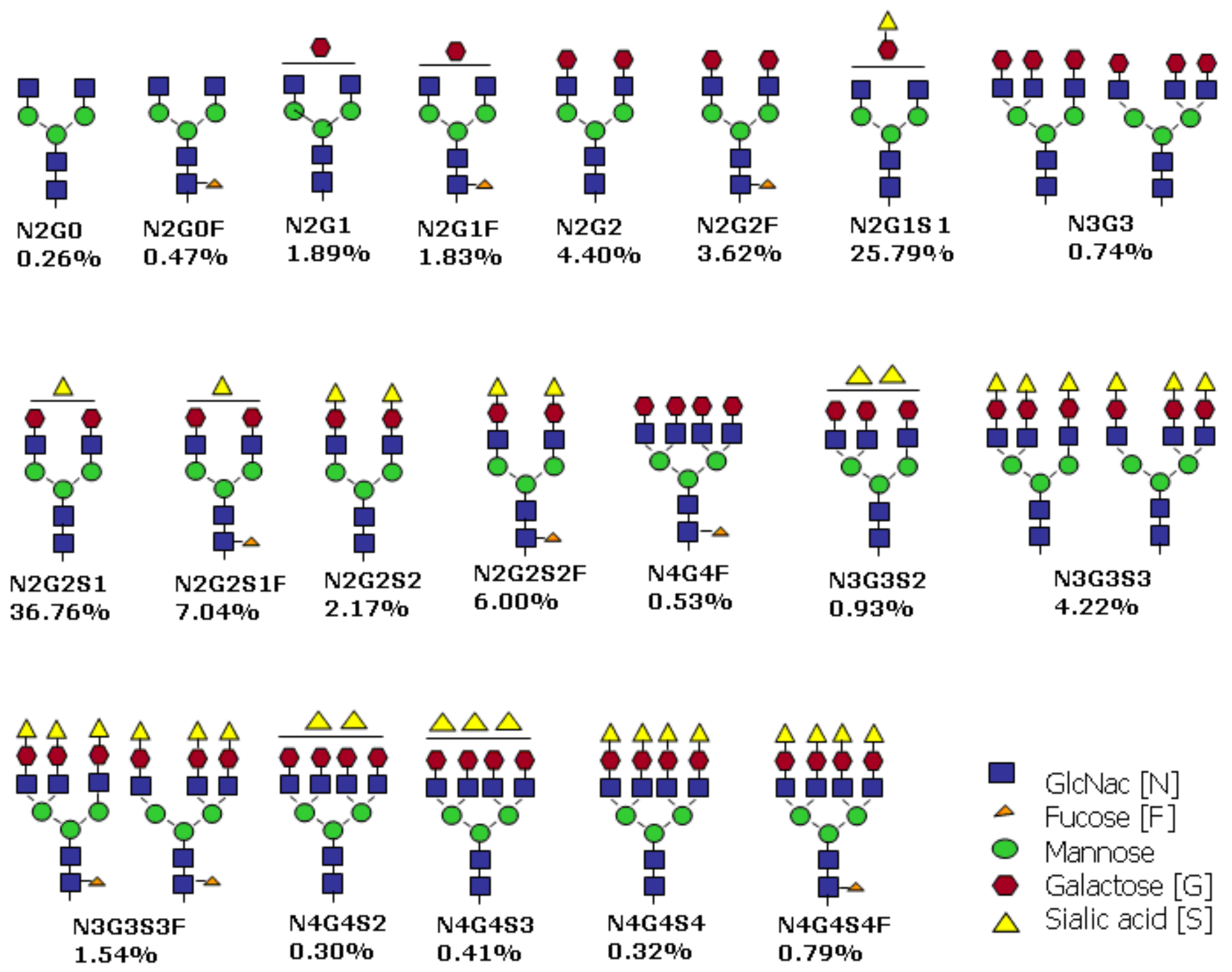

Figura 14 N-glicanos da preparação de r-hTSH IPEN (-CO 


\section{r-hTSH$\left(+\mathrm{CO}_{2}\right)$}
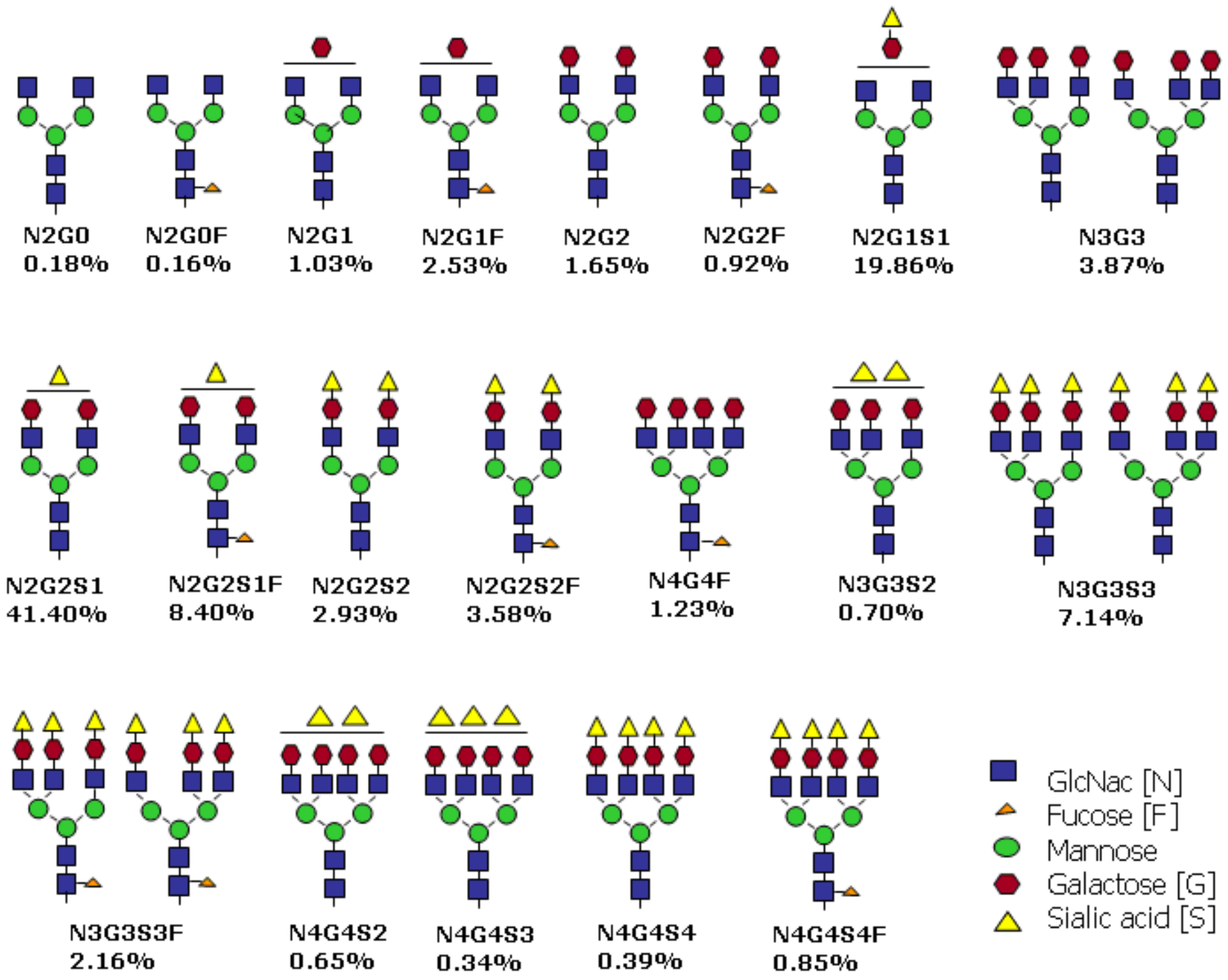

Figura $15 \mathrm{~N}$-glicanos da preparação de r-hTSH IPEN $\left(+\mathrm{CO}_{2}\right)$ 


\section{Thyrogen}

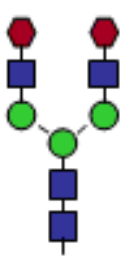

N2G2

$1.72 \%$

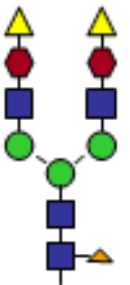

N2G2S2F

$5.99 \%$

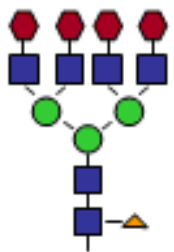

N4G4F

$1.19 \%$

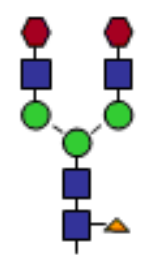

N2G2F

$3.56 \%$

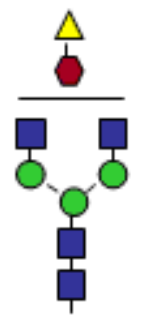

N2G1S1

$21.75 \%$

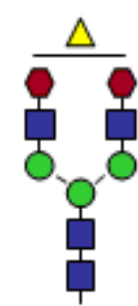

N2G2S1

$36.02 \%$

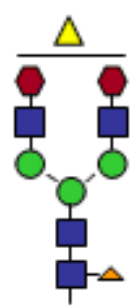

N2G2S1F $10.68 \%$

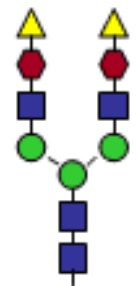

N2G2S2 $1.04 \%$
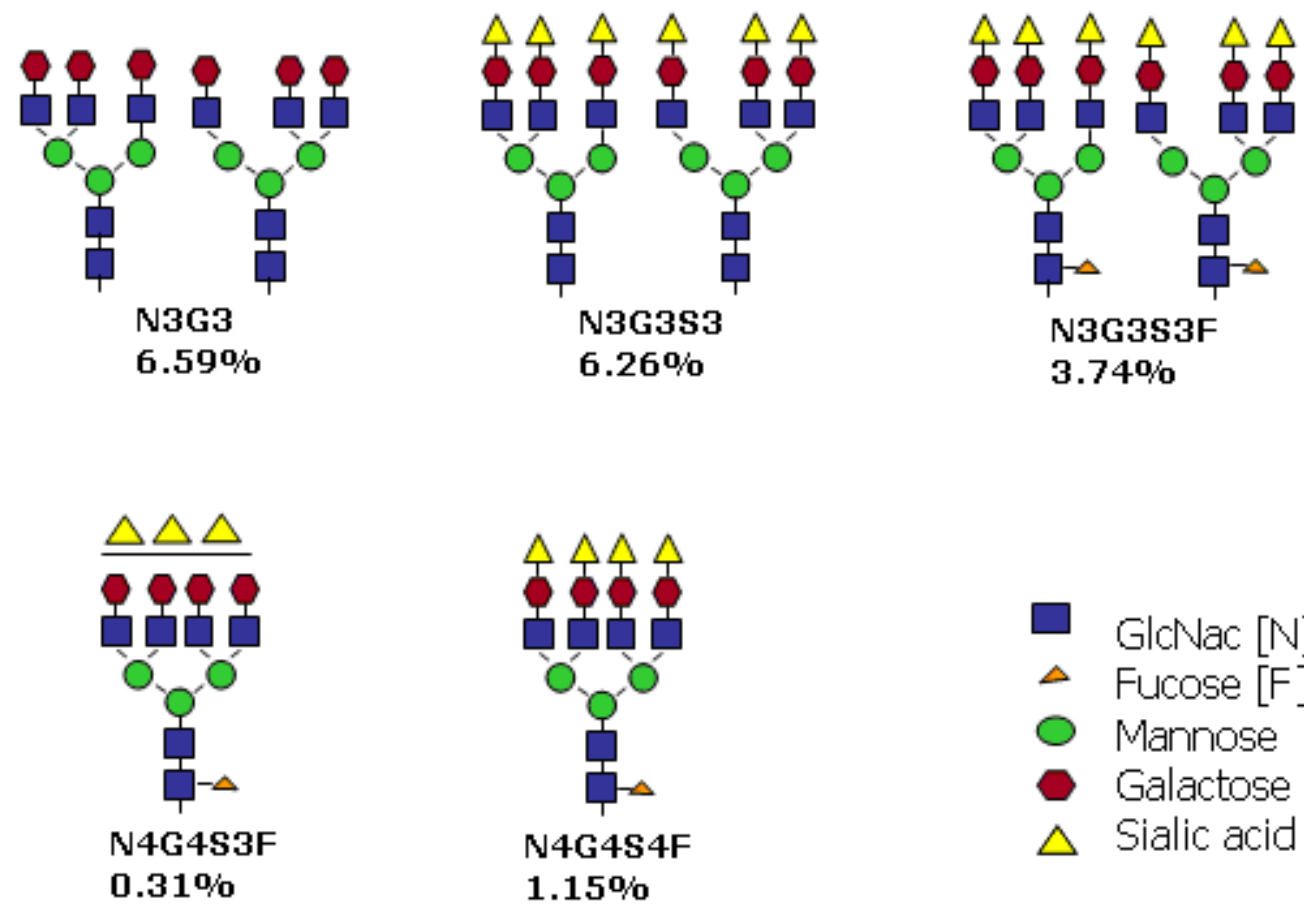

GlcNac [N]

$\triangle$ Fucose [F]

- Mannose

- Galactose [G]

$\triangle$ Sialic acid [S]

Figura 16 N-glicanos da preparação de r-hTSH Thyrogen 
Tabela 12 Distribuição dos N-glicanos em três preparações de rec-hTSH, quanto à antenaridade e o nível de sialilação

\begin{tabular}{|c|c|c|c|c|c|c|c|c|c|c|c|c|}
\hline \multirow{5}{*}{$\begin{array}{l}\text { Nível de } \\
\text { sialilação }\end{array}$} & \multicolumn{3}{|c|}{ bi-antenária } & \multicolumn{3}{|c|}{ tri-antenária } & \multicolumn{3}{|c|}{ tetra-antenária } & \multirow{2}{*}{\multicolumn{3}{|c|}{$\begin{array}{l}\text { Nível total de } \\
\text { sialilação }\end{array}$}} \\
\hline & IPEN & IPEN & THY & IPEN & IPEN & THY & IPEN & IPEN & THY & & & \\
\hline & $\left(-\mathrm{CO}_{2}\right)$ & $\left(+\mathrm{CO}_{2}\right)$ & & $\left(-\mathrm{CO}_{2}\right)$ & $\left(+\mathrm{CO}_{2}\right)$ & & $\left(-\mathrm{CO}_{2}\right)$ & $\left(+\mathrm{CO}_{2}\right.$ & & IPEN & IPEN & THY \\
\hline & & (\%) & & & (\%) & & & (\%) & & $\left(-\mathrm{CO}_{2}\right)$ & $\left(+\mathrm{CO}_{2}\right)$ & \\
\hline & & & & & & & & & & & (\%) & \\
\hline 0 & 12,47 & 6,47 & 5,28 & 0,74 & 3,87 & 6,59 & 0,53 & 1,23 & 1,19 & 13,74 & 11,57 & 13,06 \\
\hline 1 & 69,59 & 69,66 & 68,45 & & 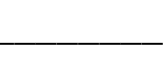 & & & 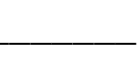 & & 69,59 & 69,66 & 68,65 \\
\hline 2 & 8,17 & 6,51 & 7,03 & 0,93 & 0,70 & n.d. & 0,30 & 0,65 & n.d. & 9,40 & 7,86 & 7,03 \\
\hline 3 & & & & 5,76 & 9,30 & 10,0 & 0,41 & 0,34 & 0,31 & 6,17 & 9,64 & 10,31 \\
\hline 4 & & 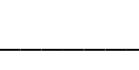 & & & - & & 1,11 & 1,24 & 1,15 & 1,11 & 1,24 & 1,15 \\
\hline $\begin{array}{l}\text { Total de } \\
\text { antenas }\end{array}$ & 90,23 & 82,64 & 80,76 & 7,43 & 13,87 & 16,59 & 2,35 & 3,46 & 2,65 & & & \\
\hline $\begin{array}{c}\text { Total de } \\
\text { sialilados }\end{array}$ & & & & & & & & & & 86,27 & 88,40 & 87,14 \\
\hline
\end{tabular}




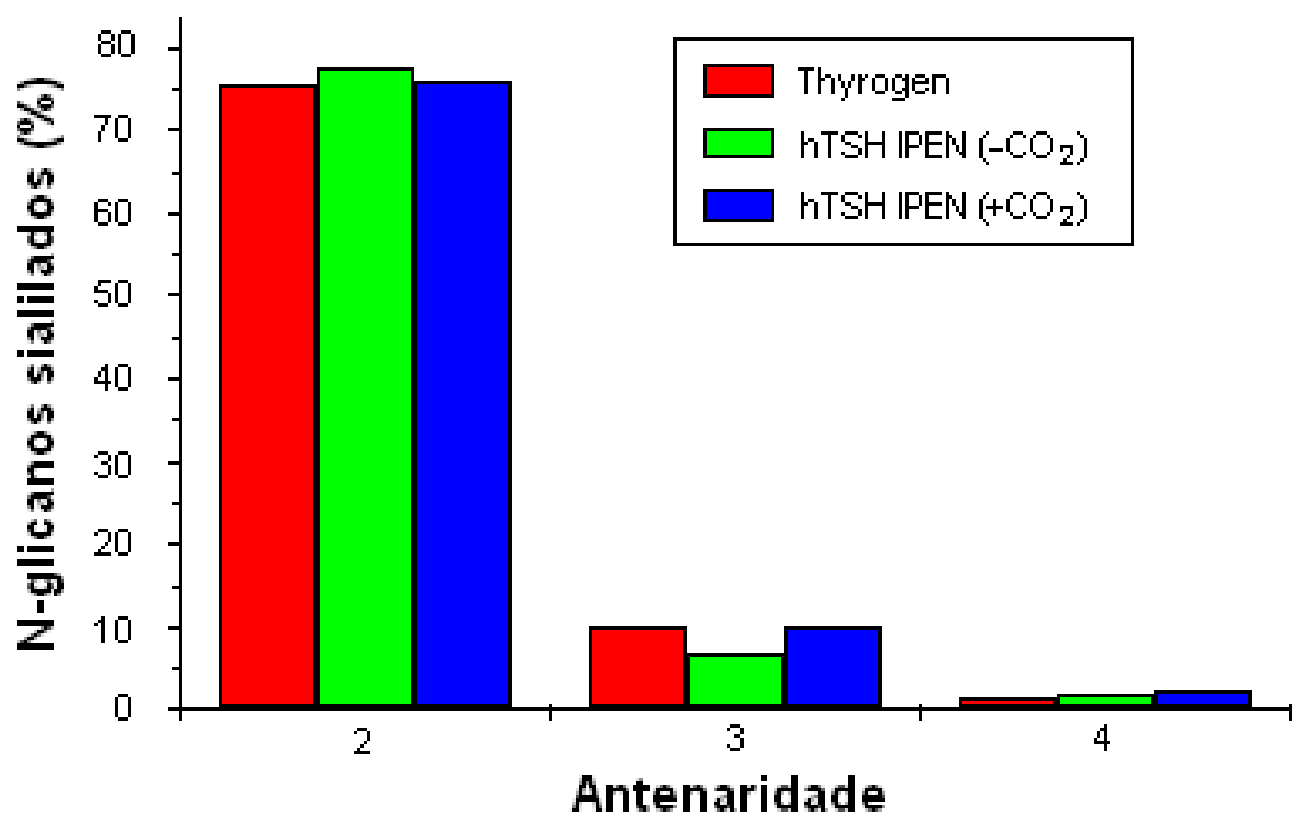

Figura 17 Freqüência (\%) de $\mathrm{N}$-glicanos sialilados com estruturas bi-tri e tetraantenárias em diferentes preparações de hTSH.

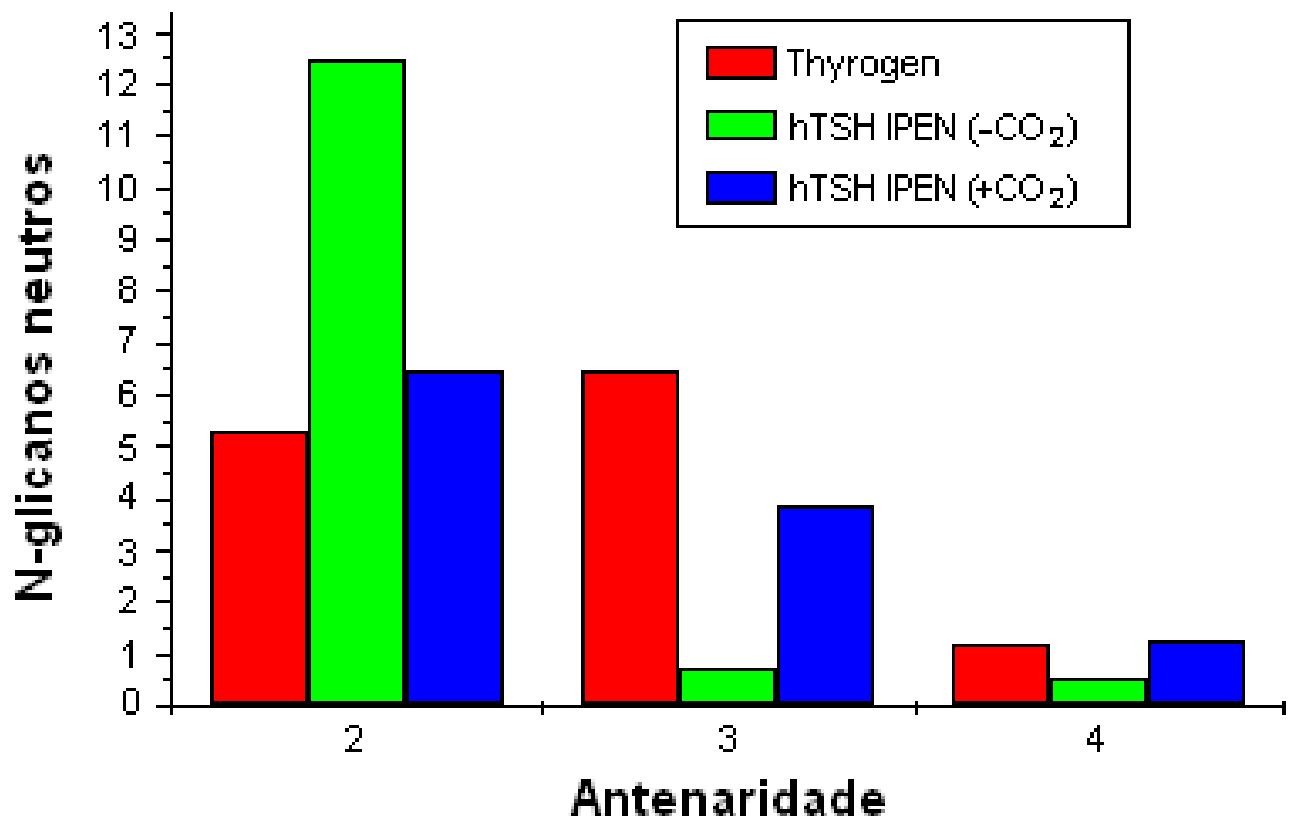


Figura 18 Freqüência (\%) dos $\mathrm{N}$-glicanos neutros com estruturas bi-tri e tetraantenárias em diferentes preparações de hTSH.

No caso do hTSH hipofisário (NIDDK), foram identificadas estruturas do tipo oligo-manose, do tipo híbrido e do tipo complexo, bi-, tri- e tetra-antenárias, sendo $16 \%$ das estruturas neutras e o restante com terminação em sulfato e/ou ácido siálico (Figura 19). Do total destas estruturas carregadas, $81 \%$ contêm sulfato e $38 \%$ contém ácido siálico, sendo que em $19 \%$ delas há a presença dessas duas terminações. Todas as estruturas sialiladas identificadas no hTSH hipofisário contém somente um ácido siálico (monosialiladas), enquanto as espécies sulfatadas apresentam número variável de sulfatos (um a três), sendo a maioria delas ( $70 \%)$ com apenas um sulfato, que aparece ou ligado à N-acetilgalactosamina (GalNAc$\mathrm{SO}_{4}{ }^{-2}$ ) ou à Galactose (Gal-SO ${ }_{4}^{-2}$ ). A técnica de análise dos N-glicanos empregada para o hTSH hipofisário não foi quantitativa, não sendo possível ter a porcentagem das diferentes estruturas. As glicoformas com terminações Gal-SO ${ }_{4}^{-2}$ e GalNAc$\left(\mathrm{SO}_{4}{ }^{-2}\right)_{2}$, ligadas respectivamente a uma e a três galactoses, foram as glicoformas predominantes: $\mathrm{N}_{1} \mathrm{G}_{1} \mathrm{SO}_{4}^{-}$e $\mathrm{N}_{3} \mathrm{G}_{3} \mathrm{GN}_{3}\left(\mathrm{SO}_{4}{ }^{-}\right)_{2}$.

Ainda com relação à preparação pituitária de $\mathrm{hTSH}$, foi feita a análise da ligação do ácido siálico nas conformações $\alpha 2-3$ e $\alpha 2-6$. A Figura 20 mostra as intensidades relativas da composição de Neu5 Ac $\alpha 2-3$ e/ou de Neu5 Ac $\alpha 2-6$ no phTSH. No caso do TSH sem ácido siálico, obtido após tratamento com neuraminidase (asialo-TSH), observa-se um decréscimo na intensidade do sinal de ligação de $85 \%$ no caso da lectina específica de $\alpha 2-6$ e $90 \%$ no caso da lectina específica de $\alpha 2-3$. Quando o TSH foi submetido a um tratamento com neuraminidase ativa preferencialmente para a ligação $\alpha 2-3$ ( $\alpha 2-3$ asialo-TSH) houve um decréscimo de $80 \%$ no sinal de ligação com a lectina específica para $\alpha 2-3$ e praticamente não houve alteração do sinal com a lectina específica para $\alpha 2-6$. 


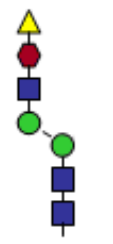

N1G1S1

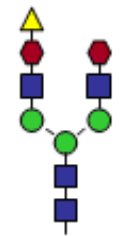

N2G2S1

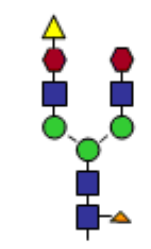

N2G2S1F1

A

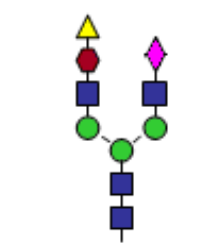

N2G1S1GN1

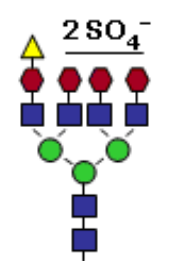

N4G4S1- $\left(\mathrm{SO}_{4}\right)_{2}$

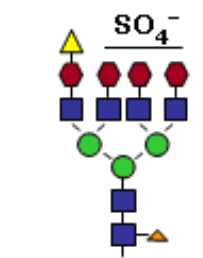

N4G4S1F1- $\mathrm{SO}_{4}$

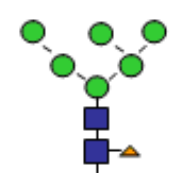

M3F1

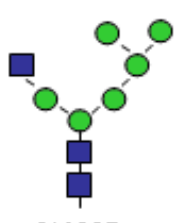

N1M3

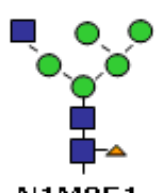

N1M2F1

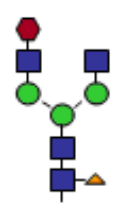

N2G1F1

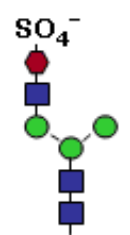

N1G1-SO ${ }_{4}^{-}$

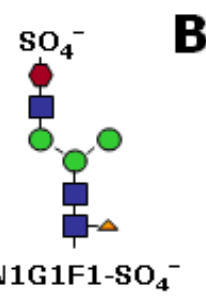

$\mathrm{N} 1 \mathrm{G} 1 \mathrm{~F} 1-\mathrm{SO}_{4}{ }^{-}$
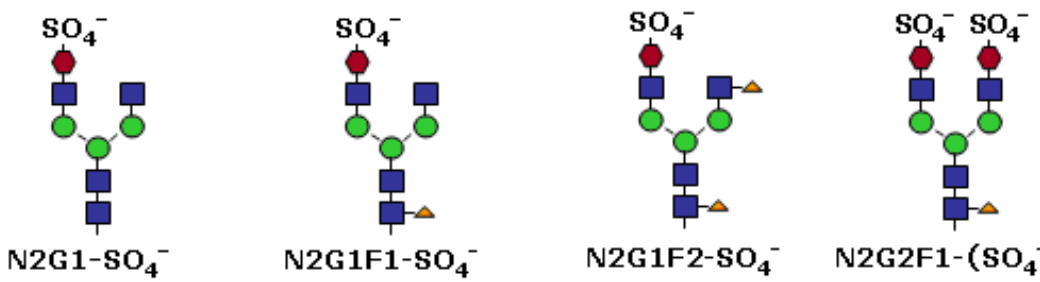

$\mathrm{N} 2 \mathrm{G1}-\mathrm{SO}_{4}^{-}$

$\mathrm{N} 2 \mathrm{G} 1 \mathrm{~F} 2-\mathrm{SO}_{4}{ }^{-}$

N2G2F1- $\left(\mathrm{SO}_{4}^{-}\right)_{2}$

$\mathrm{N} 2 \mathrm{GN} 2-\left(\mathrm{SO}_{4}^{-}\right) 2 \quad \mathrm{~N} 2 \mathrm{G} 2 \mathrm{GN} 1 \mathrm{~F} 1-\mathrm{SO}_{4}^{-}$

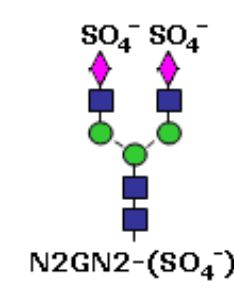

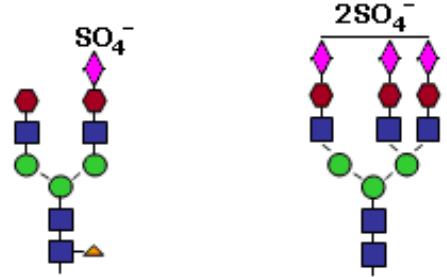

N3G3GN3- $\left(\mathrm{SO}_{4}^{-}\right) 2$

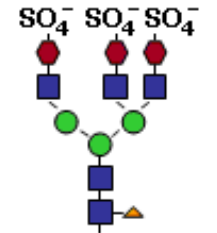

N3G3F1- $\left(\mathrm{SO}_{4}^{-}\right)_{3}$

N2G1GN1-SO ${ }_{4}^{-}$

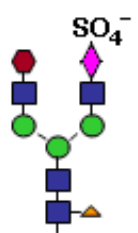

N2G1GN1F1- $\mathrm{SO}_{4}^{-}$

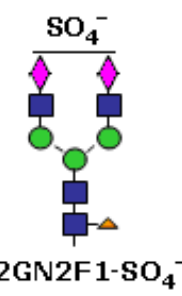

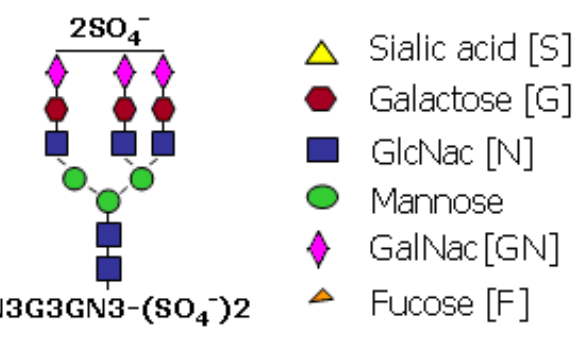

Figura $19 \mathrm{~N}$-glicanos da preparações p-hTSH-NIDDK;
(A) N-glicanos sialilados
(B) N-glicanos s/ ácido siálico 


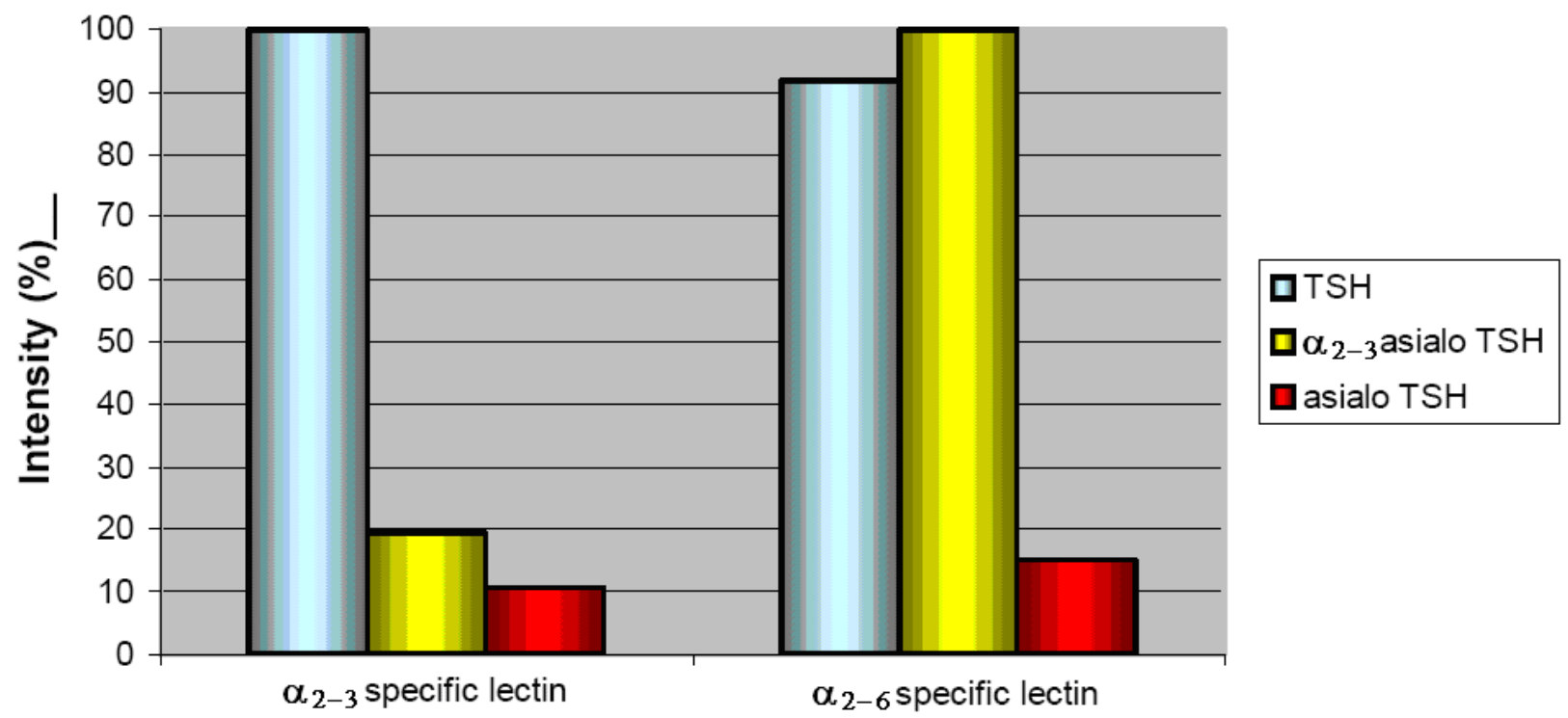

Figura 20 Intensidade de Neu5Ac $\alpha$ 2-3 e de Neu5Ac $\alpha$ 2-6 no p-hTSH-NIDDK

Este tipo de experimento foi repetido, juntamente com outra glicoproteína utilizada como controle, para ter certeza que o fraco sinal de ligação observado reflete a pequena quantidade de ácido siálico presente no $\mathrm{p}-\mathrm{hTSH}$, fato este já detectado na análise dos $\mathrm{N}$-glicanos e também na análise composicional de carboidratos $(0,018 \mathrm{nmoles} / \mu \mathrm{g}$ hTSH) (Figura 21). Com base nas intensidades de ligação, as proporções dos dois tipos de ligação foram de $68 \pm 10 \%$ para Neu5A $\alpha 2-3$ e de $32 \pm 10 \%$ para Neu5Ac $\alpha 2-6$ (Figura 22). 


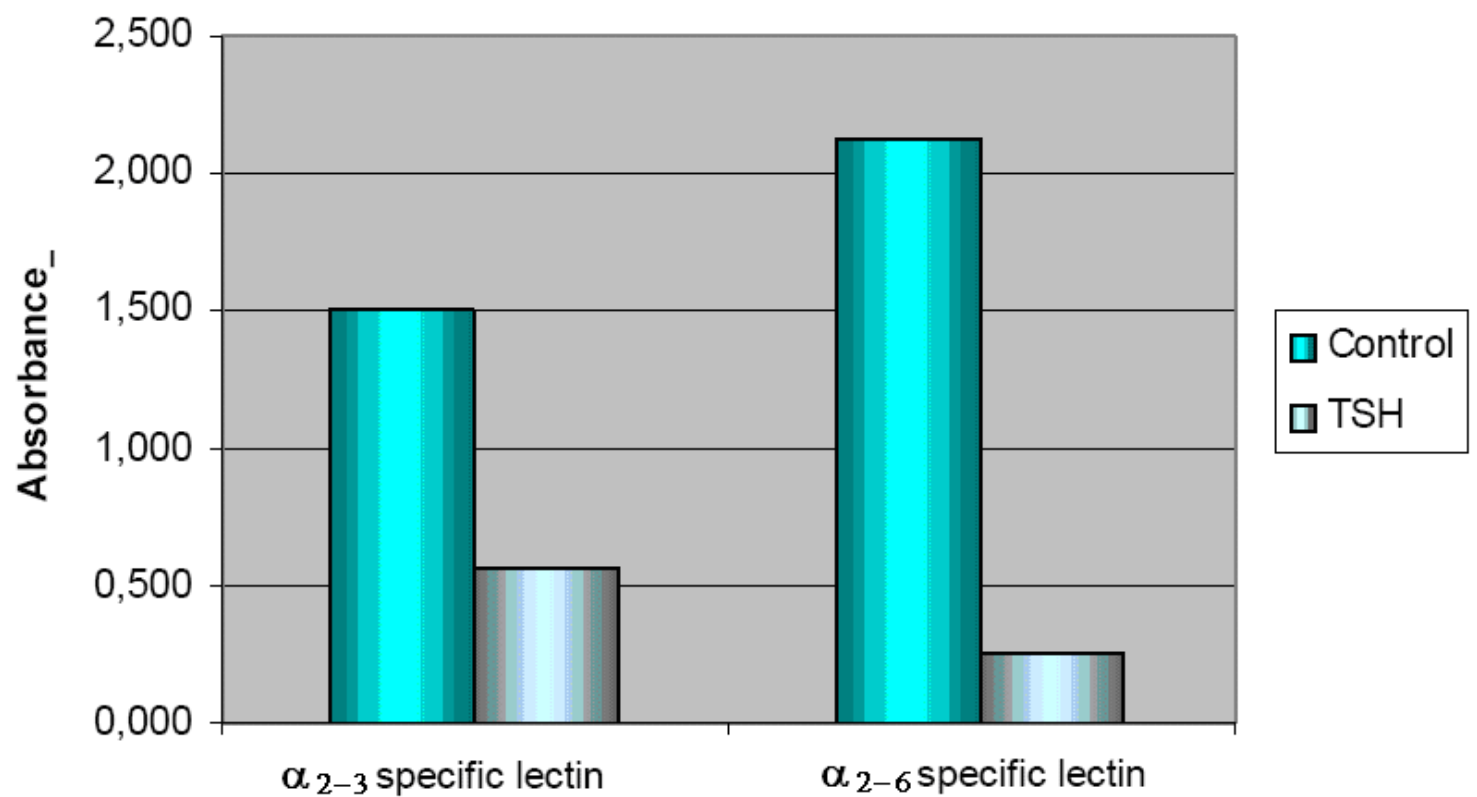

Figura 21 Quantidade de Neu5Ac $\alpha 2-3$ e de Neu5Ac $\alpha 2-6$ no p-hTSH-NIDDK e em glicoproteína controle.

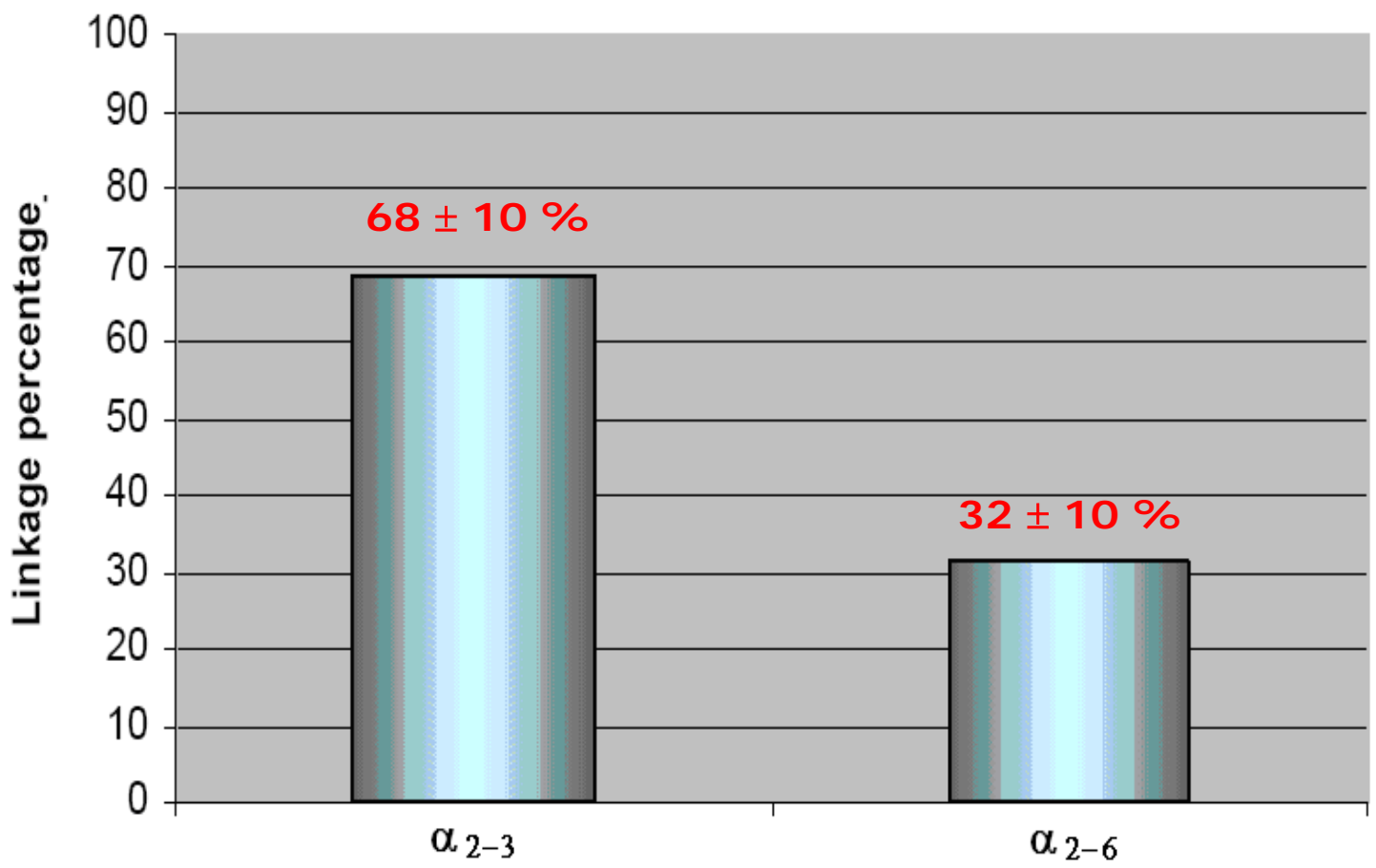

Figura 22 Proporções de ligações $\alpha$ 2-3 e $\alpha$ 2-6 no p-hTSH-NIDDK 


\section{DISCUSSÃO}

No presente trabalho foram focados dois aspectos fundamentais com relação à tireotrofina humana:

- a estratégia do cultivo celular, para obter uma maior produtividade de hTSH compativelmente com sua qualidade, no caso das preparações recombinantes;

- a origem da preparação: derivada de células $\mathrm{CHO}$ (r-hTSH) ou derivada da hipófise (p-hTSH).

Os efeitos destes dois aspectos foram estudados nas propriedades da molécula tais como massa, hidrofobicidade, distribuição de isoformas e atividade biológica bem como nas características da porção glicídica, seja na composição que na estrutura dos carboidratos.

Com relação à influência da estratégia de cultivo na produtividade do $\mathrm{hTSH}$, utilizando a redução da temperatura como estratégia de cultivo celular na fase de produção da proteína, os nossos dados não confirmaram os efeitos benéficos preconizados na literatura, para várias proteínas, $(22,23,24,25,37,66,68,70,84$, $85,87,89,90,91)$. De fato, abaixando a temperatura de $37^{\circ} \mathrm{C}$ para $30^{\circ} \mathrm{C}$ na fase de produção de hTSH não obtivemos aumento na sua produtividade. Yoon e colaboradores (88) também não obtiveram aumento de produtividade do anticorpo anti-4-1BB produzido em células $\mathrm{CHO}$ utilizando este tipo de estratégia. Estes mesmos autores, entretanto, obtiveram, com a redução da temperatura, um significativo aumento (2,6 vezes) na produtividade da eritropoietina expressa nesse mesmo hospedeiro $\mathrm{CHO}$ e com os mesmos promotores (87), o que mostra, portanto, ser este fator proteína-dependente.

Quando na estratégia de cultivo foram feitas alterações no nível de $\mathrm{CO}_{2}$, diminuindo-o de $5 \%$ para $0,03 \%$, na fase de produção, obtivemos um significativo incremento de produtividade de hTSH da ordem de $60 \%$. Nossos dados estão em 
acordo com aqueles obtidos, com estratégias análogas, por Yoon e colaboradores (86) na produção de eritropoietina recombinante (EPO). Estes autores obtiveram um aumento de produtividade um pouco maior que o nosso: aproximadamente 2,2 vezes. Salientamos que a possibilidade de analisar qualitativamente e quantitativamente a proteína de interesse ainda no produto bruto, diretamente no meio condicionado, só foi possível graças à técnica de RP-HPLC anteriormente desenvolvida em nosso laboratório (52), cujas potencialidades são bem discutidas em recente revisão da metodologia de HPLC (62). A possibilidade de avaliar, já em uma etapa inicial, a qualidade da proteína expressa pelas células $\mathrm{CHO}$ é de extrema importância para o desenvolvimento de um processo biotecnológico consistente e rápido.

A avaliação dos produtos recombinantes gerados nas condições de $5 \%$ e $0,03 \%$ de $\mathrm{CO}_{2}$ mostrou não haver diferenças significativas no nível de sialilação e na estrutura dos $\mathrm{N}$-glicanos destes dois produtos, bem como na distribuição dos isômeros de carga. Quanto à atividade biológica, embora em presença de 0,03\% de $\mathrm{CO}_{2}$ tendo sido discretamente menor do que aquela obtida na presença de $5 \%$ de $\mathrm{CO}_{2}$, esta ainda mostrou-se bem maior do que a da preparação nativa.

Para realizar as metas previstas, foi desenvolvida uma estratégia de purificação de duas etapas, eficiente, prática, econômica e rápida, consistindo de uma cromatografia clássica de troca iônica e uma cromatografia líquida de alta eficiência de fase reversa, recentemente publicada (53).

A etapa de RP-HPLC semi-preparativa proposta para a estratégia de purificação do hTSH foi fundamental para obtenção de um produto com pureza > $99 \%$, com altos rendimentos ( $80 \%)$. Apesar de exatidão, sensibilidade, resolução, versatilidade e rapidez serem características bem conhecidas da RP-HPLC, o seu uso no campo de purificação dos hormônios hipofisários recombinantes tem sido bastante restrito. Para estes hormônios só se tem conhecimento da utilização da RPHPLC preparativa para o hormônio de crescimento $(\mathrm{hGH})(32)$ e para o FSH, neste último caso utilizada em uma etapa final ("polishing") quando o material inicial, cuja 
fração de massa era de $2 \%$, já havia atingido um fator de purificação de 41 vezes, após três colunas convencionais (44). O grande poder de purificação da coluna semipreparativa de fase reversa utilizada no presente trabalho ficou ainda mais evidenciado quando ela foi utilizada como primeira etapa de purificação. Nestas condições, o "pool" resultante desta etapa apresentou fração de massa de $80 \%$ e, portanto um fator de purificação de 228 vezes.

Para a purificação do hTSH as estratégias descritas na literatura envolvem métodos cromatográficos convencionais tais como interação hidrofóbica, afinidade, troca iônica e exclusão molecular $(15,49,61,74)$. O material de partida da purificação aqui detalhada era um produto $\sim 8$ vezes menos concentrado e $\sim 8$ vezes menos puro do que aquele relatado anteriormente em trabalho de purificação por nós publicado (49). Com a presente estratégia de purificação obtivemos um produto com a mesma pureza, em menos do que a metade do tempo de processamento e com rendimentos bem maiores $(70 \%$ contra $37 \%)$, particularmente interessantes para trabalho laboratorial. Comparando os nossos resultados com o único processo reportado com detalhes na literatura (15) observa-se que, mesmo tendo começado com um produto 42 vezes menos concentrado e 74 vezes menos puro, foi possível obter, com o mesmo número de etapas de purificação, um produto tão puro quanto aquele obtido por Cole e colaboradores (15). Salientamos também a enorme concentração de volume (4000 vezes) que foi obtida nas duas etapas cromatográficas, sem considerável agregação ou perda de atividade de hTSH.

É importante ressaltar que o r-hTSH-IPEN obtido por esta técnica mostrou-se equipotente à preparação Thyrogen, fármaco cujo uso terapêutico tem sido bem estudado $(\mathbf{4 7}, \mathbf{7 2})$. Não é confirmada, dessa forma, a hipótese freqüentemente levantada da instabilidade da proteína em virtude da presença de altas concentrações de solvente orgânico (acetonitrila) na fase móvel deste tipo de HPLC.

A espectrometria de massa MALDI-TOF tem-se mostrado uma ferramenta bastante importante para estabelecer a identidade de, ou diferenças chaves entre preparações recombinantes e nativas, especialmente quando o uso destas 
preparações é para fins terapêuticos (21). No presente trabalho as duas preparações recombinantes analisadas mostraram uma massa maior ( $7 \%)$ em comparação com a preparação hipofisária. Esta diferença é possivelmente explicada pela diferença na parte glicídica entre estas preparações. A massa molecular experimental determinada para o Thyrogen, por espectrometria de massa MALDI-TOF, apresentou um ótimo acordo (diferença $<1 \%$ ) com aquela teórica relatada na literatura por Cole e colaboradores (15), estimada com base na seqüência de aminoácidos e acrescida da porção de carboidratos, determinada experimentalmente.

Graças às condições utilizadas na espectrometria de massa, foi possível detectar simultaneamente o heterodímero e as subunidades $\alpha$ e $\beta$. Já tínhamos observado este fato também para os outros glicohormônios da mesma família do hTSH, hFSH (45) e hLH (2). A obtenção direta da massa do heterodímero, sem a necessidade de se efetuar uma ligação química para impedir sua dissociação, aumenta ainda mais o potencial desta técnica de determinação de massa molecular, cuja exatidão é bem conhecida. Isto foi confirmado pelo acordo encontrado entre os valores experimentais diretos das massas dos heterodímeros e aqueles calculados pela soma das massas das respectivas subunidades.

Nossos dados mostraram uma diferença significativa entre os tempos de retenção na RP-HPLC da preparação hipofisária e das três preparações recombinantes. A RP-HPLC de fato mostrou-se extremamente sensível em detectar diferenças estruturais pequenas, provavelmente relacionadas à diferenças de carboidratos, o que está de acordo com a afirmação de Rassi (59), de que a microheterogeneidade dos carboidratos contribui de alguma forma nas interações moleculares em RP-HPLC. O tempo de retenção na RP-HPLC, um tipo de índice de hidrofobicidade, poderia, portanto, ser usado como um teste de identidade e qualidade, rápido e altamente sensível para tais variabilidades $(45,52,71)$. 
O novo esquema de bioensaio in vivo proposto no presente trabalho, baseado em um número maior de replicatas para uma única dose de hTSH $(10 \mu \mathrm{g})$, forneceu uma precisão perfeitamente aceitável, com coeficientes de variação em geral da ordem de $15 \%$. Destacamos ser esta uma variabilidade abaixo daquela normalmente encontrada para ensaios in vivo, cuja baixa precisão (CV >25\%) é bem conhecida.

A escolha da dose de $10 \mu \mathrm{g}$ baseou-se em resultados obtidos em trabalhos anteriores nos quais esta dose de hTSH fornecia sempre respostas reprodutíveis, na região linear da curva dose-resposta $(49,57)$.

O rec-hTSH IPEN demonstrou ter uma atividade biológica próxima ao único produto recombinante existente no comércio e bem superior ao produto de origem hipofisária. A menor atividade biológica in vivo encontrada para a preparação hipofisária é provavelmente um reflexo do menor conteúdo de ácido siálico encontrado nesta preparação $(\mathbf{1 9}, \mathbf{7 4}, \mathbf{8 0})$.

As preparações de hTSH recombinante mostraram, por focalização isoelétrica, aproximadamente o mesmo número de glicoformas que aquelas encontradas para 0 Thyrogen por Zhou e colaboradores (94). Estas foram, entretanto, distribuídas em uma região levemente mais ácida, com pls aproximadamente entre 4 e 7 . Por outro lado, uma distribuição de glicoformas em uma região mais básica ( $p l$ entre 6,2 e 8,8) foi reportada por Szkudlinski e colaboradores (77) para preparações de hTSH recombinante com diferentes níveis de sialilação. Da mesma maneira, para as glicoformas das preparações hipofisárias encontramos uma distribuição em uma região levemente mais ácida $(4,82-7,35)$ do que a reportada na literatura $(6,8-8,3)$ (69). A distribuição dos isômeros de carga mostrou-se bastante similar entre os produtos recombinantes e consideravelmente diferente daquele hipofisário. Achamos isto bastante surpreendente, especialmente considerando as diferentes condições de produção existentes entre o nosso produto e o produto da Genzyme (Thyrogen). 
Comparando os dados de Szkudlinski e colaboradores (74) com os nossos observamos um conteúdo de ácido siálico 3,5 vezes superior no caso do Thyrogen e aproximadamente 2,5 vezes maior, no caso do p-hTSH-NIDDK.

Foi também observado na literatura $(\mathbf{1 5}, \mathbf{7 4})$, um maior conteúdo de ácido siálico nas preparações recombinantes do que nas preparações hipofisárias. Segundo Cole e colaboradores (15), este grau de sialilação muito maior ( 5 vezes) é especialmente um reflexo do nível mais baixo de galactose no hTSH hipofisário, uma vez que a razão ácido siálico/galactose é idêntica para os dois hormônios. De fato observamos, no nosso trabalho, uma relação constante $(0,7)$ entre ácido siálico e galactose, tanto para a preparação r-hTSH-IPEN como para a preparação p-hTSH. No entanto esta razão foi bastante inferior no caso da preparação recombinante da Genzyme (0,3). O valor do ácido siálico determinado para esta preparação recombinante foi surpreendentemente menor (2,5 vezes) do que para a preparação IPEN, também recombinante. Isso põe dúvidas a respeito desta determinação, especialmente porque não encontramos entre estas preparações diferenças de atividade biológica, que é influenciada pelo nível de sialilação. Além disso, o nível de sialilação calculado a partir da análise estrutural destas preparações, mostrou-se semelhante entre a preparação IPEN e Thyrogen. De fato, a razão molar ácido siálico:galactose $(\mathrm{S} / \mathrm{G})$ determinada a partir da análise das estruturas glicídicas para as três preparações recombinantes, r-hTSH-IPEN $\left(+\mathrm{CO}_{2}\right)$, r-hTSH-IPEN $\left(-\mathrm{CO}_{2}\right)$ e r-hTSH-Thyrogen foram respectivamente $0,61,0,61$ e 0,59 , confirmando as observações de Cole e colaboradores (15). A partir dos dados destes autores foi possível calcular as razões de 0,66 para o r-hTSH e 0,68 para o p-hTSH e, assim pudemos demonstrar a existência de uma excelente precisão inter laboratorial relativamente a este parâmetro: $\bar{X}=0,63 \pm 0,038(C V=6,0 \%, n=5)$.

Uma análise das estruturas dos N-glicanos do hTSH recombinante, análoga à realizada no presente trabalho, foi reportada na literatura por Morelle e colaboradores (51). Estes autores apresentaram uma análise semi-quantitativa e determinaram o tipo de glicano ligado a cada sítio de glicosilação. Tal como no presente trabalho os glicanos foram clivados com a glicosidase PNGase $F$, mas a análise deles foi feita através de técnicas de HPLC, cromatografia de afinidade por concavalina $A$ e 
espectrometria de massa. Enquanto em nosso caso conseguimos identificar e quantificar 23 estruturas diferentes, Morelle e colaboradores (51) identificaram 16 estruturas, tendo entre elas uma estrutura penta-antenária tetra-sialilada (N5G5S4F), não identificada em nosso estudo. Além disso, os três glicanos mais abundantes encontrados por estes autores foram estruturas bi-antenárias mono- ou bi-sialiladas, enquanto em nossos estudos as estruturas mais abundantes foram mono-sialiladas. Uma comparação interessante pode ser feita entre as estruturas dos glicanos identificadas em nossa preparação recombinante de hTSH e aquelas reportadas por Loumaye e colaboradores (44) para o hFSH recombinante derivado de células $\mathrm{CHO}$. Nos dois casos, foram identificadas até 20 diferentes estruturas (excluindo as formas enantioméricas), 14 das quais foram comuns para os dois hormônios.

A técnica de análise dos $\mathrm{N}$-glicanos empregada para o hTSH hipofisário não foi quantitativa, não sendo possível ter a porcentagem das diferentes estruturas. Ressaltamos que inesperadamente foi encontrada para o hTSH hipofisário do NIDDK, a ligação Gal-SO ${ }_{4}^{-2}$ nunca descrita na literatura para o $\mathrm{hTSH}$.

Não há nada relatado na literatura referente à determinação das percentagens de ligação do ácido siálico à galactose nas conformações $\alpha 2-3$ e $\alpha$ 2-6 para o hTSH. Este tipo de determinação constitui um importante parâmetro para a realização de estudos comparativos entre as preparações recombinantes (fármacos em uso) e o produto natural. Um cálculo teórico para as preparações hipofisárias, realizado a partir das estruturas glicídicas em trabalho fundamental de Green e Baenziger (31) (72,3\% para $\alpha 2,3$ e $27,7 \%$ para $\alpha 2,6)$, mostrou valores próximos aos por nós obtidos experimentalmente (68\% para $\alpha 2,3$ e $32 \%$ para $\alpha 2,6)$.

Salientamos que a maioria dos dados aqui apresentados foram incluídos em trabalho aceito em Molecular Biotechnology (54). 


\section{CONCLUSÕES}

- $\quad$ Os rendimentos de secreção de hTSH por parte das células CHO mostraram-se consideravelmente superiores em condições de $\mathrm{CO}_{2}$ reduzida.

- Diferentes estratégias de produção, especialmente aquelas utilizadas por nós em comparação com a Genzyme, não influenciaram de forma substancial as estruturas dos $\mathrm{N}$-glicanos, os isômeros de cargas ou a atividade biológica do produto.

- Diferenças substanciais foram encontradas nas estruturas dos $\mathrm{N}$-glicanos entre o produto recombinante e aquele hipofisário, o que era esperado. Foram detectadas porém estruturas de $\mathrm{N}$-glicanos nunca descritas para o hTSH hipofisário. Diferenças análogas foram encontradas também na análise dos isômeros de carga mediante focalização isoelétrica.

- Pela primeira vez foram determinadas as porcentagens de ligações na conformação $\alpha 2,3$ e $\alpha 2,6$ entre o ácido siálico e a galactose, confirmando valores teóricos derivado de trabalho fundamental neste campo, publicado em 1988.

- A técnica de espectrometria de massa por MALDI-TOF permitiu a determinação simultânea da forma heterodimérica e das subunidades $\alpha$ e $\beta$. Pela primeira vez foram determinadas estas massas moleculares comparando o produto hipofisário e recombinante.

- Para realizar os trabalhos de expressão, purificação e caracterização destes produtos tornou-se necessário padronizar uma nova técnica de purificação para o hTSH, extremamente rápida, flexível e econômica, já publicada em uma das principais revistas internacionais da área. 


\section{REFERÊNCIAS BIBLIOGRÁFICAS}

1. AL-FAGEEH MB, MARCHANT RJ, CARDEN MJ, SMALES CM. The coldshock response in cultured mammalian cells: Harnessing the response for the improvement of recombinant protein production. Biotechnol Bioeng., v. 93, p. 829-835, 2006.

2. ALMEIDA BE, OLIVEIRA JE, BARTOLINI P, RIBELA MTCP. Analysis of human luteotropin hormone preparations by reversed-phase high-performance liquid chromatography. Em preparação.

3. ANDERSEN DC, KRUMMEN L. Recombinant protein expression for therapeutic applications. Curr. Opin. Biotechnol., v. 13, p. 117-123, 2002.

4. AZZAM N, BAR-SHALOM R, KRAIEM Z, FARES, F. Human thyrotropin (TSH) variants designed by site-directed mutagenesis block TSH activity in vitro and in vivo. Endocrinology, v. 146, p. 2845-2850, 2005.

5. BARBARO D, BONI G. Radioiodine ablation of post-surgical thyroid remnants after preparation with recombinant human TSH: Why, how and when. EJSO, v. 33, p. 535-540, 2007.

6. BASARIA M, GRAF H, COOPER DS. The use of recombinant thyrotropin in the follow-up of patients with differentiated thyroid cancer. Am. J. Med., v. 112, p. 721-725, 2002.

7. BI JX, SHUTTLEWORTH J, AL-RUBEAI M. Uncoupling of cell growth and proliferation results in enhancement of productivity in p21CIP1-arrested $\mathrm{CHO}$ cells. Biotechnol. Bioeng., v. 85, p. 741-749, 2004. 
8. BOMBARDIERI E, SEREGNI E, VILLANO C, ALIBERTI G, MATTAVELLI F. Recombinant human thyrotropin (rhTSH) in the follow-up and treatment of patients with thyroid cancer. Tumori, v. 89, p. 533-536, 2003.

9. BOUSFIELD GR, BUTNEV VY, WALTON WJ, NGUYEN VT, HUNEIDI J, SINGH V, KOLLI VSK, HARLEY DJ, RANCE NE. All-or-none N-glycosylation in primate follicle-stimulating hormone b-subunits. Mol. Cel. Endocrinol., v. 260-262, p. 40-48, 2007.

10. BUTLER M. Animal cell cultures: recent achievements and perspectives in the production of biopharmaceuticals. Appl. Microbiol. Biotechnol., v. 68, p. 283291, 2005.

11.BUTLER M. Optimisation of the cellular metabolism of glycosylation for recombinant proteins produced by mammalian cell systems. Cytotechnology, v. 50, p. $57-76,2006$.

12. CANONNE C, PAPANDREOU MJ, MEDRI G, VERRIER B, RONIN C. Biological and immunochemical characterization of recombinant human thyrotrophin. Glycobiology, v. 5, p. 473-481, 1995.

13. CARVALHAL AV, MARCELINO I, CARRONDO MJT. Metabolic changes during cell growth inhibition by p27 overexpression. Appl. Microbiol. Biotechnol., v. 63, p. 164-173, 2003.

14. CHEN P, HARCUM SW. Effects of amino acid additions on ammonium stressed CHO cells. J. Biotechnol., v. 117, p. 277-286, 2005. 
15. COLE, E.S.; LEE, K.; LAUZIERE, K.; KELTON, C.; CHAPPEL, S.; WEINTRAUB, B.; FERRARA, D.; PETERSON, P.; BERNASCONI, R.; EDMUNDS, T.; RICHARDS, S.; DICKRELL, L.; KLEEMAN, J.M.; MC PHERSON, J.M., PRATT, B. Recombinant human thyroid stimulating hormone: development of a biotechnology product for detection of metastatic lesions of thyroid carcinoma. Bio-Technol., v. 11, p. 1014-1023, 1993.

16. DALMORA S, OLIVEIRA JE, AFFONSO R, GIMBO E, RIBELA MT, BARTOLINI P. Analysis of recombinant human growth hormone directly in osmotic shocks fluids. J. Crhromatogr. A, v. 782, p. 199-210, 1997.

17. DeZENGOTITA VM, KIMURA R, MILLER WM. Effects of $\mathrm{CO}_{2}$ and osmolality on hybridoma cells: growth, metabolism and monoclonal antibody production. Cytotechnology, v. 28, p. 213-227, 1998.

18. DRAPEAU D, LUAN Y-T, WHITEFORD JC, LAVIN DP, ADAMSON SR. Cell culture scale-up in stirred tank reactors. Presented at The Annual Meeting of the Society of Industrial Microbiology, Orlando FL., 1990.

19. EAST-PALMER J, SZKUDLINSKI MW, LEE J, THOTAKURA NR, WEINTRAUB BD. A novel, nonradioactive in vivo bioassay of thyrotropin (TSH). Thyroid, v.5,p. 55-59, 1995.

20. FARES $\mathrm{F}$. The role of $\mathrm{O}$-linked and $\mathrm{N}$-linked oligosaccharides on the structurefunction of glycoprotein hormones: Development of agonists and antagonists. Biochem. Biophys. Acta. V. 1760, p. 560-567, 2006.

21. FLENSBURG J, BELEW M. Characterization of recombinant human serum albumin mass using spectrometry matrix-assisted laser desorption ionization time-of-flight. J. Chromatogr. A, v. 1009, p. 111-117, 2003. 
22. FOGOLIN MB, WAGNER R, ETCHEVERRIGARAY M, KRATJE R. Impact of temperature reduction and expression of yeast pyruvate carboxylase on hGMCSF-producing CHO cells. J. Biotechnol., v. 109, p. 179-191, 2004.

23. FOGOLIN MB, FORNO G, NIMTZ M, CONRADT HS, ETCHEVERRIGARAY M, KRATJE R. Temperature reduction in cultures of hGM-CSF-expressing $\mathrm{CHO}$ cells: effect on productivity and product quality. Biotechnol. Prog., v. 21, p. 17-21, 2005.

24.FOX SR, PATEL UA, YAP MGS, WANG DIC. Maximizing interferon- $\gamma$ production by Chinese hamster ovary cells through temperature shift optimization. Biotechnol. Bioeng., v. 85, p. 177-184, 2004.

25. FURUKAWA K, OHSUYE K. Effect of culture temperature on a recombinant $\mathrm{CHO}$ cell line producing a C-terminal $\alpha$-amidating enzyme. Cytotechnology, v. 26, p. $153-164,1998$.

26. GOOCHEE CF, MONICA T. Environmental effects on protein glycosylation. Biotechnology, v. 8, p. 421-427, 1990.

27. GOOCHEE CF, GRAMER MJ, ANDERSEN DC, BAHR JB, RASMUSSEN JR. The oligosaccharides of glycoproteins: bioprocess factors affecting oligosaccharide structure and their effect on glycoprotein properties. Biotechnology, v.9, p. 1347-1355, 1991.

28. GOOCHEE CF, GRAMER MJ, ANDERSEN DC, BAHR JB. The oligosaccharides of glycoproteins: factors affecting their synthesis and their influence on glycoprotein properties. In: Sikdar TP, Bier SK (Eds) Frontiers in Bioprocessing. Washington: American Chemical Society, v. 11, p. 199-240, 1992. 
29. GRAMPP GE, BLUMEN TK, KELLY K, DERBY P, SLEEMAN LA, HETTWER D. Environmental control of sialic acid composition in glycoproteins secreted by mammalian cells. Presented at the Cell Culture Engineering IV Meeting, San Diego, CA, USA, 1994.

30. GRAY DR, CHEN S, HOWARTH W, INLOW D, MAIORELLA BL. Carbon dioxide in large-scale and high density $\mathrm{CHO}$ cell perfusion culture. Cytotechnology, v. 22, p. 65-78, 1996.

31. GREEN ED, BAENZIGER JU. Asparagine-linked oligosaccharides on Lutropin, Follitropin and Thyrotropin. II - Distributions of sulfated and sialylated oligosaccharides on bovine, ovine, and human pituitary glycoprotein hormones. J. Biol. Chem., v. 263, p. 36-44, 1988.

32. GRINNAN EL, LOGSDON EE, US Pat. 4612 367, 1986.

33. GROSSMANN M, WONG R, TEH NG, TROPEA JE, EAST PALMER J, WEINTRAUB BD, SZKUDLINSKI MW. Expression of biologically active human thyrotropin (hTSH) in a baculovirus system: Effect of insect cell glycosylation on hTSH activity in vitro and in vivo. Endocrinology, v. 138, p. 92-100, 1997.

34. HARTREE AS, RENWICK AGC. Molecular structures of glycoprotein hormones and functions of their carbohydrate components. Biochem. J., v. 287, p. 665-679, 1992.

35. HAUGHEN BR, PACINI E, REINERS C, SCHLUMBERGER M, LADENSON PW, SHERMAN SI, COOPER DS, GRAHAM KE, BRAVERMAN LE, SKARULIS MC, DAVIES TF, DEGROOT LJ, MAZZAFERRI EL, DANIELS GH, ROSS DS, LUSTER M, SAMUELS MH, BECKER DV, MAXON HR, CAVALIERI RR, SPENCER CA. A comparison of recombinant human 
thyrotropin and thyroid hormone withdrawal for the detection of thyroid remnant or cancer. J. Clin. Endocrinol. Metab., v. 84, p. 3877-3885, 1999.

36. HIYAMA J, WEISSHAAR G, RENWICK AGC. The asparagine-linked oligosaccharides at individual glycosylation sites in human thyrotrophin. Glycobiology, v. 2, p. 401-409, 1992.

37. KAUFMANN H, MAZUR X, FUSSE NEGGER M, BAILEY JE. Influence of low temperature on productivity, proteome and protein phosphorylation of $\mathrm{CHO}$ cells. Biotechnol. Bioeng., v. 63, p. 573-582, 1999.

38. KIMURA R, MILLER WM. Effects of elevated $\mathrm{pCO}_{2}$ and/or osmolality on the growth and recombinant tPA production of $\mathrm{CHO}$ cells. Biotechnol. Bioeng., $\mathrm{v}$. 52, p. 152-160, 1996.

39. KIMURA R, MILLER WM. Glycosylation of CHO-derived recombinant tPA produced under elevated pCO2. Biotechnol. Prog., v. 13 p. 311-317, 1997.

40. KIRKPATRICK CH, MEEK JC, RICH RR. Mechanism of allergy to components of commercial bovine thyrotropin. J. Allergy Clin. Immunol., v. 51, p. $296-$ $302,1973$.

41. KRISHNAMURTHY GT. Human reaction to bovine TSH: concise communication. J. Nucl. Med., v. 19, p. 284, 1978.

42. KUMAR N, GAMMEL P, CLYNES M. Proliferation control strategies to improve productivity and survival during $\mathrm{CHO}$ based production culture. Cytotechnology, v. 53, p. 33-46, 2007. 
43. KUYSTERMANS D, KRAMPE B, SWIDEREK H, Al-RUBEAI. Using cell engineering and omic tools for the improvement of cells cultures process. Cytotechnology, v. 53, p. 3-22, 2007.

44. LOUMAYE E, DREANO M, GALAZKA A, HOWLES C, HAM L, MUNAFO A, ESHKOL A, GIUDICE E, DE LUCA E, SIRNA A, ANTONETTI F, GIARTOSIO CE, SCAGLIA L, KELTON C, CAMPBELL R, CHAPPEL S, DUTHU B, CYMBALISTA S, LEPAGE P. Recombinant follicle stimulating hormone: development of the first biotechnology product for the treatment of infertility. Hum. Reprod. Update, v. 4, 862-881, 1998.

45. LOUREIRO RF, OLIVEIRA JE, TORJESEN PA, BARTOLINI P, RIBELA MTCP. Analysis of intact human follicle-stimulating hormone preparations by reversed-phase high-performance liquid chromatography. J Chromatogr. A, v. 1136, p. 10-18, 2006.

46. LUSTER M, LASSMANN M, HAENSCHEID $H$. Use of recombinant human thyrotropin before radiodine therapy in patients with advanced differentiated thyroid carcinoma. J. Clin. Endocrinol. Metab., v. 85, p. 3640-3645, 2000.

47. LUSTER M. Present status of the use recombinant human TSH in thyroid cancer management. Acta Oncol., v. 45, p. 1018-1030, 2006.

48. MELEADY P. Proteomic profiling of recombinant cells from large-scale mammalian cell culture processes. Cytotechnology, v. 53, p. 23-31, 2007.

49. MENDONÇA F, OLIVEIRA JE, BARTOLINI P, RIBELA MTCP. Two-step chromatographic purification of recombinant human thyrotropin and its immunological, biological, physico-chemical and mass spectral characterization. J Chromatogr. A, v. 1062, p. 103-112, 2005. 
50.MORELLE W, MICHALSKI J-C. Glycomics and mass spectrometry. Curr. Pharm. Des., v. 11, p. 2615-2645, 2005.

51. MORELLE W, DONADIO S, RONIN C, MICHALSKI J-C. Characterization of $\mathrm{N}$-glycans of recombinant human thyrotropin using mass spectrometry. Rapid Commun. Mass Spectrom., v. 20, p. 331-345, 2006.

52. OLIVEIRA JE, MENDONÇA F, PERONI CN, BARTOLINI P, RIBELA MTCP. Determination of chinese hamster ovary cell-derived recombinant thyrotropin by reversed-phase liquid chromatography. J. Chromatogr. B, v. 787 , p. 345$355,2003$.

53. OLIVEIRA JE, DAMIANI R, BARTOLINI P, RIBELA MTCP. Pratical reversedphase high-performance liquid chromatography method for laboratory-scale purification of recombinant human thyrotropin. J. Chromatogr. A, v. 1164, p. 206-211, 2007.

54. OLIVEIRA JE, DAMIANI R, VORAUER-UHL K, BARTOLINI P, RIBELA MTCP. Influence of a reduced $\mathrm{CO}_{2}$ environment on the secretion yield, potency and glycan strutures of recombinant thyrotropin (hTSH) from $\mathrm{CHO}$ cells. Mol. Biotechnol., 2007. Aceito para publicação.

55. PACINI F, LADENSON PW, SCHLUMBERGER M, DRIEDGER A, LUSTER M, KLOOS RT, SHERMAN S, HAUGEN B, CORONE C, MOLINARO E, ELISEI R, CECCARELLI C, PINCHERA A, WAHL RL, LEBOULLEUX S, RICARD M, YOO J, BUSAIDY NL, DELPASSAND E, HANSCHEID H, FELBINGER R, LASSMANN M, REINERS C. Radioiodine ablation of thyroid remnants after preparation with recombinant human thyrotropin in differentiated thyroid carcinoma: Results of an international, randomized, controlled study. J. Clin. Endocrinol. Metabol., v. 91, p. 926-932, 2006. 
56. PERONI CN, RIBELA MTCP, BARTOLINI P. Sensitive human thyrotropin immunoradiometric assay set up by the identification and minimization of non specific bindings. J. Immunoassay, v.18, p. 247-265, 1997.

57.PERONI CN, SOARES CRJ, GIMBO E, MORGANTI L, RIBELA MTCP, BARTOLINI P. High-level expression of human thyroid-stimulating hormone in chinese hamster ovary cells by co-transfection of dicistronic expressio vectors followed by a dual-marker amplification strategy. Biotechnol. Appl. Biochem., v. 35 , p. 19-26, 2002.

58. PERSANI L, BORGAT S, ROMOLI R, ASTENA C, PIZZOCARO A, BECKPECCOZ P. Changes in the degree of sialylation of carbohydrate chains modify the biological properties of circulating thyrotropin isoforms in various physiological and phatological states. J. Clin. Endocrinol. Metab., v.83, p. 2486-2492, 1998.

59. RASSI ZE. Recent progress in reversed-phase and hydrophobic interaction chromatography of carbohydrate species. J. Chromatogr. A, v. 720 , p. 93118, 1996.

60. RIBELA, MTCP, BIANCO, A.C.; BARTOLINI, P. The use of recombinant human thyrotropin produced by chinese hamster ovary cells for the preparation of immunoassay reagents. J. Clin. Endocrinol. Metab., v. 81, p. 249-256, 1996.

61. RIBELA MTCP, GOUT PW, BARTOLINI P. Synthesis and chromatographic purification of recombinant human pituitary hormones. J. Chromatogr. B, v. 790, p. 285-316, 2003. 
62. RIBELA MTCP, GOUT PW, OLIVEIRA JE, BARTOLINI P. HPLC analysis of human pituitary hormones for pharmaceutical applications. Curr. Pharm. Anal., v. 2, p. 103-126, 2006.

63. RIGGIN RM, SHAAR CJ, DORULLA GK, LAFEBER DS, MINER DJ. Highperformance size-exclusion chromatography determination of the potency of biosynthetic human growth hormones products. J. Chromatogr., v. 435, p. 307-318, 1988.

64. ROBBINS RJ, TUTTLE RM, SHARAF RN, LARSON SM, ROBBINS AK, GHOSSEIN RA, SMITH A, DRUCKER WD, FLEISHER M, LARSON SM. Preparation by recombinant human thyrotropin or thyroid hormone withdrawal are comparable for the detection of residual differentiated thyroid carcinoma, $\mathbf{J}$. Clin. Endocrinol. Metab., v. 86, p. 619-625, 2001.

65. ROBBINS RJ, ROBBINS AK. Recombinant human thyroytopin and thyroid cancer management. J. Clin. Endocrinol. Metab., v. 88, p. 1933-1938, 2003.

66. RODRIGUEZ J, SPEARMAN M, HUZEL N, BUTLER M. Enhanced production of monomeric interferon- $\beta$ by $\mathrm{CHO}$ cells through the control of culture conditions. Biotechnol. Prog., v. 21, p. 22-30, 2005.

67. SCHAAF L, LEIPRECHT A, SAJI M, HUBNER V, USADEL KH, KOHN LD. Glycosylation variants of human TSH selectively activate signal transduction pathways. Mol. Cell Endocrinol., v. 132, p. 185-194, 1997.

68. SCHATZ SM, KERSCHBAUMER RJ, GERSTENBAUER G, KRAL M, DORNER F, SCHEIFLINGER F. Higher expression of Fab antibody fragments in a $\mathrm{CHU}$ cell line at reduced temperature. Biotechnol. Bioeng., v. 84, p. 433438, 2003. 
69. SERGI I, PAPANDREOU MJ, MEDRI G, CANONNE C, VERRIER B, RONIN C. Immunoreactive and bioactive isoforms of human thyrotropin. Endocrinology, v. 128, p. 3259-3268, 1991.

70. SHI M, XIE Z, YU M, SHEN B, GUO N. Controlled growth of Chinese hamster ovary cells and high expression of antibody-IL-2 fusion proteins by temperature manipulation. Biotechnol. Lett., v. 27, p. 1879-1884, 2005.

71. SOARES CRS, CAMARGO IMC, MORGANTI L, GIMBO E, OLIVEIRA JE, LEGOUX R, FERRARA P, BARTOLINI P. Reversed-phase high-performance liquid Chromatography method for the determination of prolactin in bacterial extracts and in its purified form. J. Chromatogr. A, v. 955, p. 229-236, 2002.

72. SUGINO K, ITO K, TAKAMI H. Management of differentiated thyroid carcinoma with radioiodine and recombinant human TSH. Endocr. J., v. 53, p. 723-728, 2006.

73. SUNG YH, LEE GM. Enhanced human Thrombopoietin production by sodium butyrate addition to serum-free suspension culture of Blc-2-overexpressing CHO Cells. Biotechnol. Prog., v. 21, p. 50-57, 2005.

74.SZKUDLINSKI MW, THOTAKURA NR, BUCCI I, JOSHI LD TSAI A, EASTPALMER J, SHILOAD J, WEINTRAUB BD. Purification and characterization of recombinant human thyrotropin (TSH) isoforms produced by chinese hamster ovary cells: the role of sialylation and sulfatation in TSH bioactivity. Endocrinology, v. 133, p. 1490-1503, 1993.

75.SZKUDLINSKI MW, THOTAKURA NR, WEINTRAUB, BD. Subunit-specific functions of $\mathrm{N}$-linked oligosaccharides in human thyrotropin: Role of terminal residues of $\alpha$ - and $\beta$-subunits oligosaccharides in metabolic clearance and bioactivity. Proc. Natl. Acad. Sci., v. 92, p. 9062-9066, 1995. 
76. SZKUDLINSKI MW, GROSSMANN M, LEITOLF H, WEINTRAUB BD. Human thyroid-stimulating hormone: structure-function analysis. Methods, v. 21, p. 67-81, 2000.

77.SZKUDLINSKI MW, FREMONT V, RONIN C, WEINTRAUB BD. Thyroidstimulating hormone and thyroid-stimulating hormone receptor structurefunction relationships. Physiol. Rev., v. 82, p. 473-502, 2002.

78. TAKAMATSU S, IONUE N, KATSUMATA T, NAKAMURA K, FUJIBAYASHI Y, TAKEUCHI $M$. The relationship between the branchi-forming glycosyltransferases and cell suface sugar chain structures. Biochemistry, v. 44, p. 6343-6349, 2005.

79. TAKATA $\mathrm{KI}$, WATANABE $\mathrm{S}$, HIRONO $\mathrm{M}$, TANAKO $\mathrm{M}$, TERAOKA $\mathrm{H}$, HAYASHIZAKI Y. The role of the carboxyl-terminal aminoacid extension of human TSH $\beta$ subunit. Biochem. Biophys. Res. Commun., v. 165, p. 10351042, 1989.

80. THOTAKURA NR, DESAI RK, BALES LG, COLE ES, PRATT BM, WEINTRAUB BD. Biological-activity and metabolic-clearance of a recombinant human thyrotropin produced in chinese hamster ovary cells. Endocrinology, v. 128, p. 341-348, 1991.

81. THOTAKURA NR, DESAI RK, SZKUDLINSKI MW, WEINTRAUB BD. The role of the oligosaccharide chains of the thyrotropin alpha-subunit and beta-subunit in hormone action. Endocrinology, v. 131, p. 82-88, 1992.

82. THOTAKURA NR, BLITHE DL. Glycoprotein hormones: glycobiology of gonadotropins, thyrotropin and free $\alpha$ subunit. Glycobiology, v. 5, p. 3-10, 1995. 
83. TORLONTANO M, CROCETTI U, D'ALOISO L, BONFITTO N, DI GIORGIO A, MODONI S, VALLE G, FRUSCIANTE V, BISCEGLIA M, FILETTI S, SCHLUMBERGER M, TRISCHITTA V. Serum thyroglobulin and I-131 whole body scan after recombinant human TSH stimulation in the follow-up of lowrisk patients with differentiated thyroid cancer. Eur. J. Endocrinol., v. 148, p19-24, 2003.

84.TRUMMER E, FAULAND K, SEIDINGER S, SCHRIEBL K, LATTENMAYER, KUNERT R, VORAUER-UHL K, WEIK R, BORTH N, KATINGER H MÜLLER D. Effect of DOT, $\mathrm{pH}$, and temperature on the performance of Epo-Fc expressing $\mathrm{CHO}$ cells cultivated in controlled batch bioreactors. Biotechnol. Bioeng., v. 94, p. 1033-1044, 2006.

85. TRUMMER E, FAULAND K, SEIDINGER S, SCHRIEBL K, LATTENMAYER, KUNERT R, VORAUER-UHL K, WEIK R, BORTH N, KATINGER H MÜLLER D. Biphasic cultivation - $A$ tool for enhancing the volumetric productivity of batch process using Epo-Fc expressing $\mathrm{CHO}$ cells. Biotechnol. Bioeng., v. 94, p. 1045-1052, 2006.

86. YOON SK, AHN Y-O, HAN K. Enhancement of recombinant erythropoietin production in $\mathrm{CHO}$ cells in an incubator without $\mathrm{CO}_{2}$ addition. Cytotechnology, v. 37, p. 119-132, 2001.

87. YOON SK, SONG JY, LEE GM. Effect of low culture temperature on specific productivity, transcription level and heterogeneity of erythropoietin in Chinese hamster ovary cells. Biotechnol. Bioeng., v. 82, p. 289-298, 2003.

88. YOON SK, KIM SH, LEE GM. Effect of low temperature on specific productivity and transcription level of Anti-4-1BB antibody in recombinant Chinese hamster ovary cells. Biotechnol. Prog., v. 19, p. 1383-1386, 2003. 
89. YOON SK, HONG JK, LEE GM. Effect of simultaneous application of stressful culture conditions on specific productivity and heterogeneity of erythropoientin in Chinese hamster ovary cells. Biotechnol. Prog., v. 20, p. 1293-1296, 2004.

90. YOON SK, CHOI SL, KIM SH, SONG JY, LEE GM. Effect of Culture pH on Erythropoietin Production by Chinese Hamster Ovary Cells Grown in Suspension at 32.5 and $37.0^{\circ} \mathrm{C}$. Biotechnol. Bioeng., v. 89, p. 345-356, 2005.

91.YOON SK, KIM SH, SONG JY, LEE GM. Biphasic culture strategy for enhancing volumetric erythropoietin productivity of Chinese hamster ovary cells. EMT, v. 39, p. 362-365, 2006.

92.ZANGHI JA, SCHMELZER AE, MENDONZA TP, KNOP RH, MILLER WM. Bicarbonate concentration and osmolality are key determinants in the inhibition of $\mathrm{CHO}$ cell polysialylation under elevated $\mathrm{pCO}_{2}$ or $\mathrm{pH}$. Biotechnol. Bioeng., v. 65, p. 182-191, 1999.

93.ZERFAOUI M, RONIN C. Glycosylation is the structural basis for changes in polymorphism and immunoreactivity of pituitary glycoprotein hormones. Eur. J. Clin. Chem. Clin. Biochem., v. 34, p. 749-753, 1996.

94.ZHOU Q, PARK S-H, BOUCHER S, HIGGINS E, LEE K, EDMUNDS T. Nlinked oligosaccharide analysis of glycoprotein bands from isoelectric focusing gels. Anal. Biochem., v. 335, p. 10-16, 2004.

95.ZHU MM, GOYAL A, RANK DL, GUPTA SK. Effects of elevated $\mathrm{pCO}_{2}$ and osmolality on growth of $\mathrm{CHO}$ cells and production of antibody-fusion protein B1: A case study. Biotechnol. Prog., v. 21, p. 70-77, 2005. 